\title{
إدارة علاقات العملاء وأثرها على جودة العلاقة والاحتفاظ بالعميل دراسة تطبيقية
}

$$
\text { آمنة أبو النجا محمد دكتور }
$$

كلية التجارة -جامعة طنطا 
تهدف هذه الدراسـة إلى التعرف على أثر أبعاد إدارة علاقات العملاء (التركيز على كبار

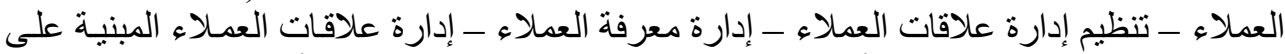

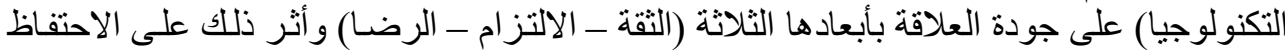

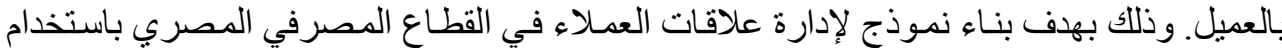

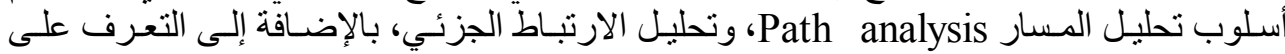
مستوى كل من رضا العميل و الاحتفاظ به في القطاع المصرفي المصري.

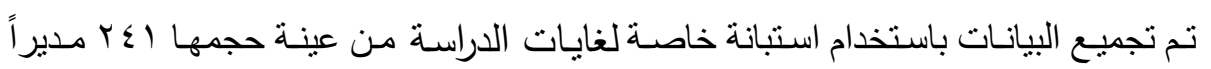

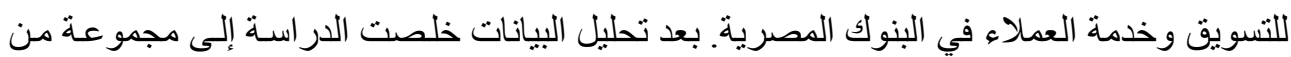

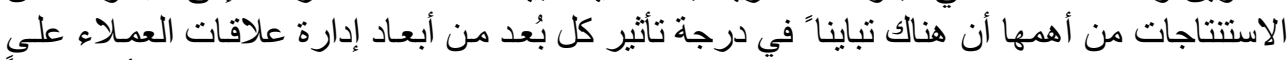

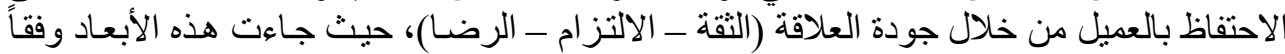

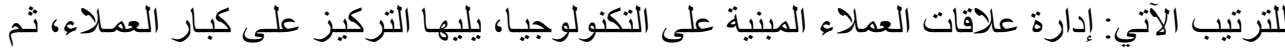

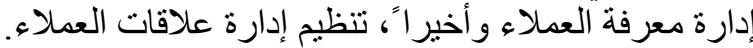

إضافة إلى أن إدارة علاقات العملاء لها تأثير غبر مباثشر على الالتزام من خـلال الثقة، كمـا

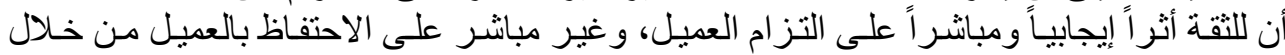

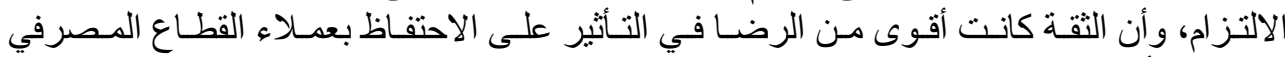

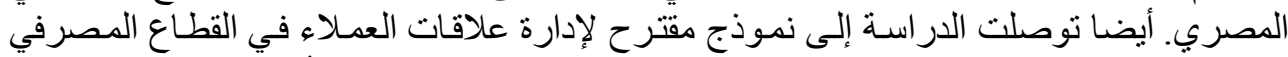

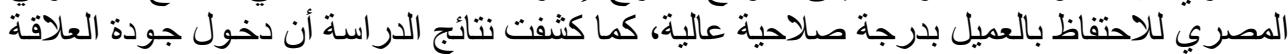

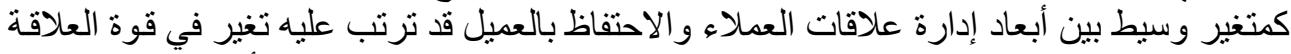

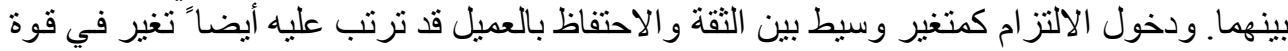
العلاقة بينهما.

$$
\text { وبناء على ما توصلت إليه الدر اسة من نتائج نم اقتر اح جملة من التوصيات. }
$$

الكلمات الدالة: إدارة علاقات العملاء- جودة العلاقة ـ الاحتفاظ بالعميل. 


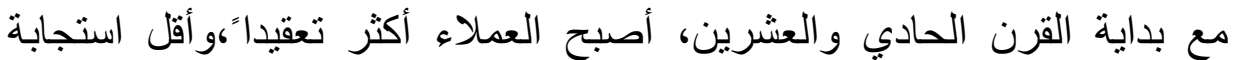

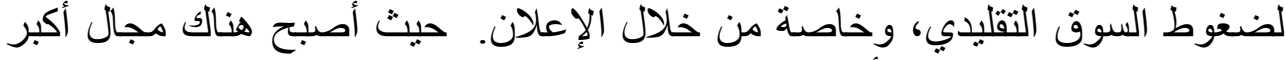

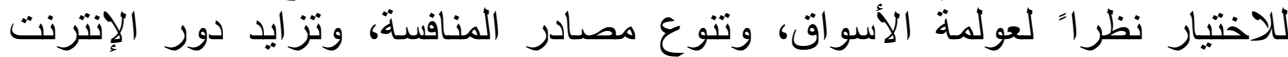
والتسويق الالكتروني، وانخفاض تكاليف دخول الأسواق العالمية وتوافر منتجات التافية

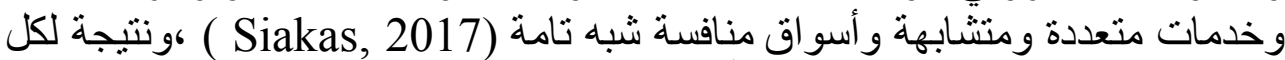

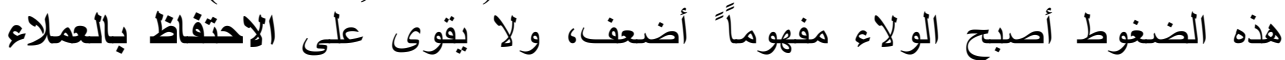

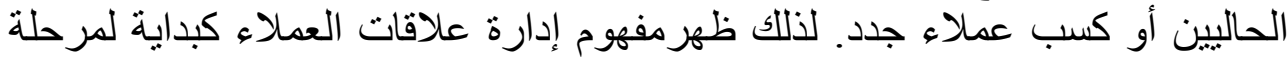
جديدة في الفكر التسويقي المعاصر تهدف بصفة أساسية إلى تعزيز الاحتفاظ بالعملاء،

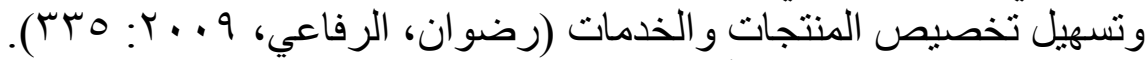

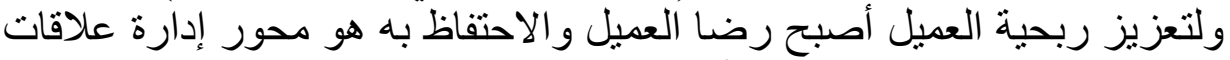

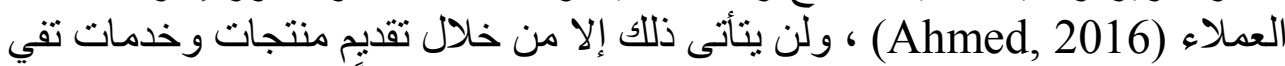

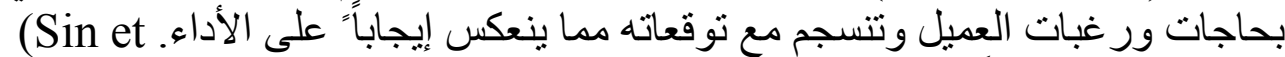

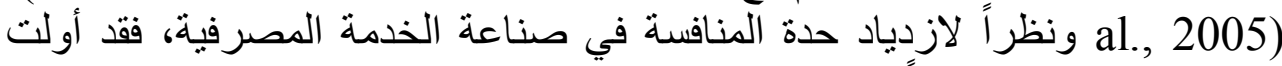

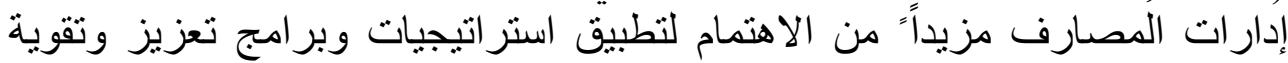

العلاقة مع العملاء وفي مقدمتها استر اتيجية إدارة علافئات العات العملاء (Chen, 2003).

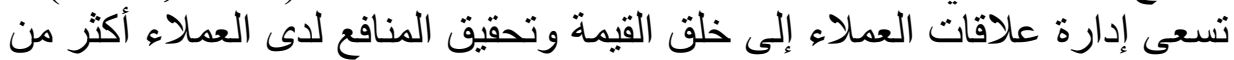

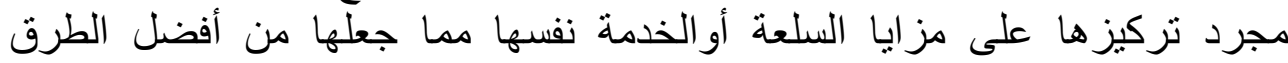

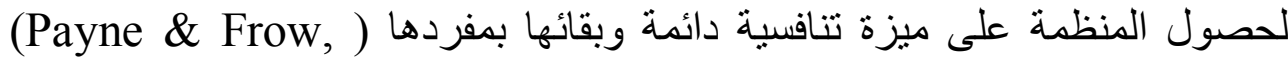

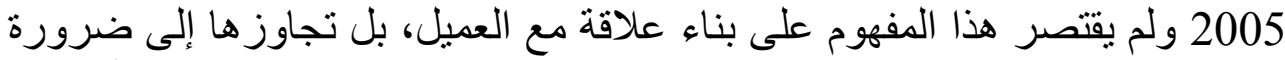

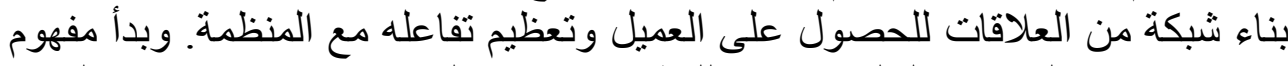

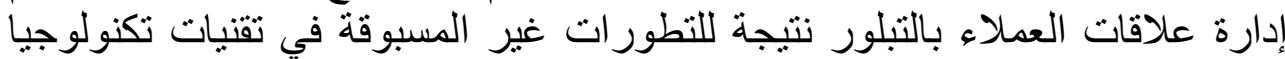
المعلومات والاتصالات، الأمر الذي دفع العديد من المنظمات إلى إنىاء إنشاء مراكز

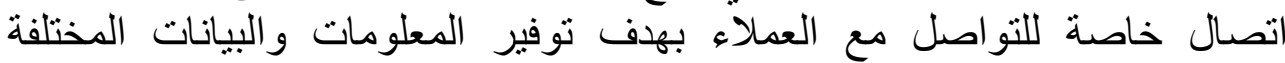
عنهم (Josiassen et al.,2014).

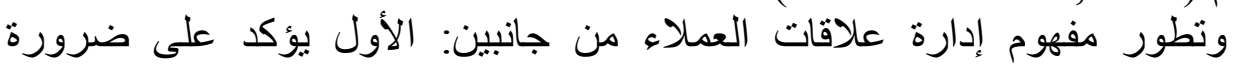

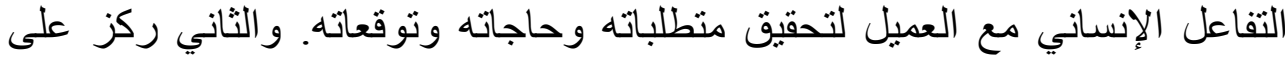

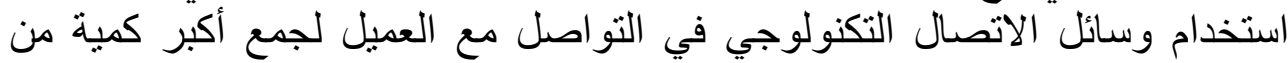
البيانات و المعلومات وتحليلها للتعرف على فلى حاجاته ورغباته لتهاته ومحاولة تلبيتها (Akroush et al.,2011)

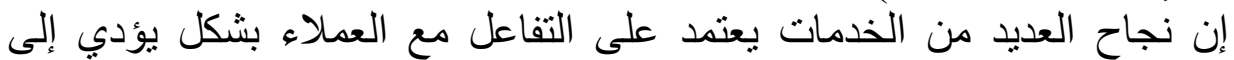

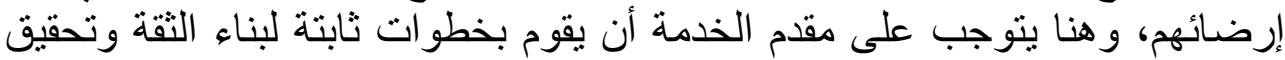

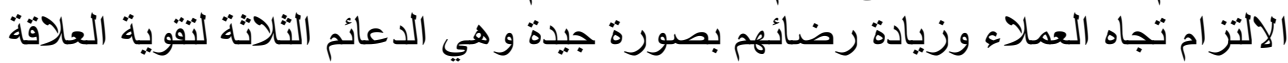

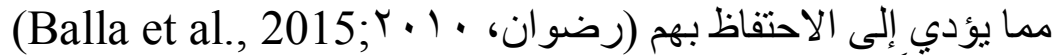

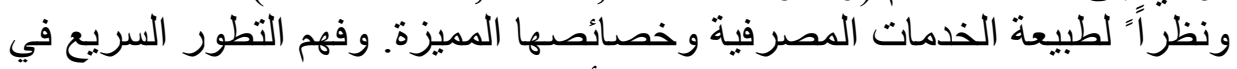

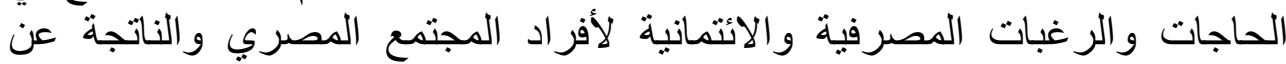

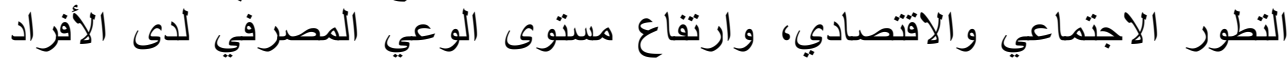




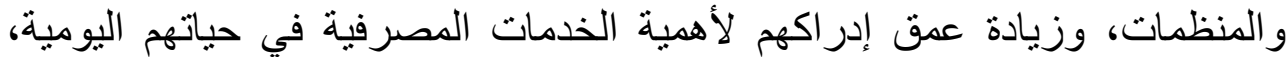

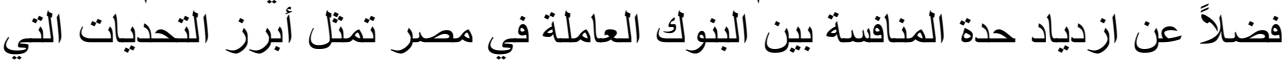

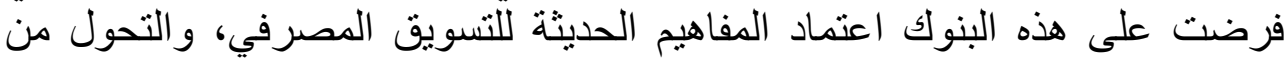

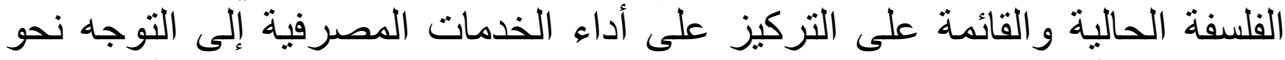

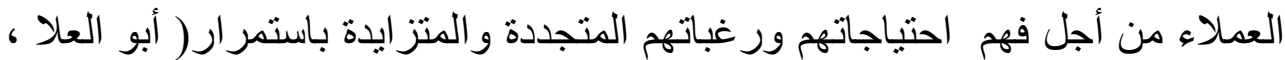

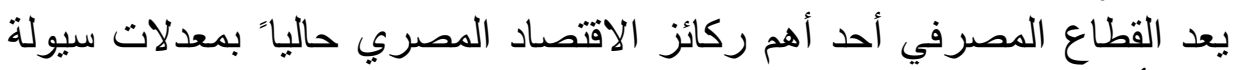

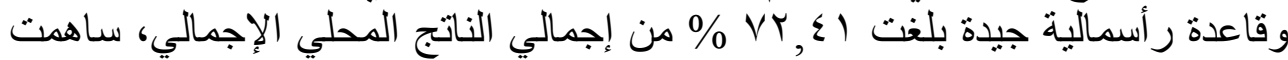

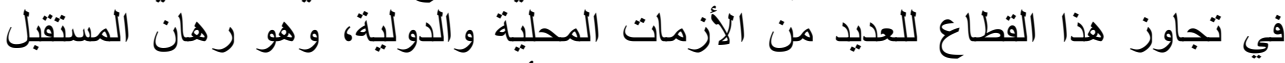

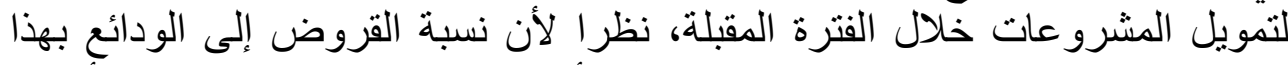

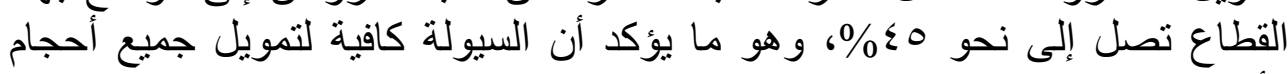

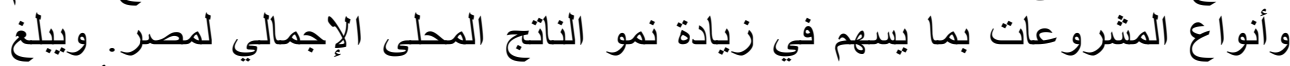

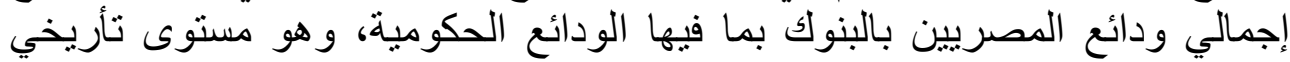

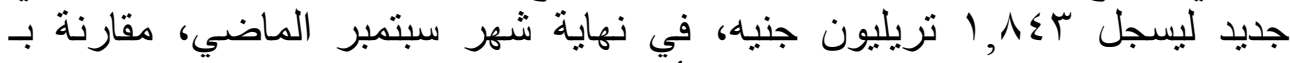

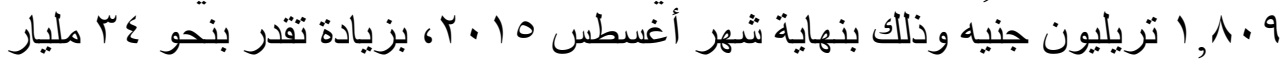

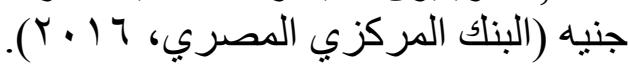

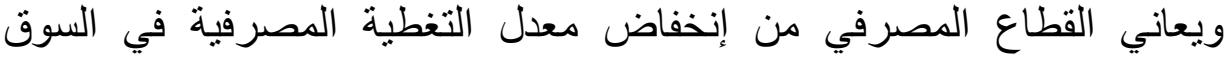

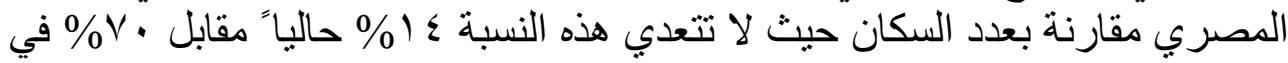

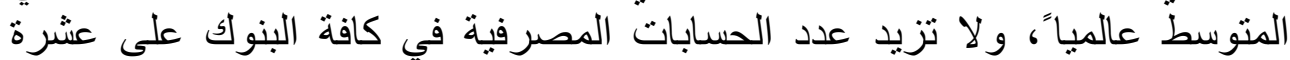

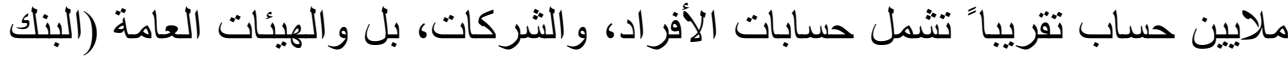

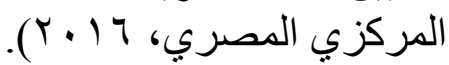
لذللك يحتاج القطاع المصرفي المصري إلى إدارة غير تقليدية للعلاقات مع العملاء

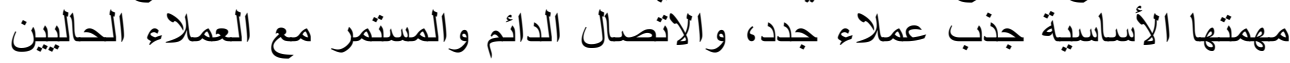

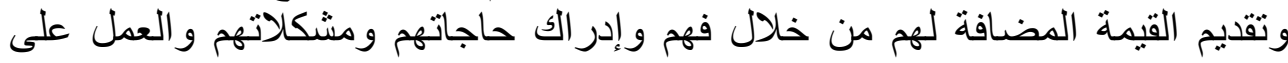

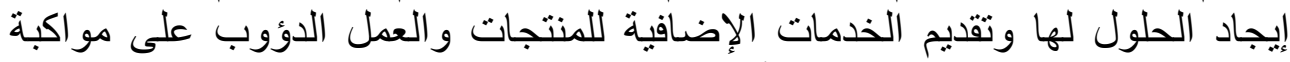

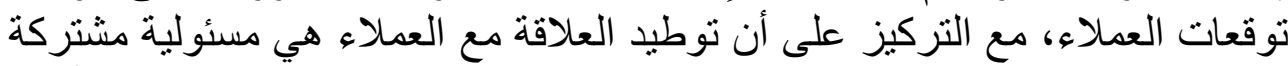

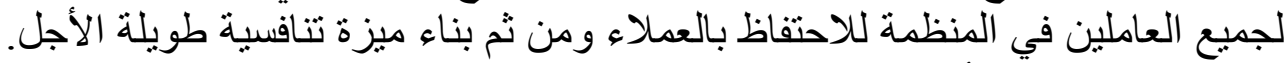

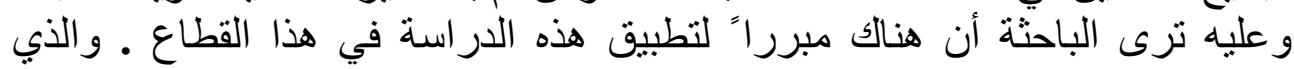

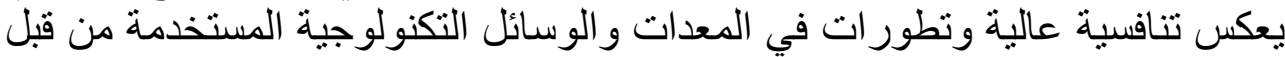

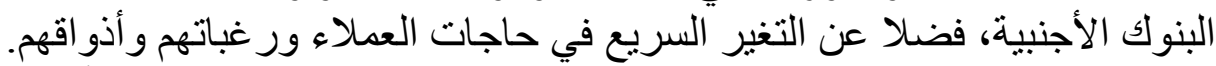

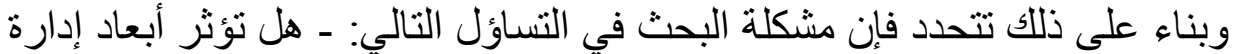

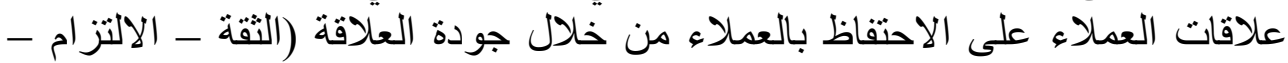

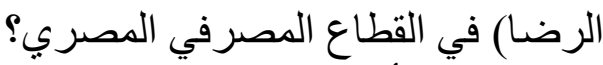

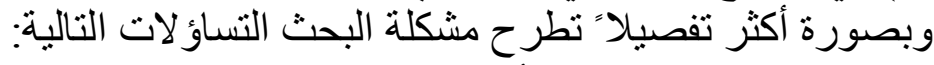

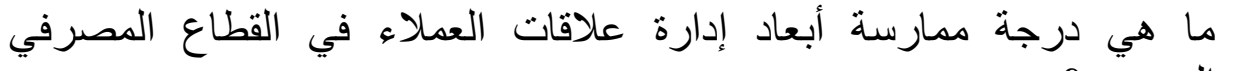

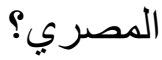




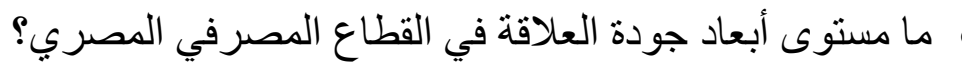

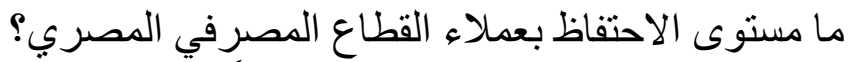

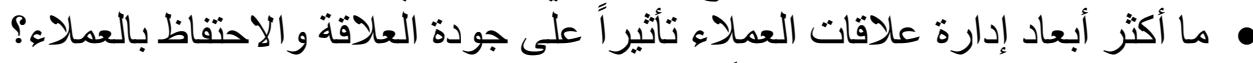

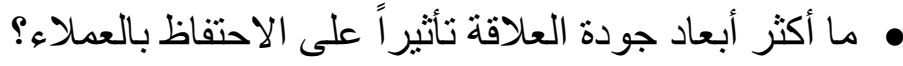

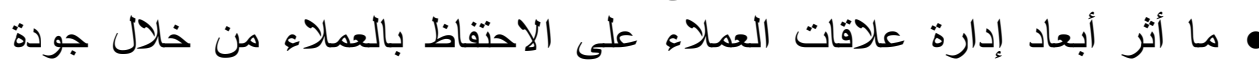

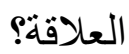

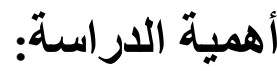

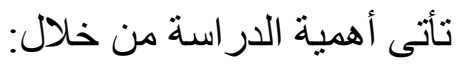

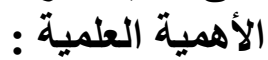

ا - فهم طبيعة العلاقة بين أبعاد إدارة علاقات العملاء، وجودة العلاقة والاحتفاظ

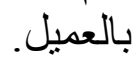

r- ترسيخ ارتباط العملاء بالمنظمات التي تمارس أنثطة إدارة علاقات العملاء

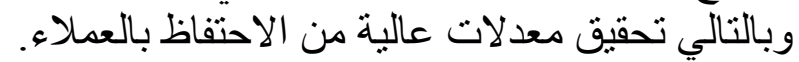

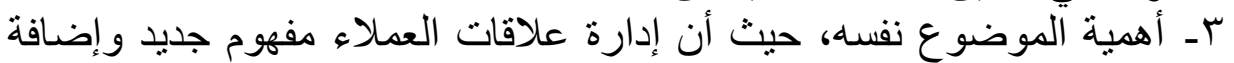

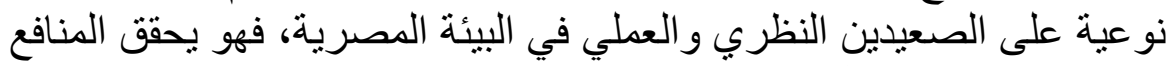

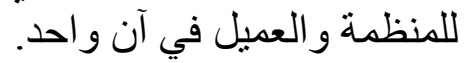
ـ ـ نركز الدراسة على كيفية الاحتفاظ بالعميل، مع نقص في الدراسات الخاصة

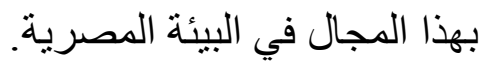
الأهمية التطبيقية : المبنية

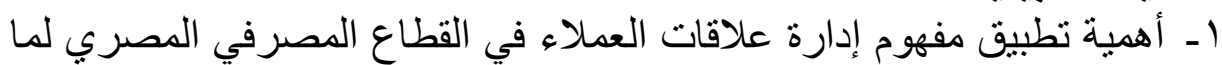

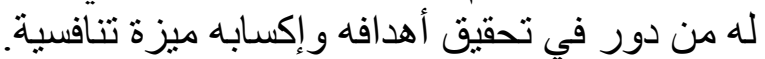

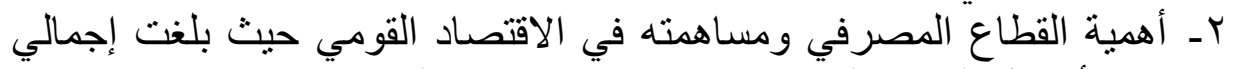

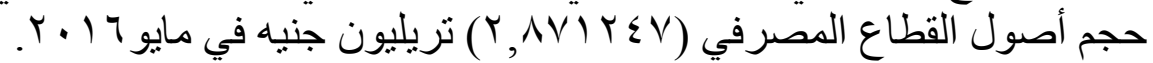
أهداف الار استة:

تهدف هذه الدراسة إلى التوصل إلى نتائج أكثر و اقعية فيما يتعلق بأتز أبعاد إدارة

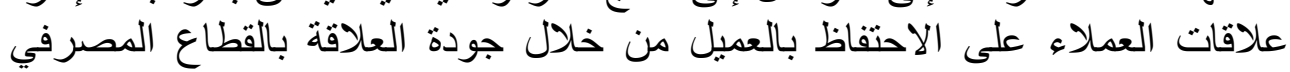

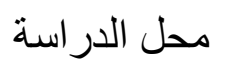
وتحديداء تهذف الدر اسة إلى تحقيق ما يلي: 1 ـ در اسة العلاقة بين إدارة علاقات العملاء وجلاء وجودة العلاقة في القطاع المصرفي.

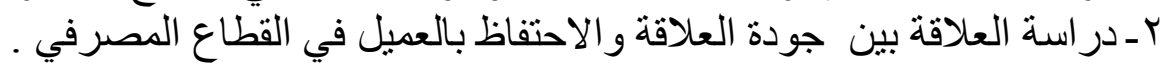

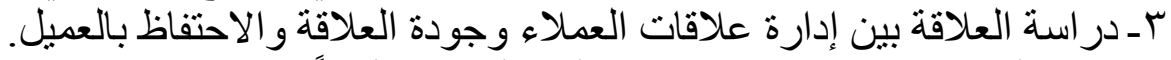

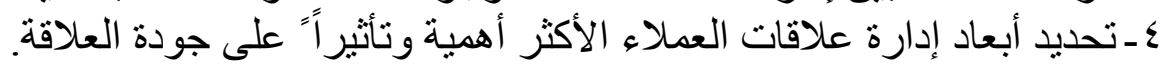

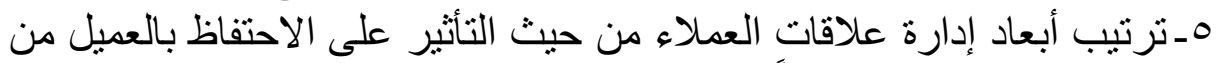
خلال جودة العلاقة استناداً إلى الدار اسلة العاء الميدانية.

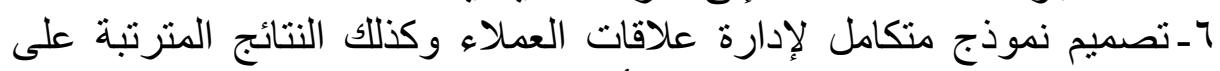
تطبيق القطاع المصرفي المصري لأبعادة. 
Vـ التوصل إلى مجموعة من النتائج و التوصبات و التي يمكن الاستفادة منها في

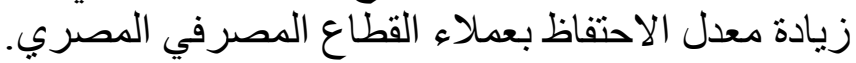

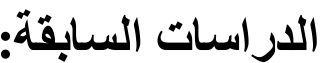

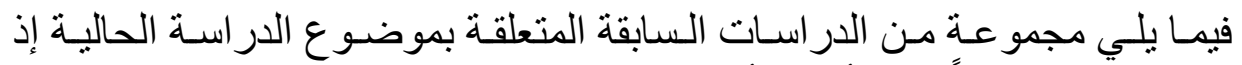

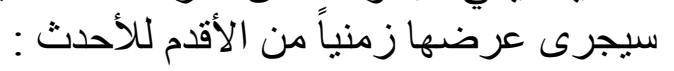

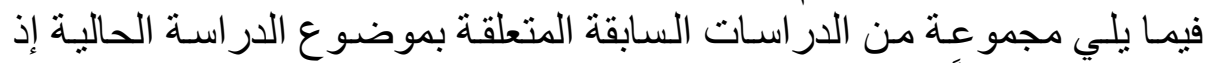

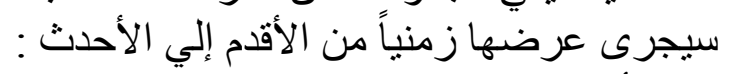

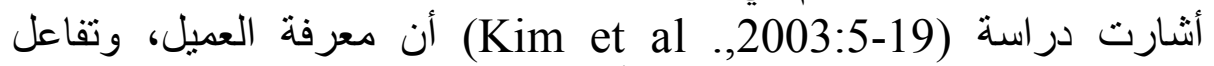

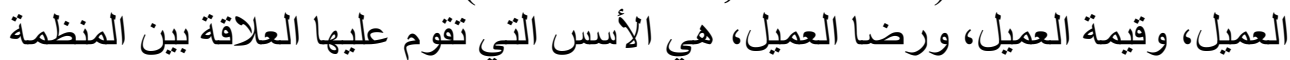

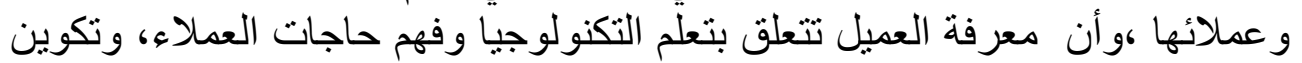

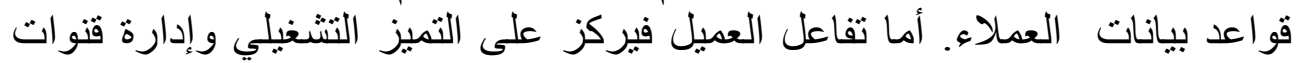

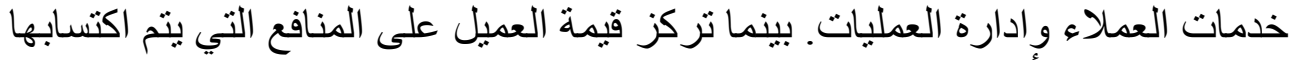

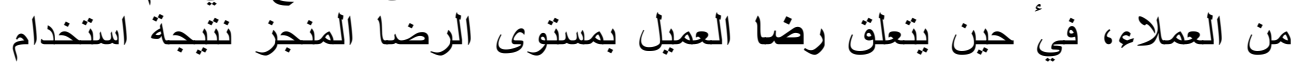

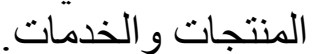

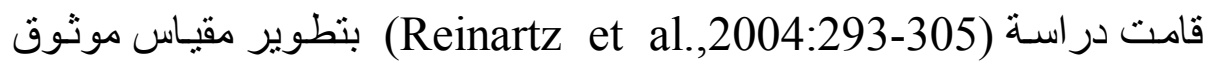

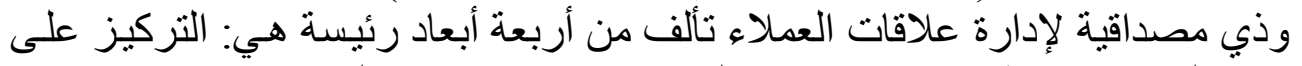

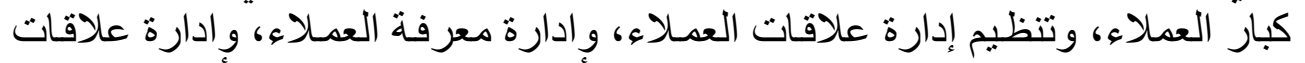

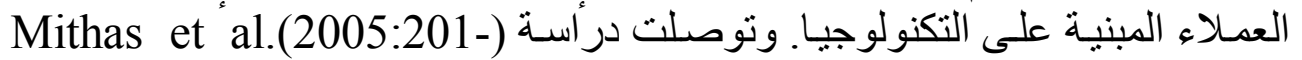

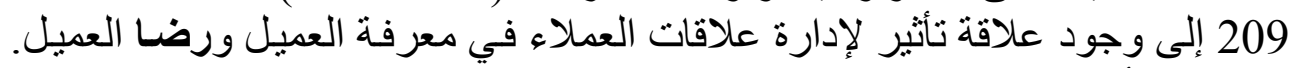

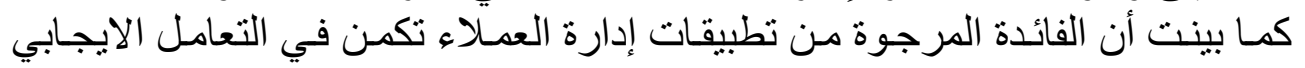

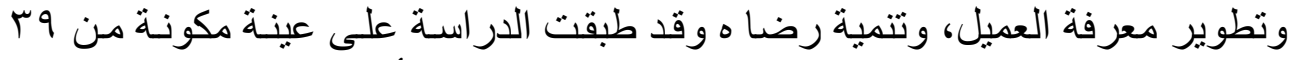

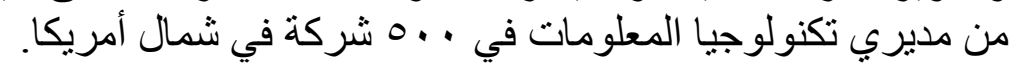

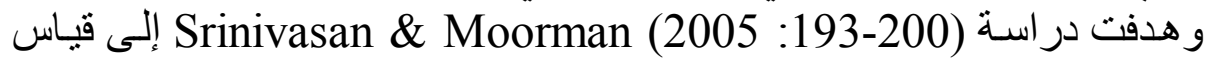

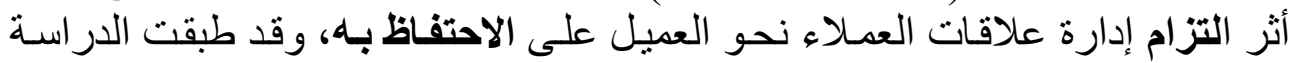

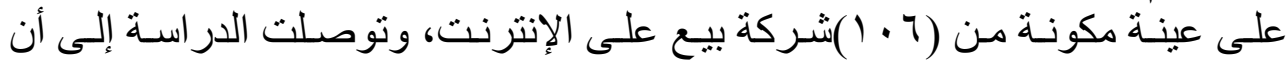

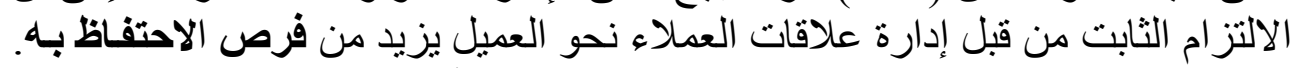

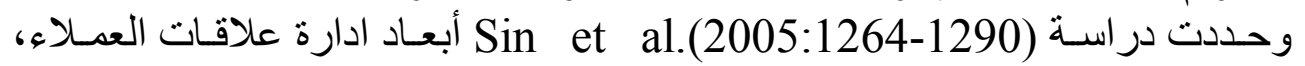

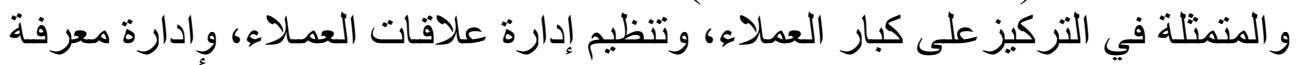

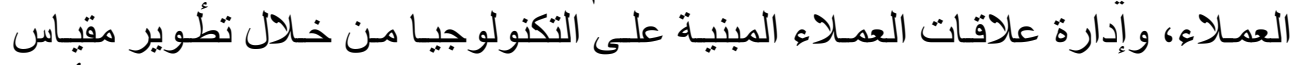

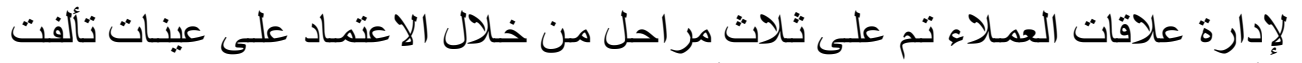

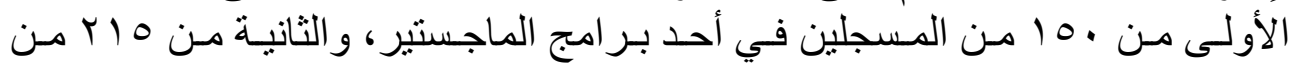

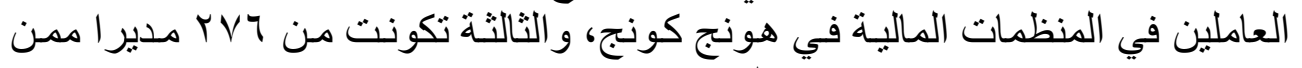
حضروا دور ات في إدارة علاقات العملاء. هونجاء

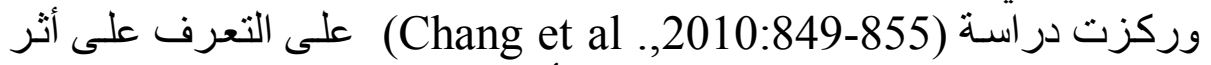

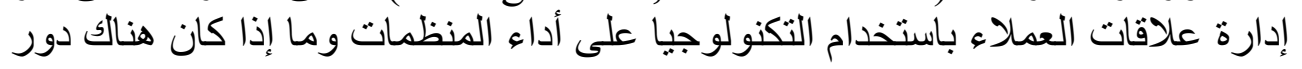

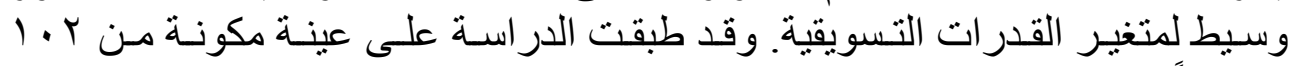

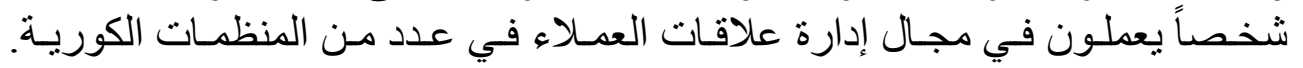


وتوصلت الدراسة أن إدارة علاقات العملاء باستخدام التكنولوجيا لها أثر إيجابي غير مباشر على أداء ادارة علاقات العملاء المبنية من خلال القداء القدات التهات التسويقية.

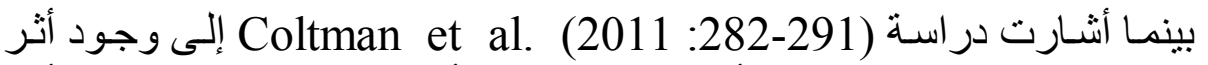

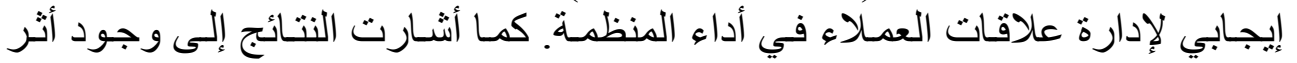

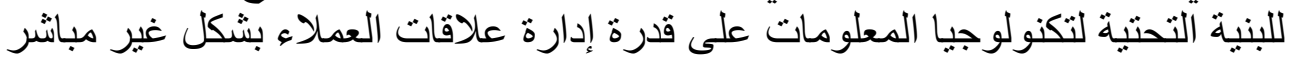

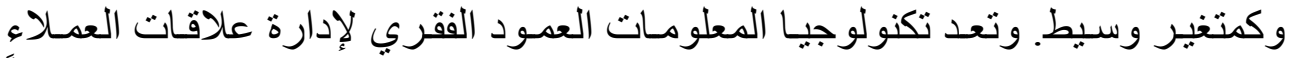

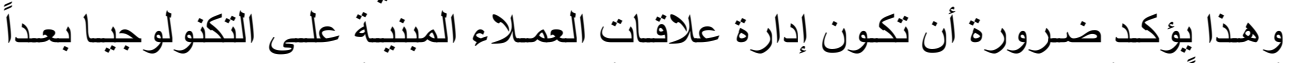
أساسياً من أبعاد إدارة علاقات العملاء لخلق أثر إيجابي في الأداء.

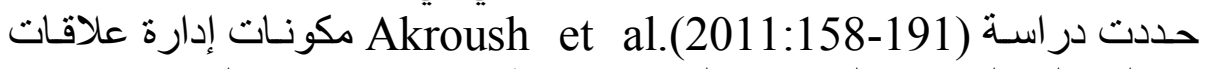

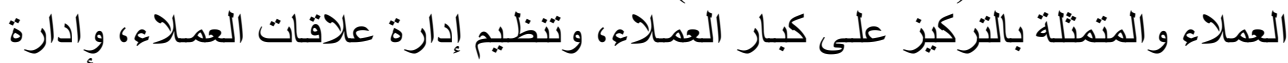

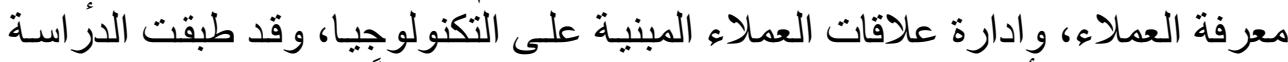

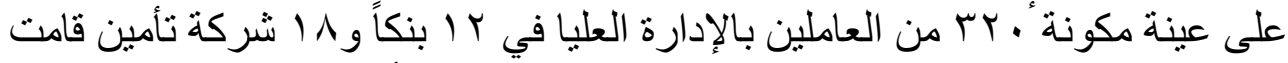

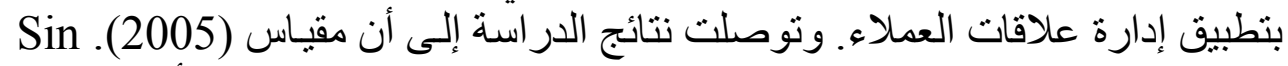
et al

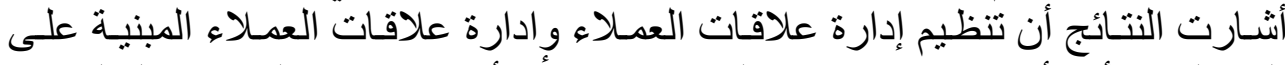
التكنولوجيا أهم أبعاد إدارة علاقات العمارة العاء في تبائن أداء منظمات الخدات الخدمات المالية.

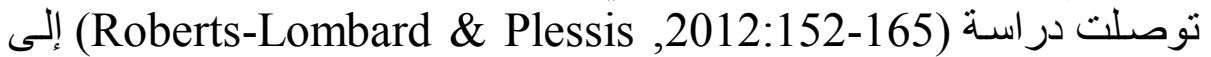

وجود علاقة إيجابية وقوية ذات دلالة إحصائية بين إدارة علاقات العماتلاء و والاحتفاظ

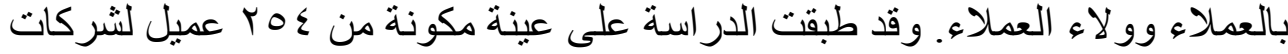

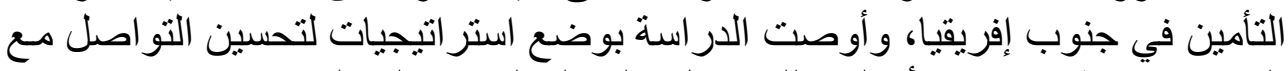

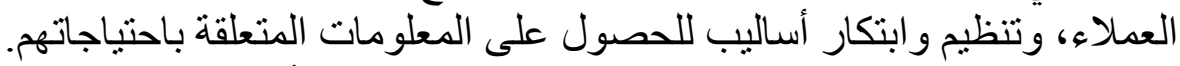

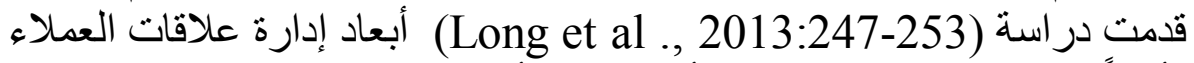

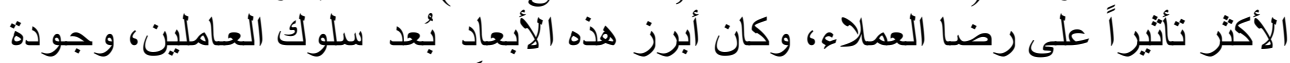

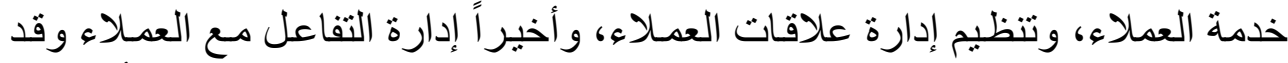

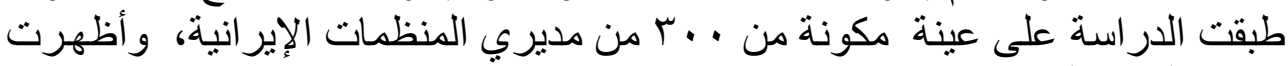

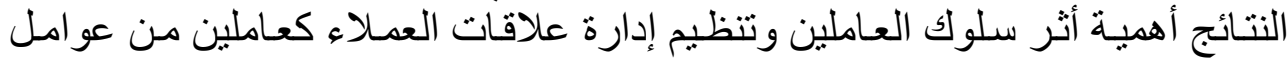
إدارة علاقات العملاء في رضا التر العملاء.

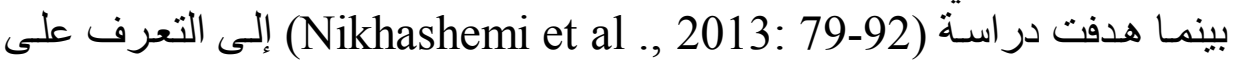

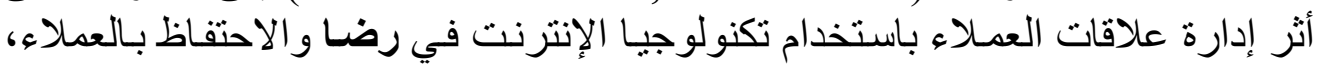

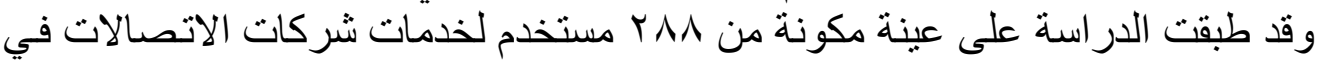

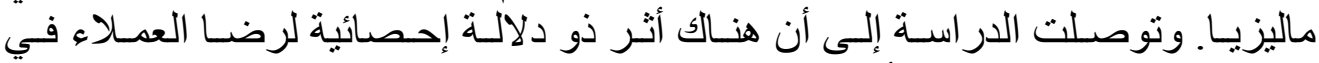

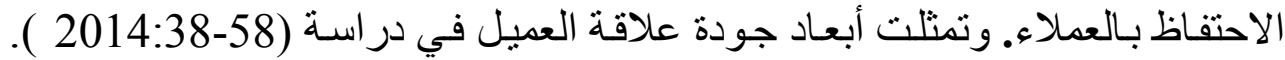
Mullins et al

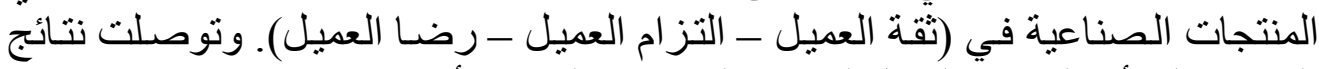
الدارسة إلى أن التوجه بالعميل له إثر على جودة العلاقة بأبعادها.

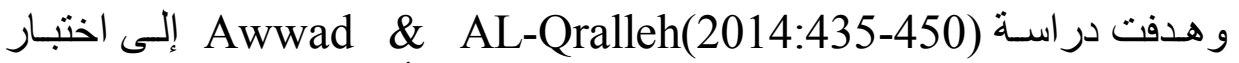

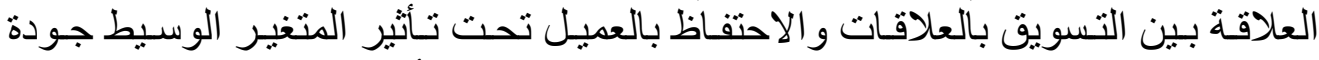

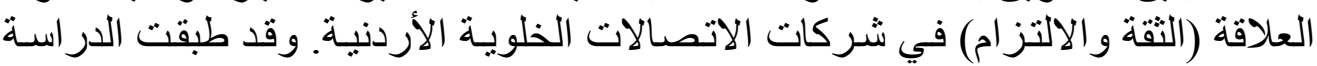




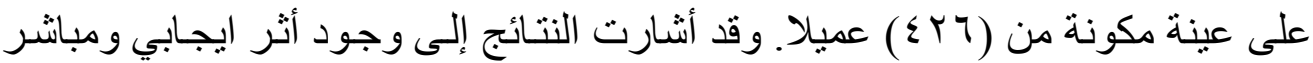

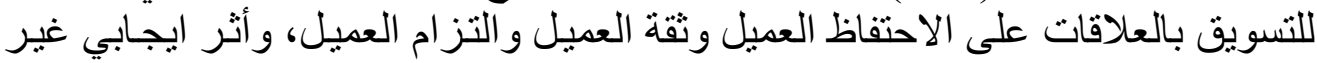

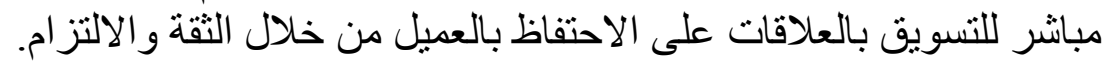

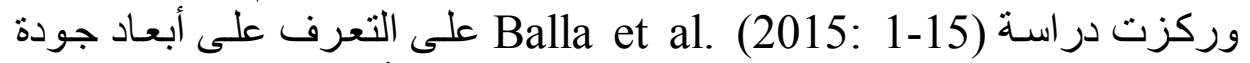

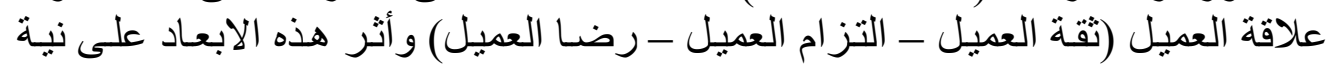

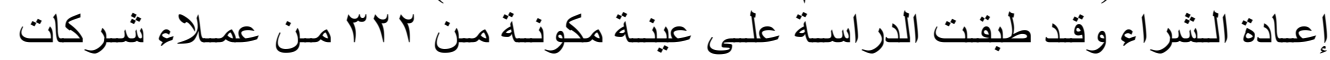

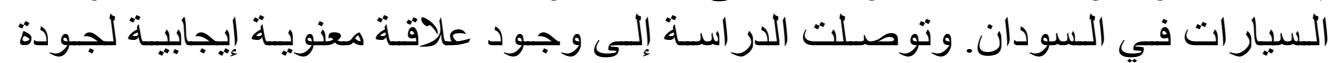

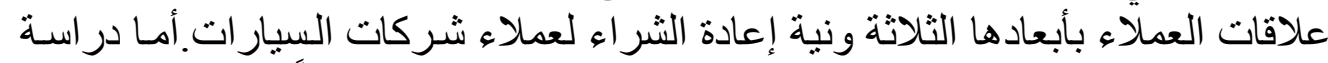

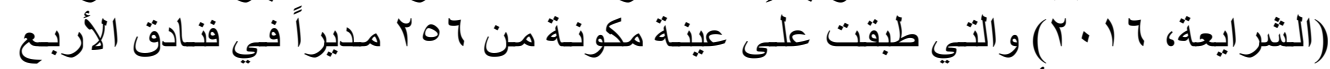

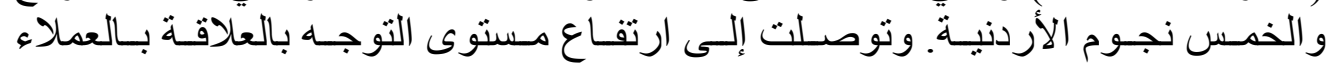

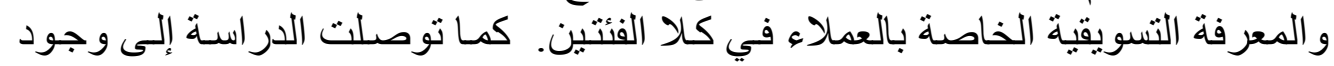
علاقة إيجابية لكل عناصر إدارة علاقات العملاء على الاحتفاظ بالعاء العملاء.

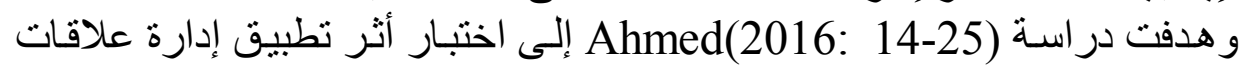

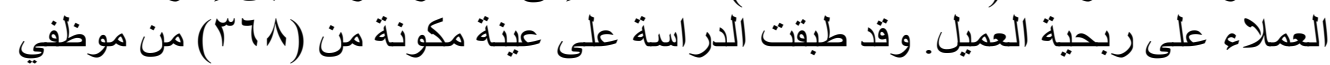

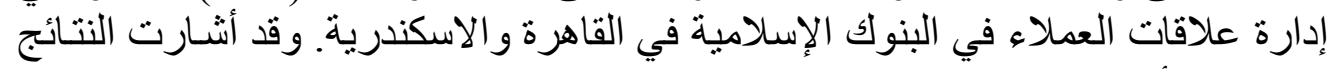

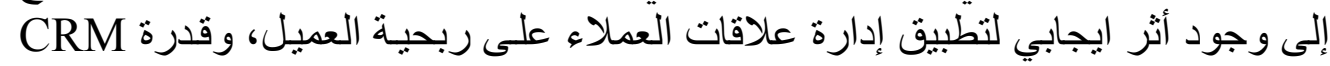

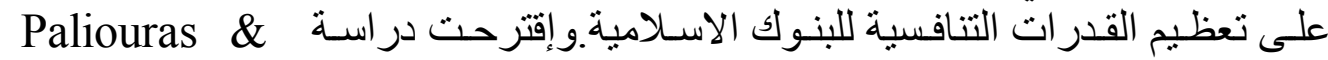

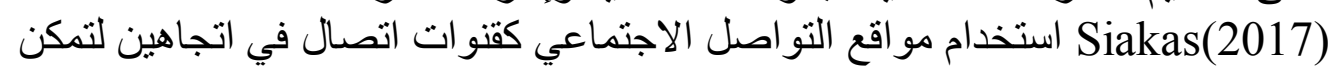

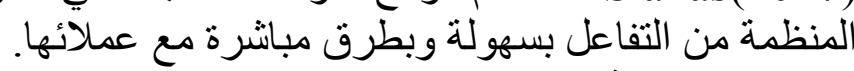

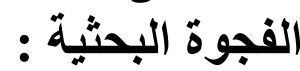

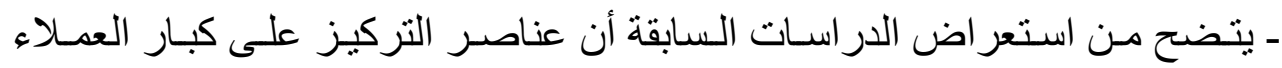

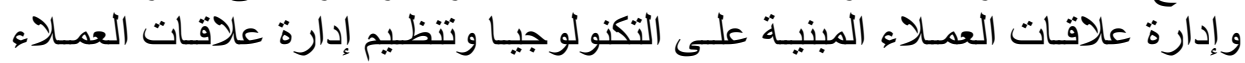

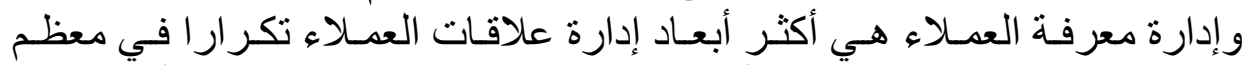

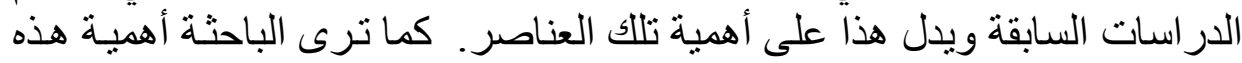

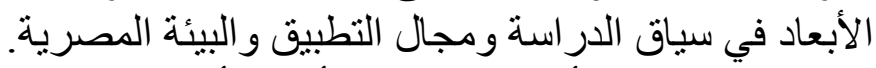

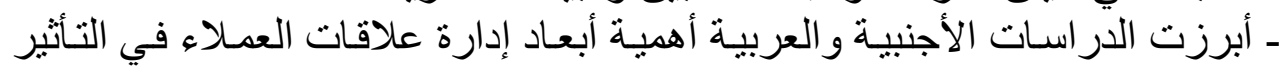

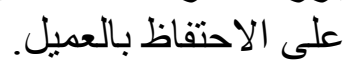

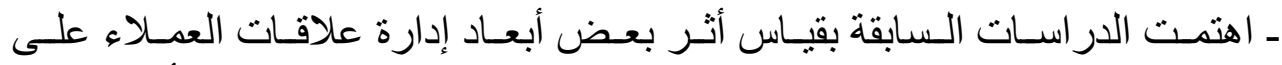

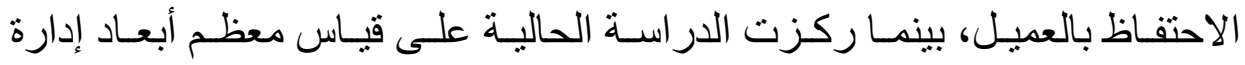

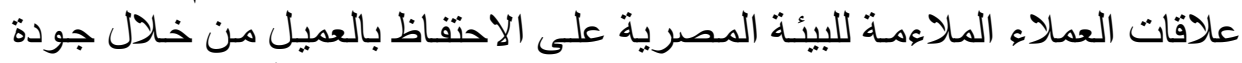

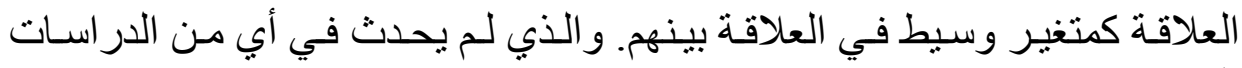

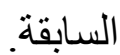

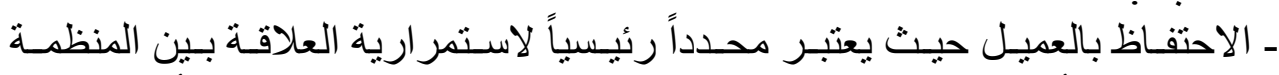

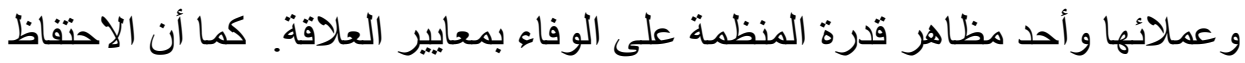
بالعميل يأتي بعد جودة العلاقة و الرضا عن خدماتها ومنتجاتها. 


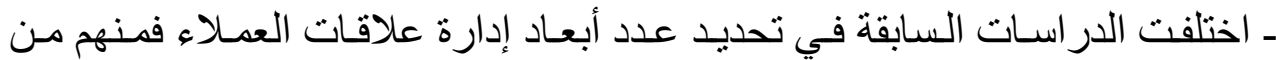
اكتفي ببعدين فقط (التركيز على كبار العملاء - إدارة علاقات العات العملاء المبنية على العي ـ التكنولوجيا) ومنهم من ركز على على أربعة أبعاد. أبعاد.

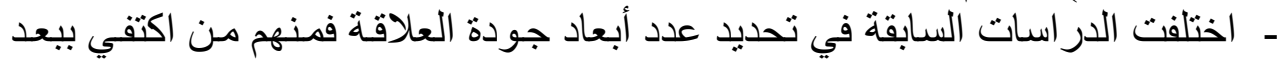

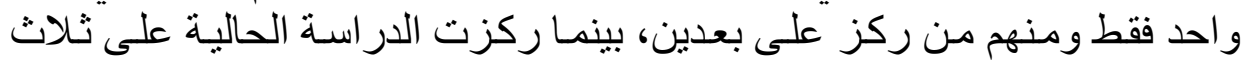

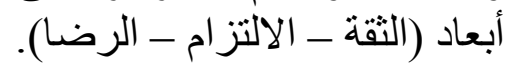

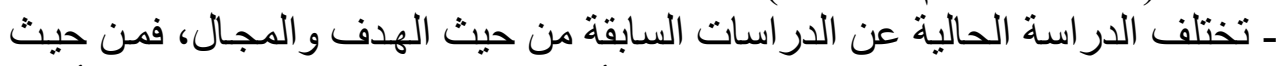

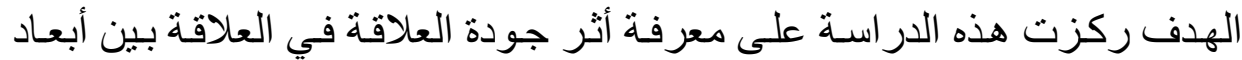

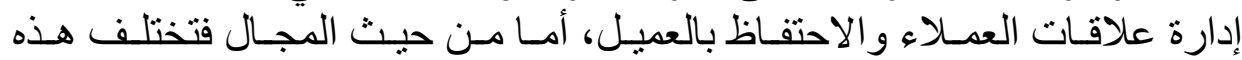

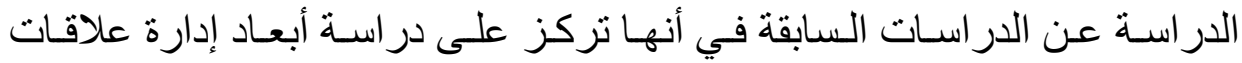

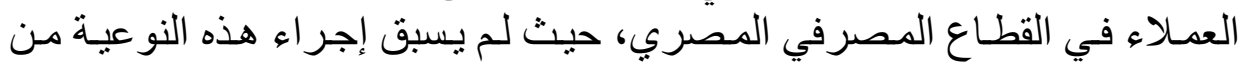

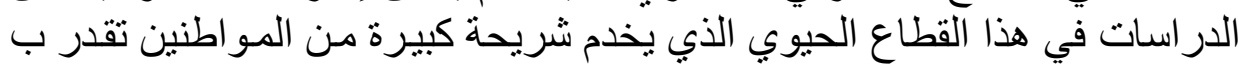

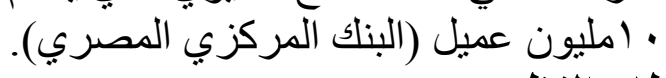

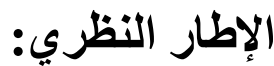

إدارة علاقات العملاء:الإ: Customer relationship management يعرف كلا من (Sawhney \& Zabin, 2001) إدارة علاقات العملاء العملاء على أنها

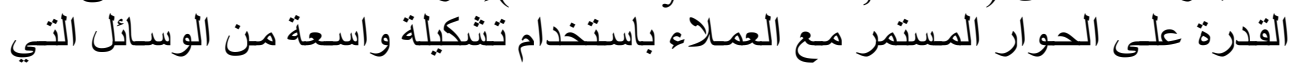

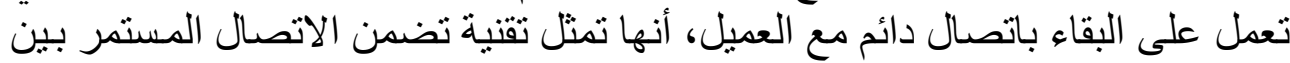

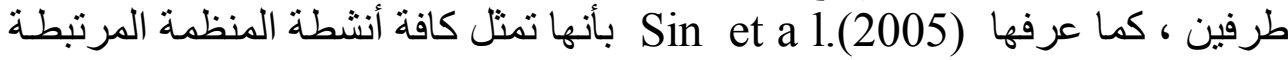

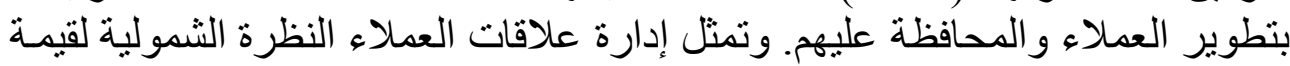

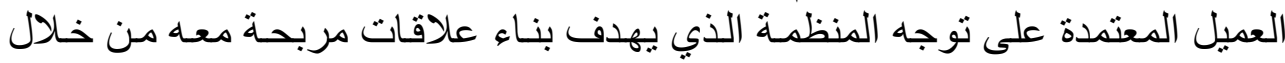

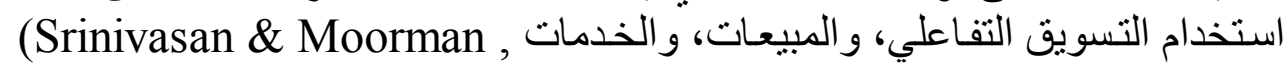

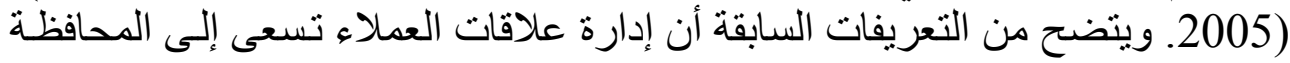

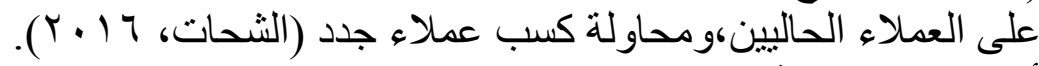

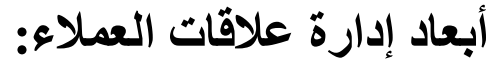

لكي تتمكن إدارة علاقات العملاء العملاء من تحقيق أهدافها، عليها أن نركز على أنى

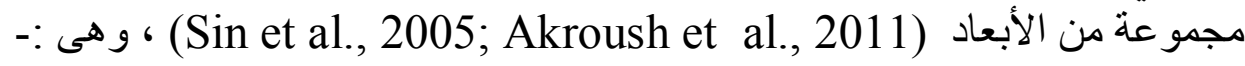

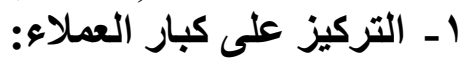
يشير بُعد التركيز على كبار العملاعلاء إلى قدرة المنظمة على الإيفاء بحاجات

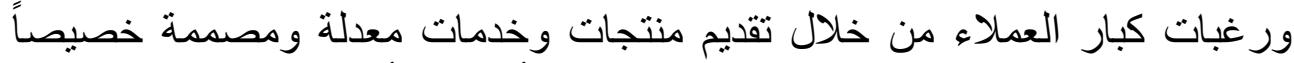

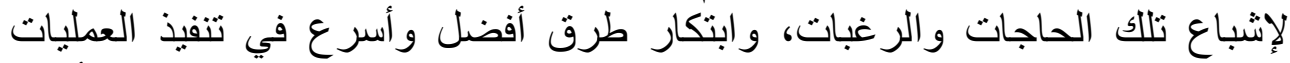

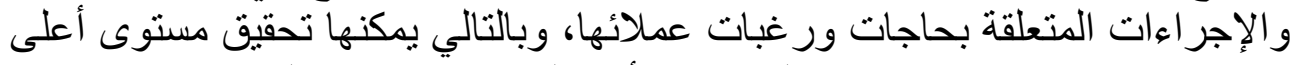

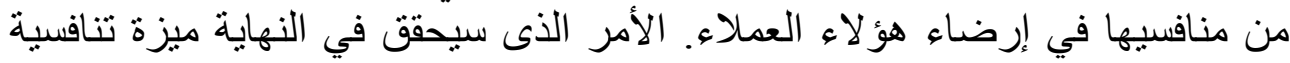
لاتلك المنظمات ويزيد من حصنها السواه السوقية (Wilson et al.,2012). r - تنظيم إدارة علاقات العملاء:

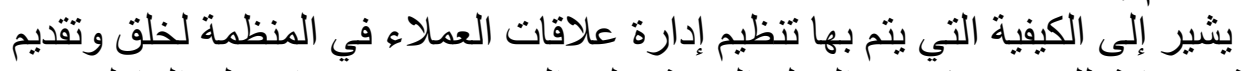

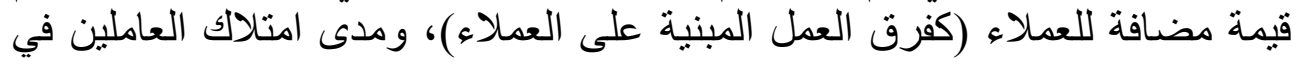




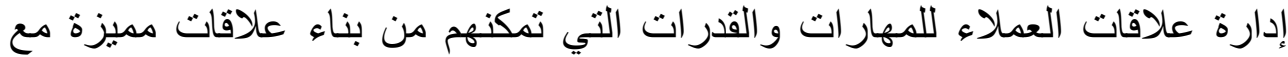

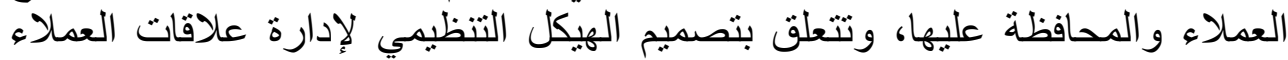

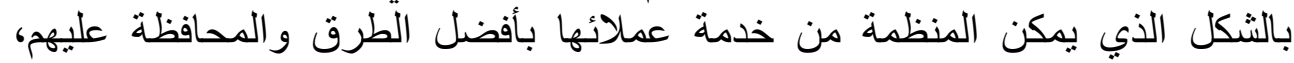

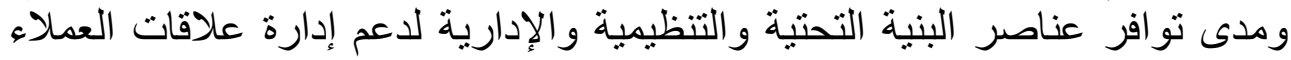

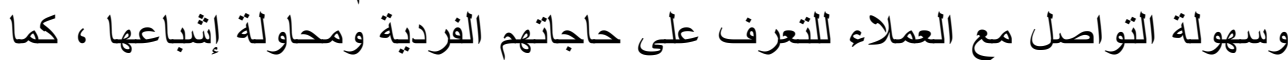
تتعلق بتبني المنظمة لثقافة تنظيمية تساعد على تحقيق احتياجات ورغبات التهات العملاء

(Ernst et al., 2011)

ولضمان نجاح إدارة العلاقة في مهمتها لابد من توفر هيكل تنظيمي ينسجم

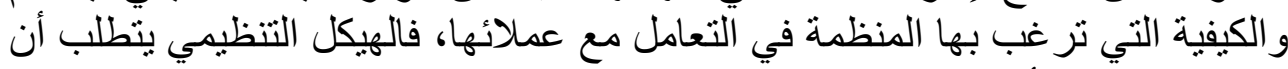

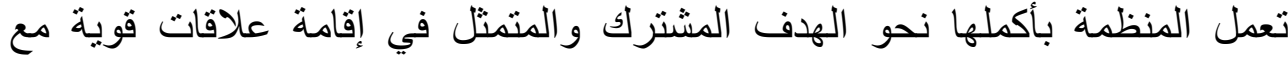

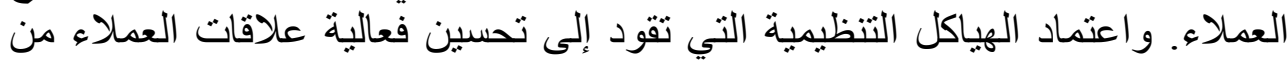

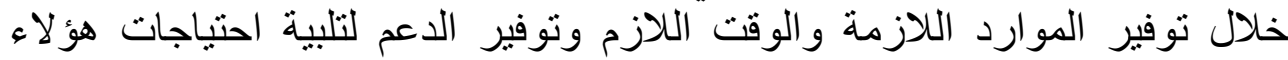

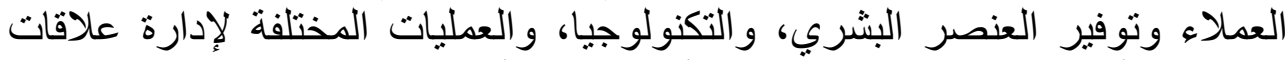

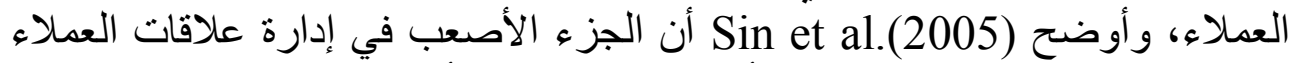

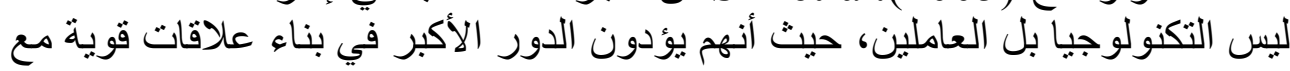

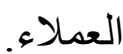

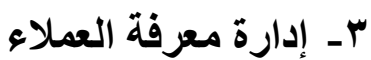

تشير إلى عمليات اكتساب وتحليل معلومات العات العملاء وتحويلها إلى معرفة مفيدة

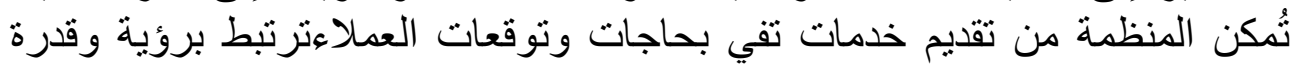

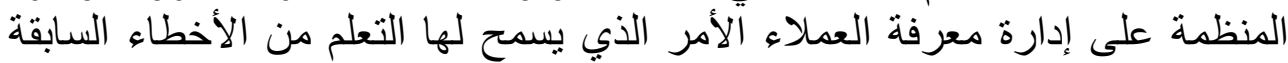

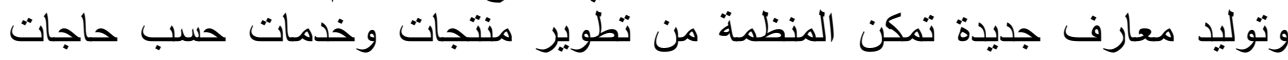

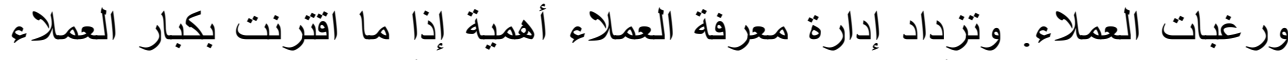

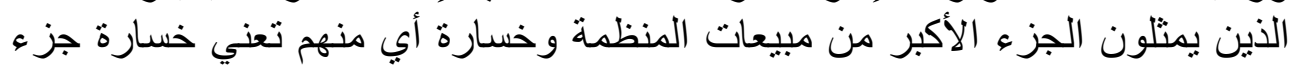

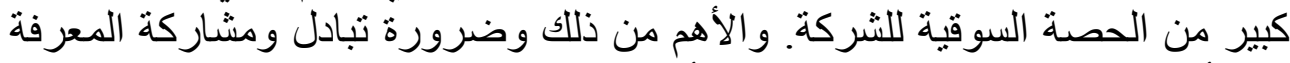

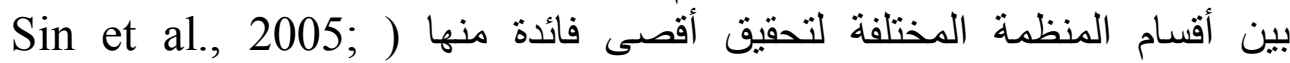
.(Akroush et al., 2011 ـ - إدارة علاقات العملاء المبنية على التكنولوجيا

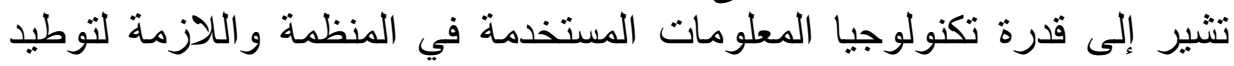

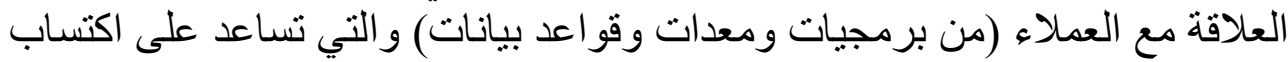

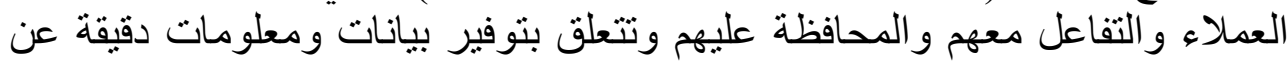

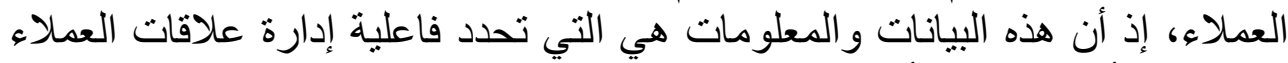

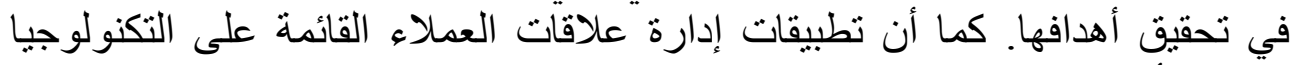

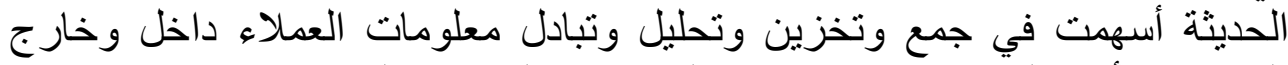
المنظمة الأمر الذي عزز من قدرة المنات ونظمات الحديثة على الاستجابة لاحتياجات

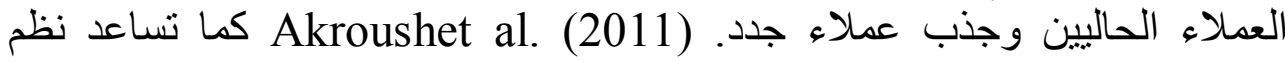
المعلومات وتكنولوجيا المعلومات الحديثة في تطوير العلاقات العات مع العملاء وفي إدارة

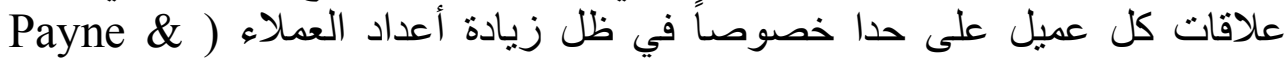

.Frow $(2005$ 
جودة العلاقة مع العميل:Customer Relationship Quality

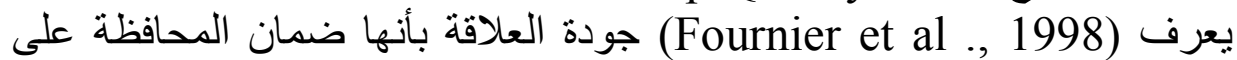

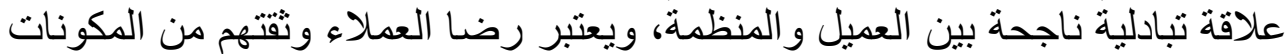

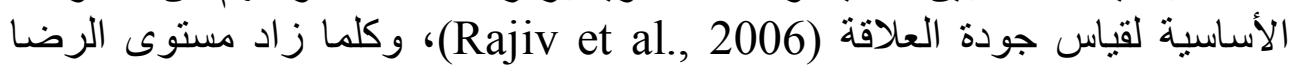

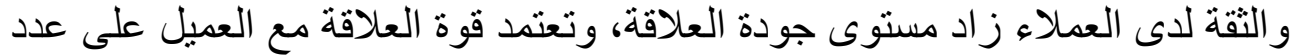

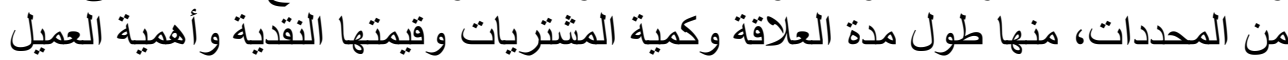

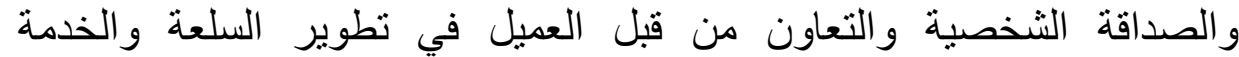
Crönroos, 1994:13)

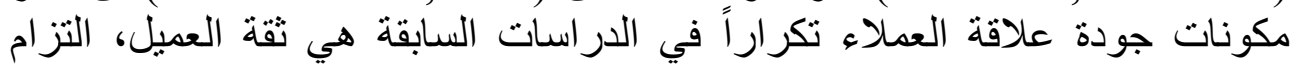

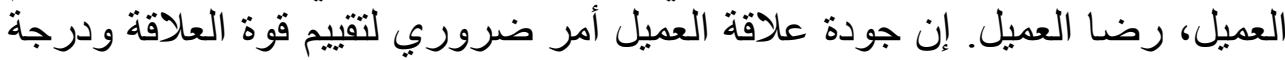

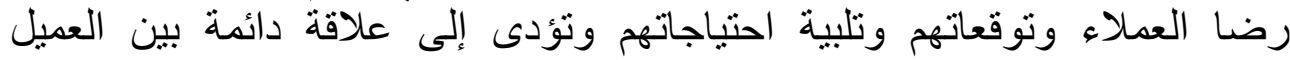

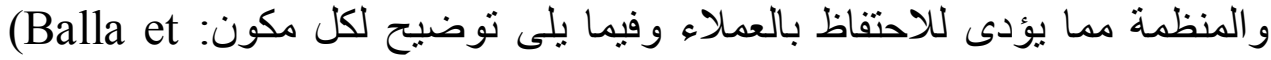
al.,2015) ـ الثقة: - 2015) -

تُعد الثقة بُعداء من أبعاد جودة العلاقة لأنها أساس التعامل وأساس بناء علاقات

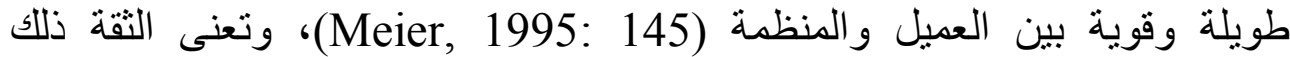

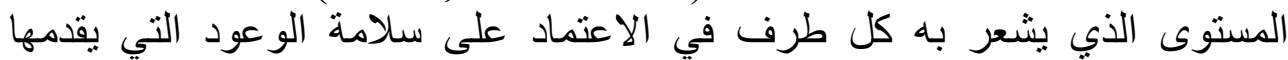

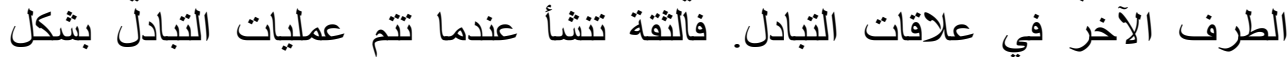

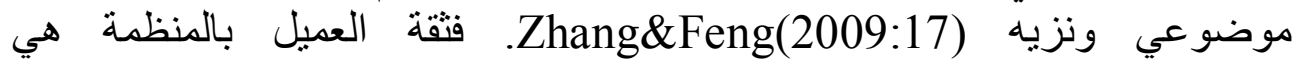

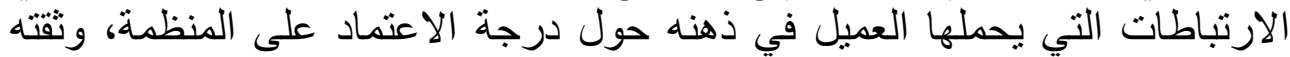

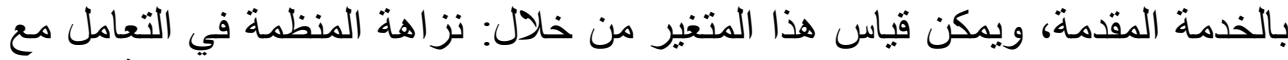

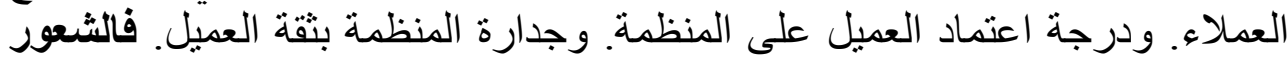

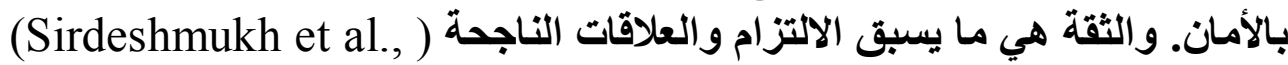
. 2002

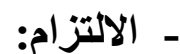

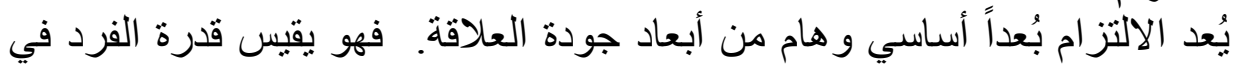

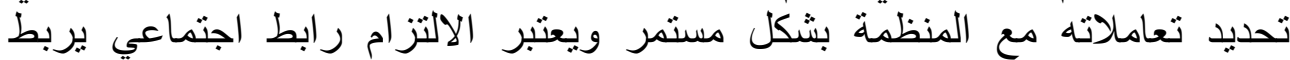

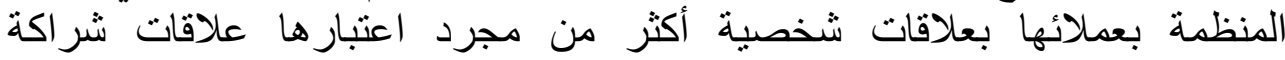

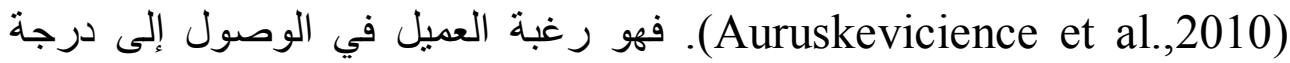

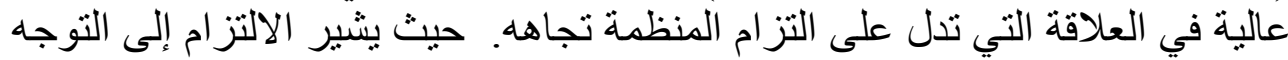

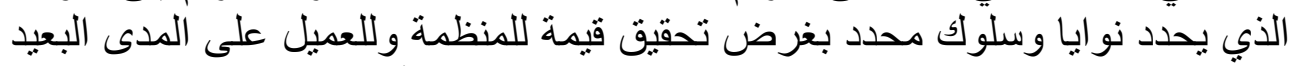

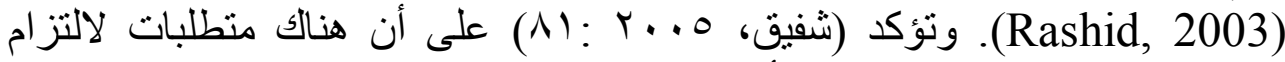

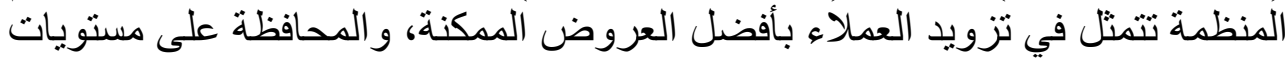

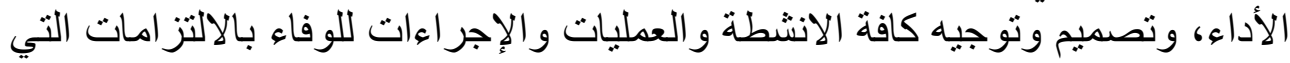

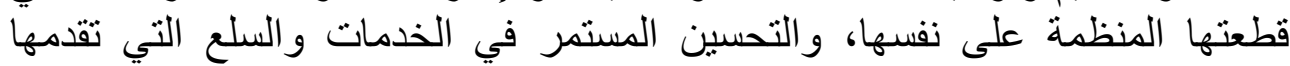


يُعرف رضا العميل بأنه رد فعل إيجابي على تجربة استهلاك سلعة أو خدمة أو

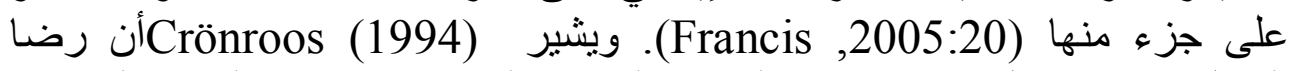
العميل يرتبط بشكل غير مباثر بالحصة السوقية التي تعتبر مقياس لنجاح النياح المنظمة.

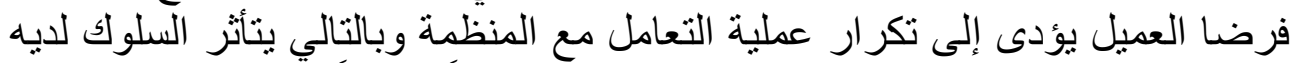

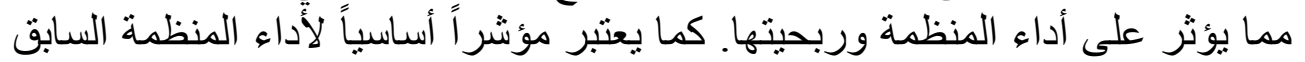
و الحالي و المتوقع في المستقبل. (Oliver, 1999) .

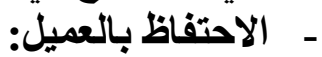

تحرص المنظمة على الاحتفاظ بالعملاء الحاليين لأن تكلفة الحصول على عملاء

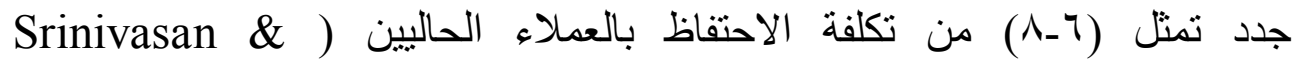

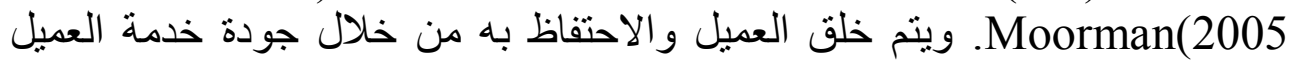

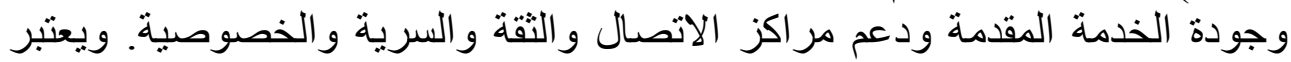

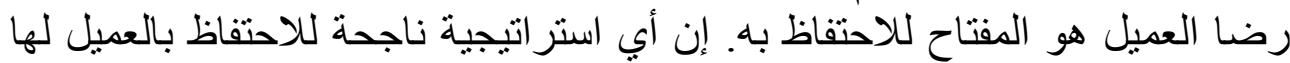

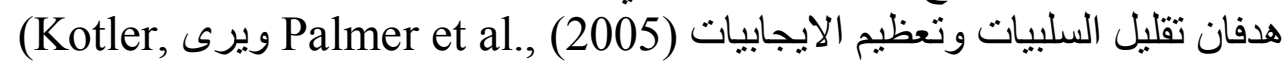

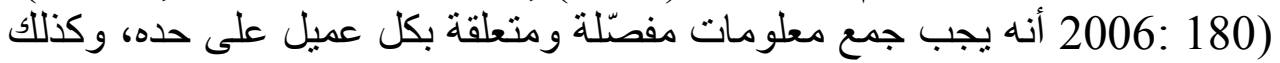

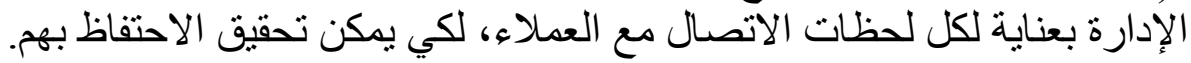

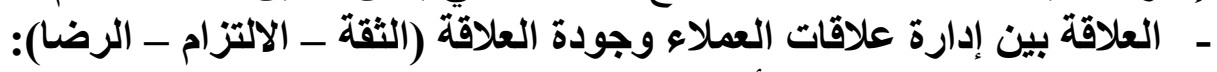

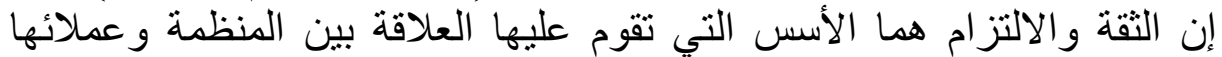

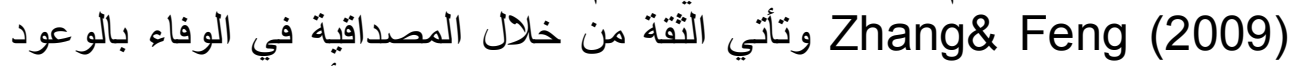
التي يقدهها المسوقون للعملاء

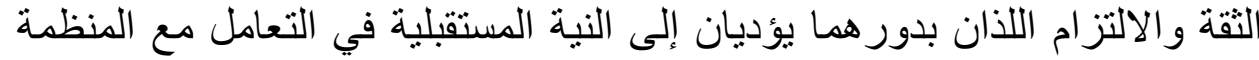

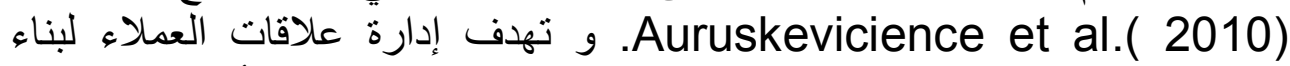

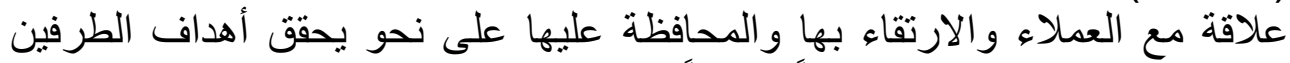

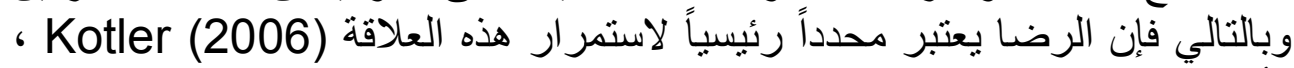

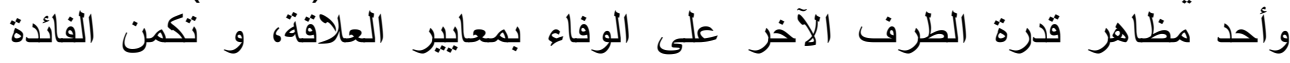

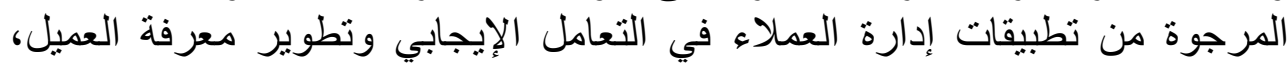

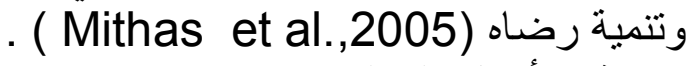
تثبير أدبيات الإدارة (Sin et al., 2005; Akroush et al., 2011). أنه لبناء

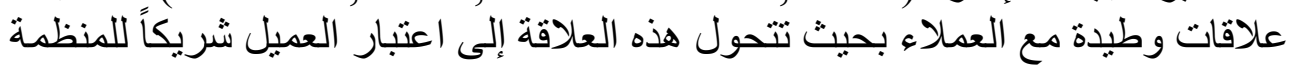

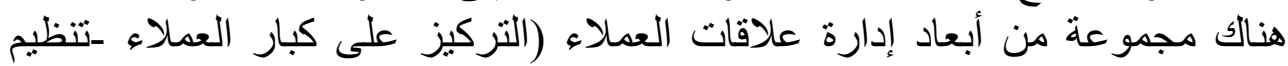

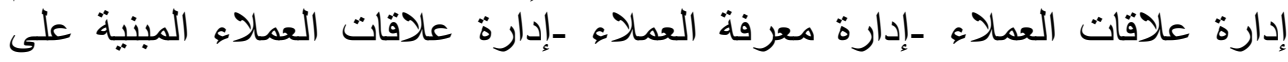
التكنولوجيا (291-82:

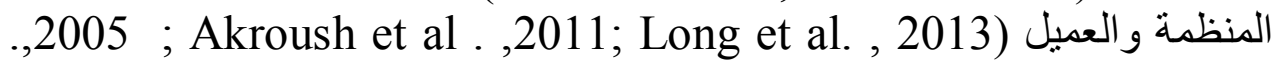
. (Sin et al العلاقة بين جودة العلاقة (الثقة ـ الالتزام ـ الرضا) والاحتفاظ بالعميل:

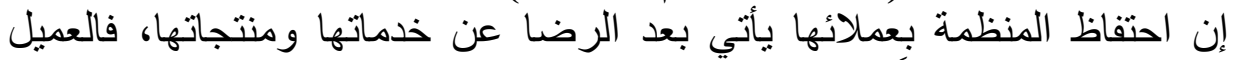

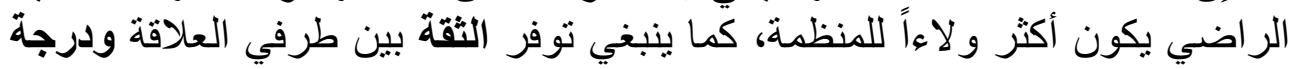

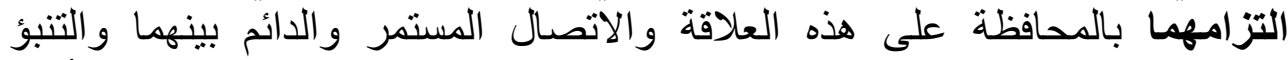

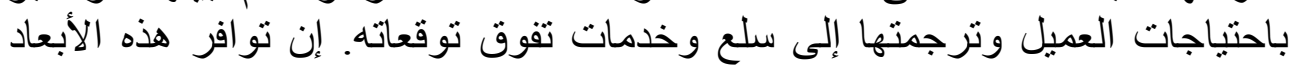


الثثلاثة لجودة العلاقة (الثقة ـ الالتزام - الرضا) يساعد المنظمة على الاحتفاظ

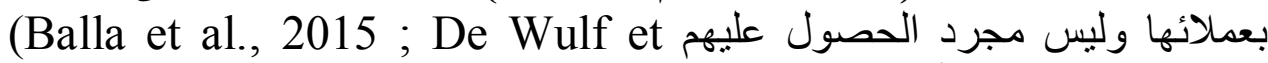
Crönroos (1994). وal.,2001)

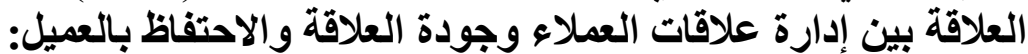

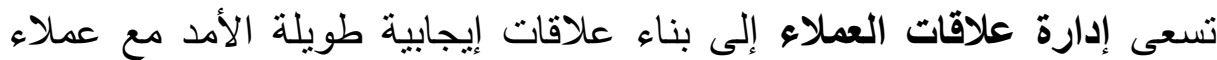

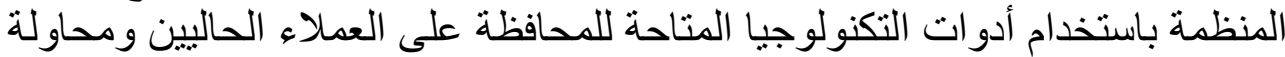

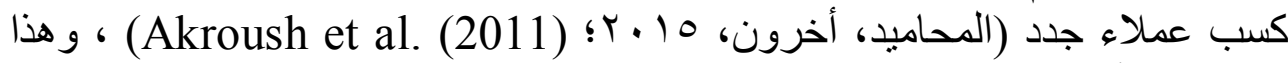

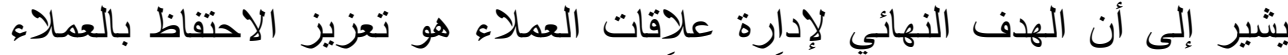

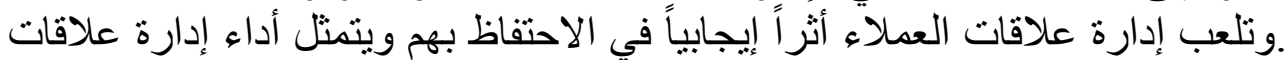

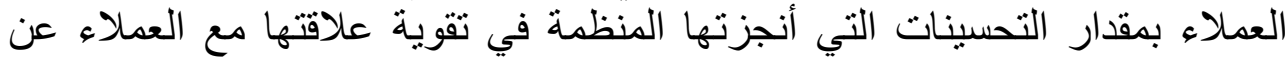

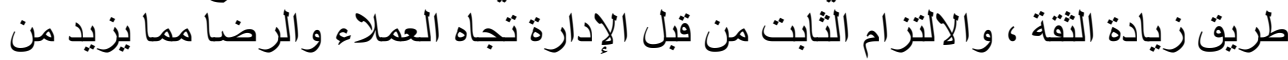

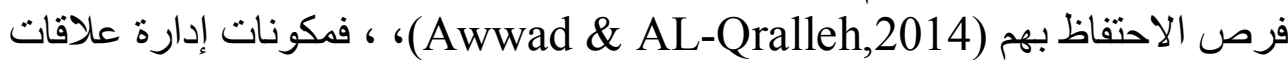

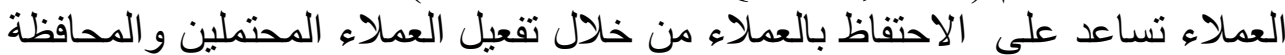

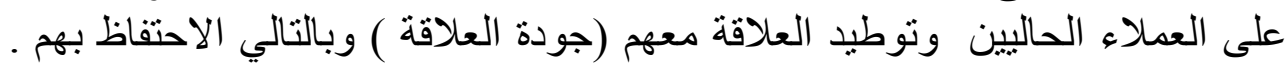

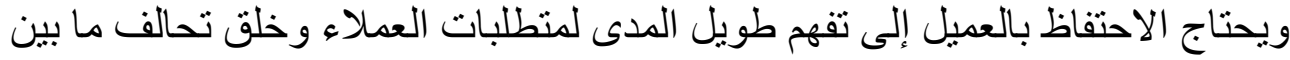

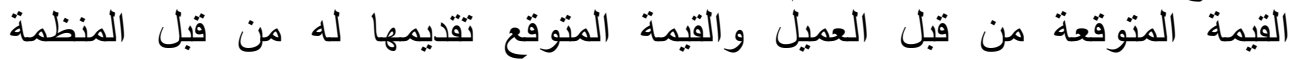
.Srinivasan \& Moorman(2005)

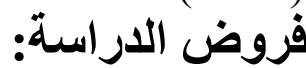

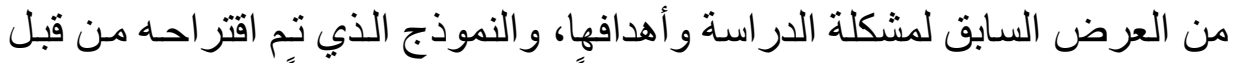
الباحثة فإنه يمكن صياغة الفروض التئن التالية تمهيداً لاختبار ها إحصائياً.

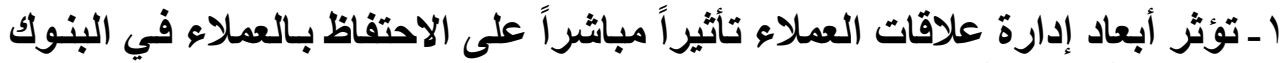

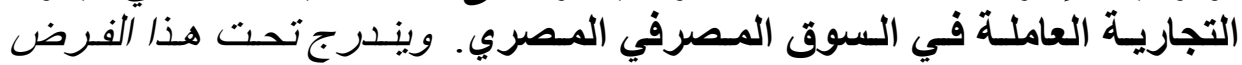
الفروض الفرعية التالية: الفيز / / ـ يؤثر التركيز على كبار العملاء تأثير اً مباشر اً على الاحتفاظ بالعملاء في البنوك

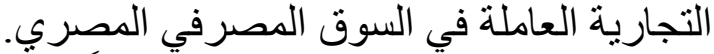

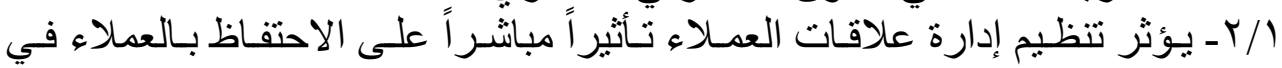

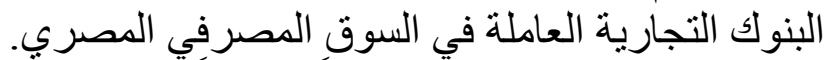

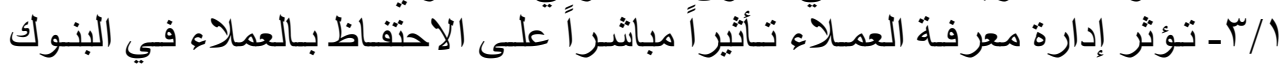

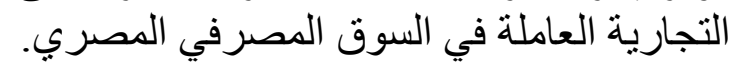

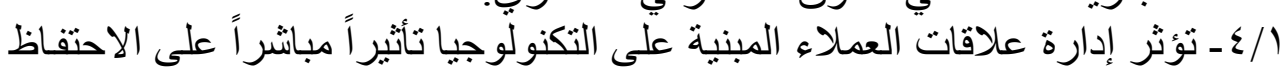

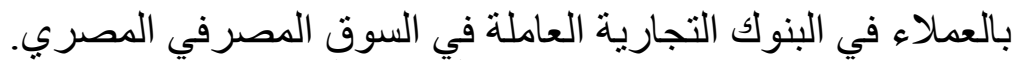

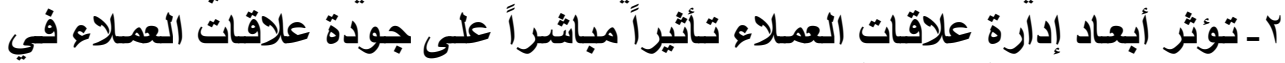

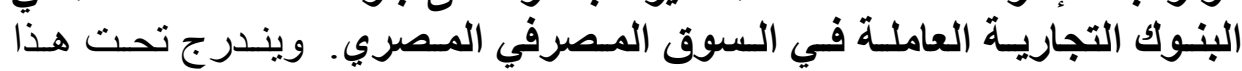

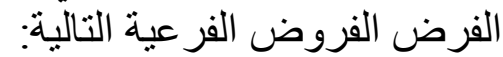

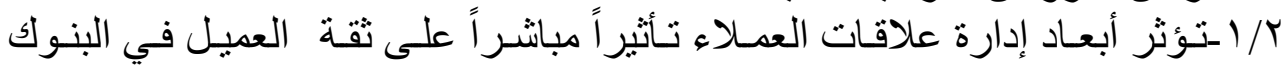

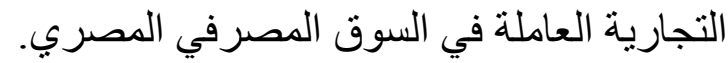




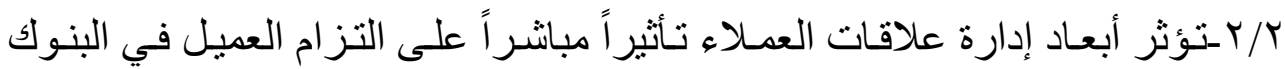

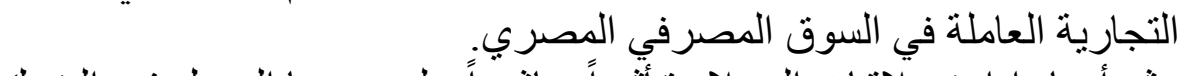

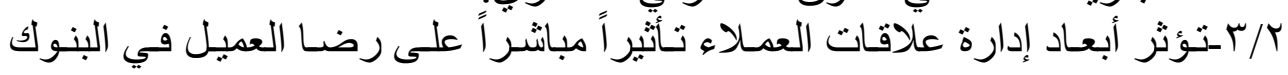

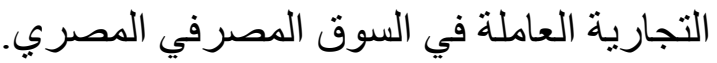

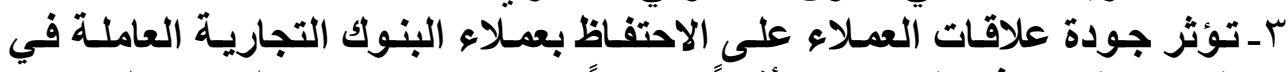

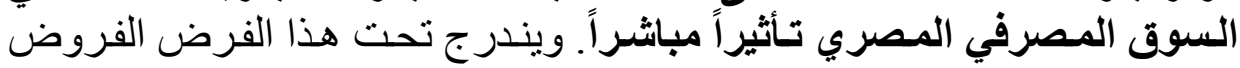

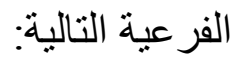
r/ اـتؤثر الثقة على الاحتفاظ بعملاء البنوك التجاريـة العاملة في السوق المصرفي

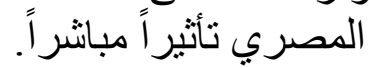

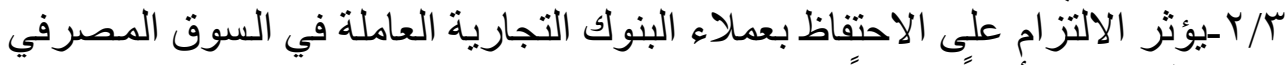

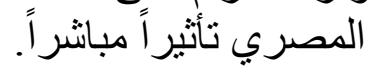

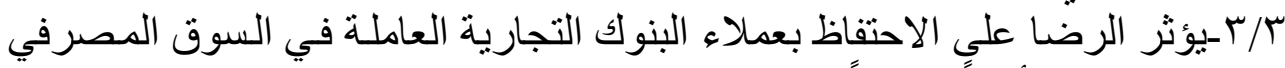
المصري تأثيراً مبانثراً.

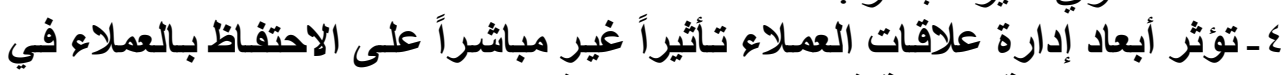

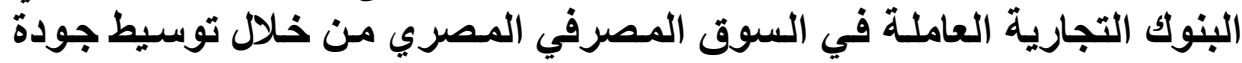

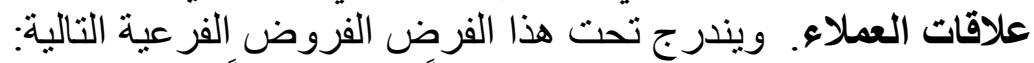

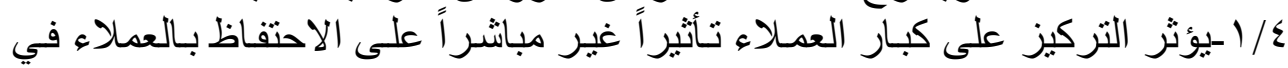

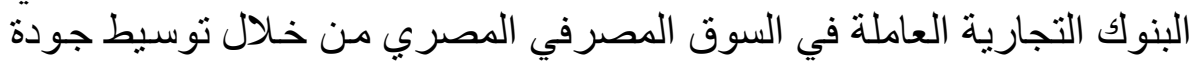

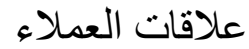

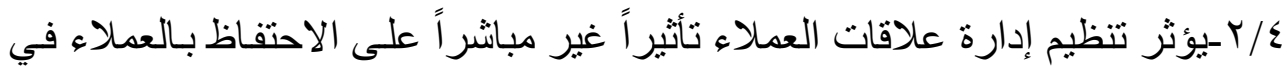

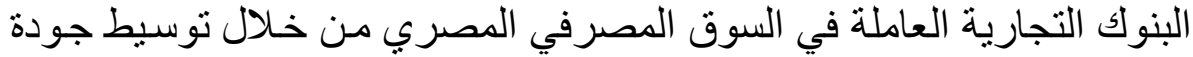

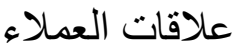

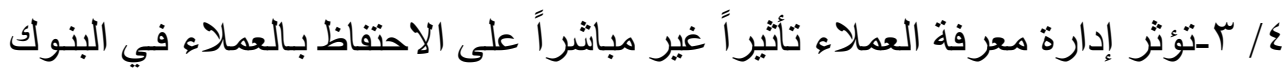

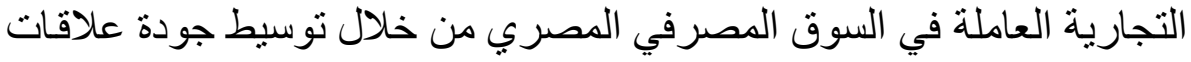

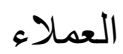

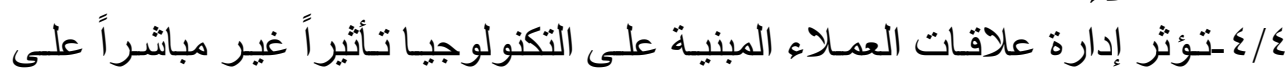

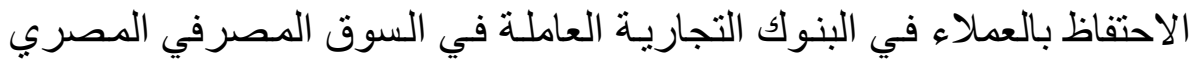
من خلال توسيط جودة علاقات العات العملاء.

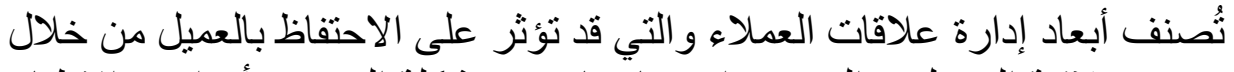

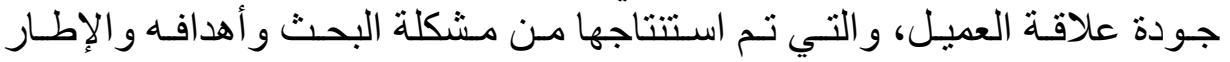

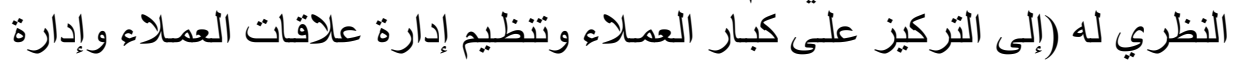
علاقات العملاء المبنية على التكنولوجيا عليا وإدارة معرفة العملاء). 


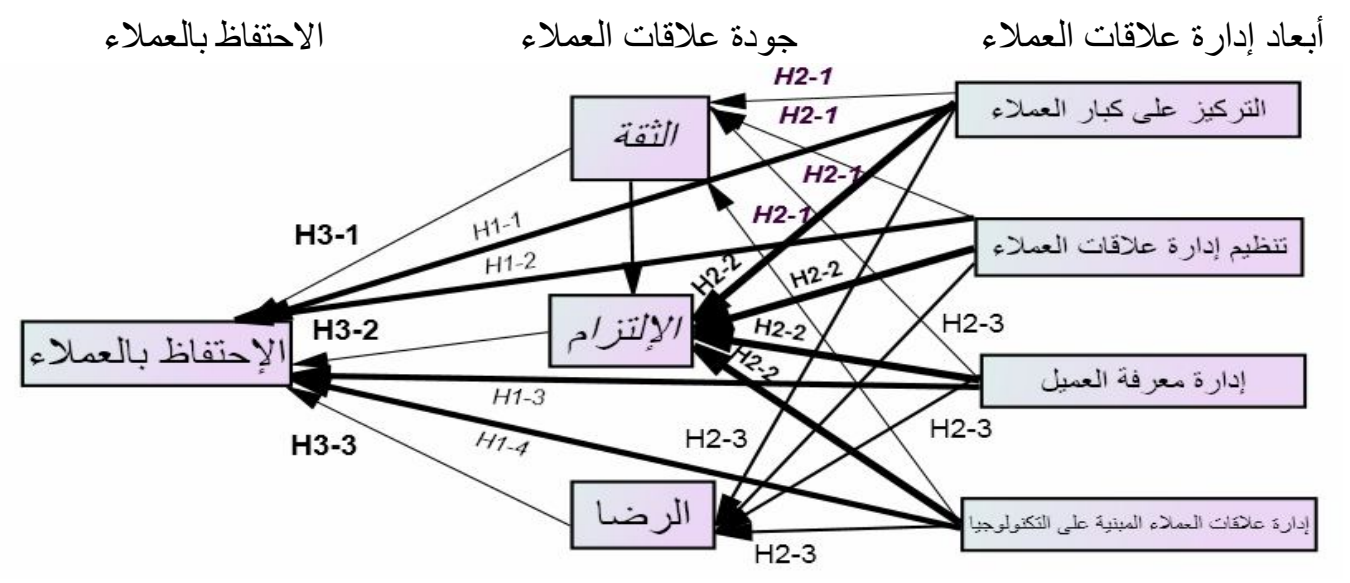

شكل رقم (1) منوذج الدراسة

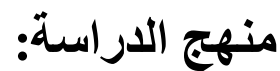

اعتمدت هذه الدراسة على المنهج الاستنباطي الذي يقوم على مر اجعة الدراسات

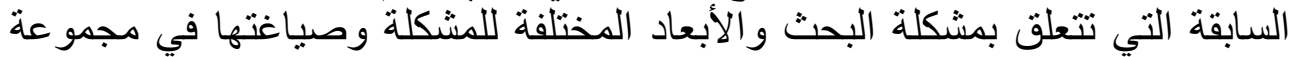

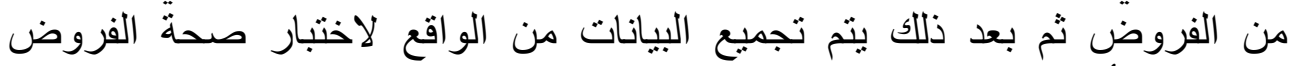
باستخدام الأساليب الإحصائية الملائمة.

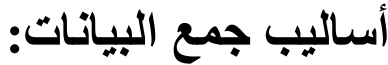
البيانات الأولية : البيان

اعتمدت الباحثة على المصادر البهات الثانوية حيث تم تجميع الكثير من البيانات الموجودة في المر اجع و الدوريات الأجنبية و العربية المتعلقة بموضوع البية البحث. البيانات الثانوية : البراتية استخدمت الدراسة المصادر الأولية للحصول على البيانات من مصادر ها الأصلية بالاعتماد على قائمة الاستقصاء المعدة لهذا لألفا الغرض.

\section{توصيف القطاع المصرفي المصنية المصري:}

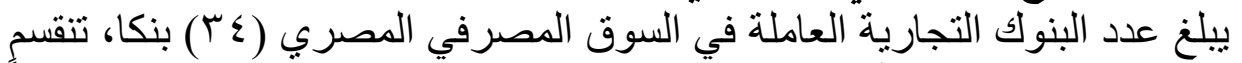

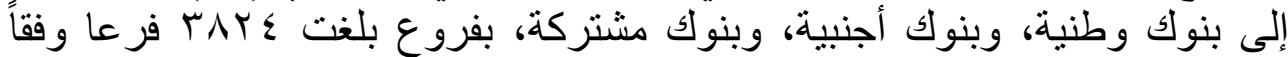

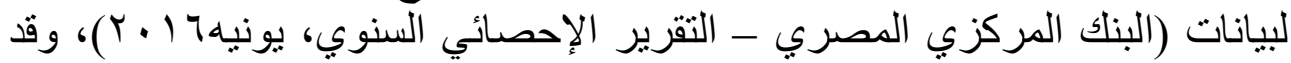

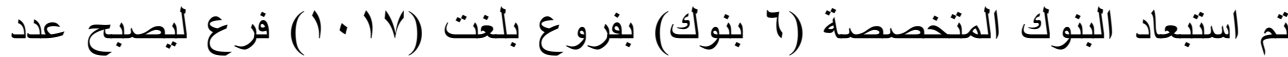

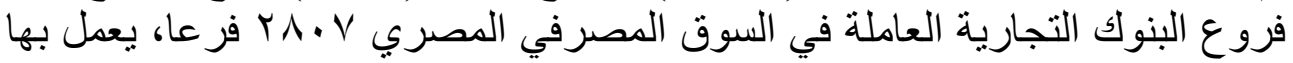

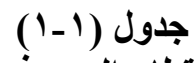
كما يتضح من الجدول رقم (1 - (1) - (1)

\begin{tabular}{|c|c|c|c|}
\hline النسية & باد فصري & S) & stivll \\
\hline$\%$. & 1114 & $r$ & بنوك وطنية \\
\hline$\%$ & 1.17 & 11 & نيو كَ مشتر كة \\
\hline$\%$ \% & TV & r & بنوك أجنبية \\
\hline$\% 1 \ldots$ & $Y \Lambda \cdot V$ & $\Gamma \varepsilon$ & إجمالي \\
\hline
\end{tabular}

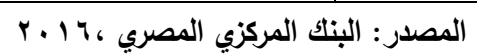


وتُرجع الباحثة إجر اء الدر اسة التطبيقية على القطاع المصرفي للأسباب التالية:

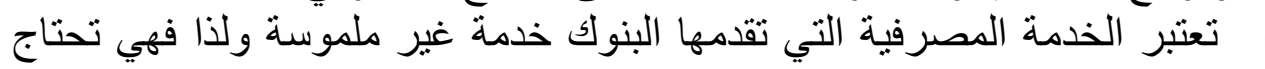

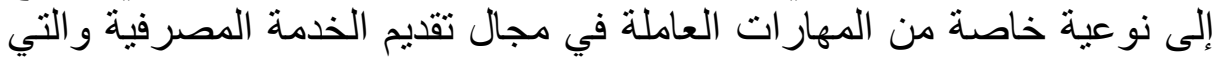

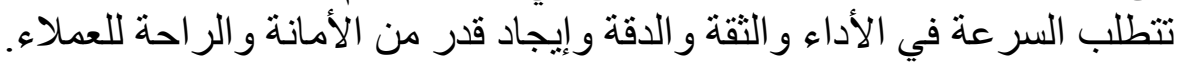

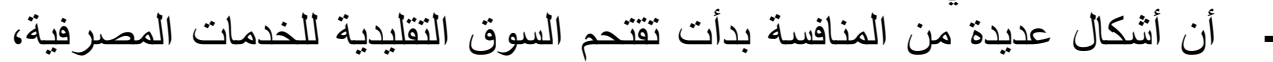

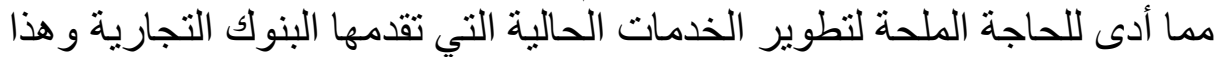

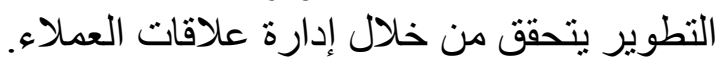

\section{مجتمع وعينة الار ماسة: ـ ت تعريف مجتمع الدراسة:}

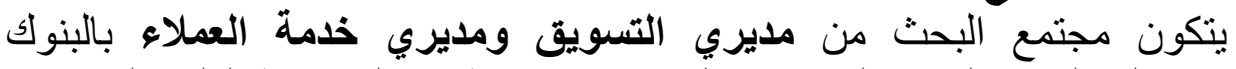

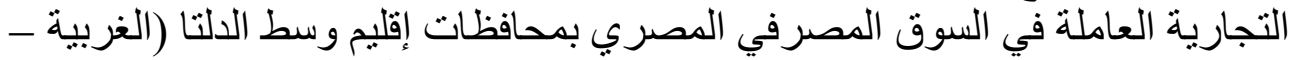

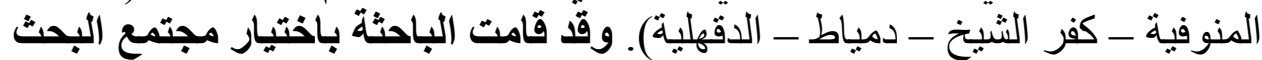

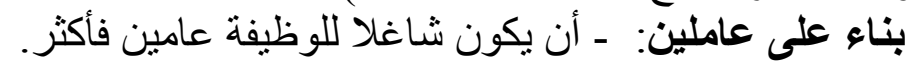

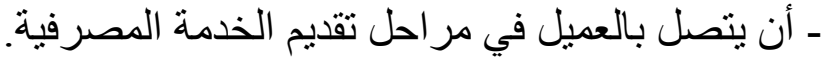

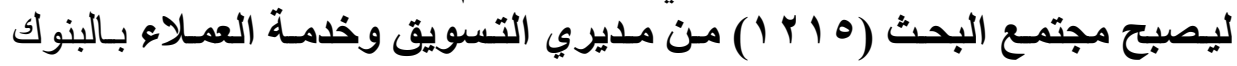

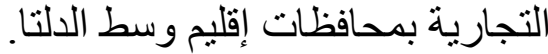

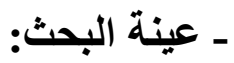

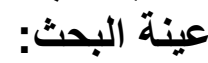

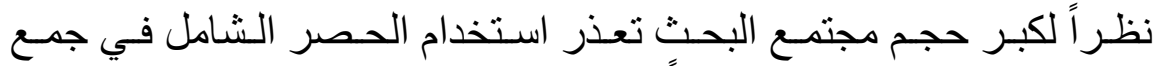

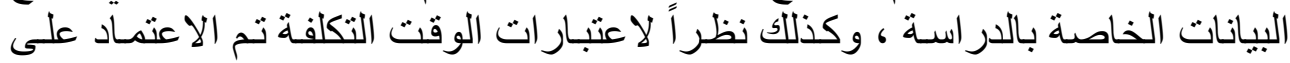

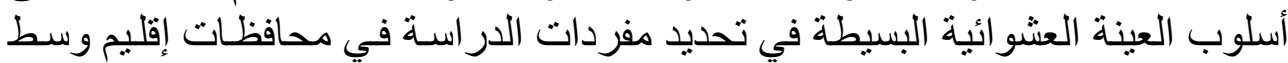

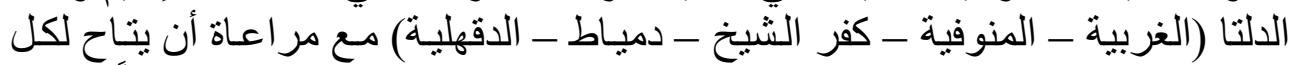

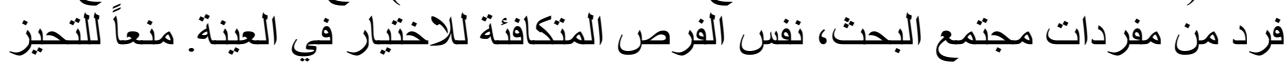
(Mullins et al ., 2014 ; Yli-Renko\& Janakiraman, 2008; Eid ,2015 Narver \& Slater, 1990; Verhoef \& Leeflang, 2009; ; Ebeid, 2014)

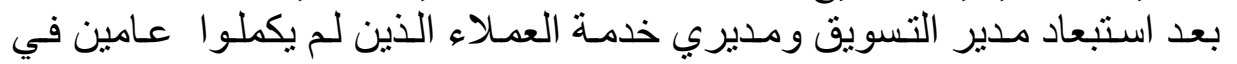

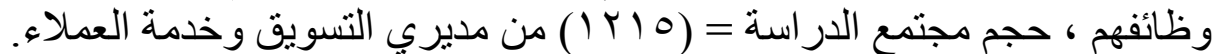

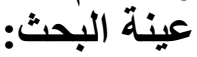

اعتمدت الباحثة في تحديد حجم العينة باستخدام المعادلة الآتية: (سرحان، ب99 1 )

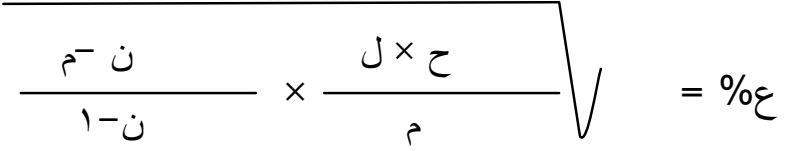

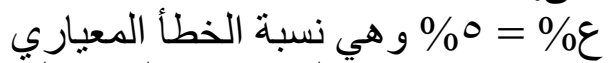

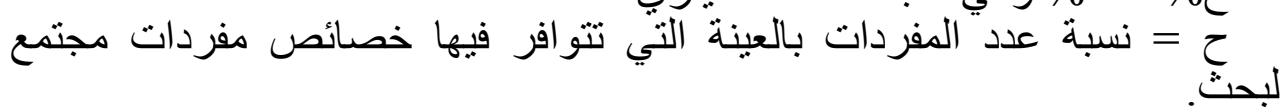

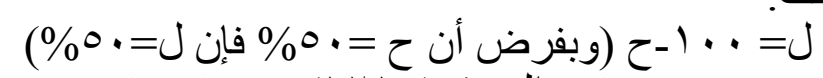

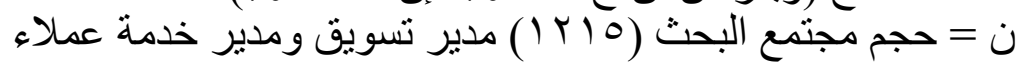




\section{م= حجم العينة.}

أي أن حجم العينة العينة بو ب مدير تسويق ومدير خدمة عملاء.

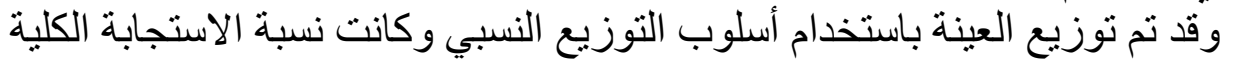

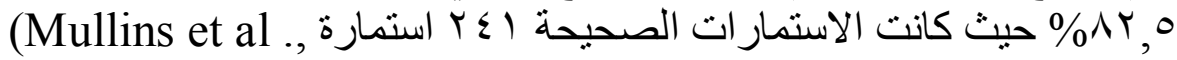
2014 ; Yli-Renko\& Janakiraman, 2008; Eid , 2015 ; Ebeid, 2014 Narver \& Slater, 1990; Verhoef \& Leeflang, 2009)

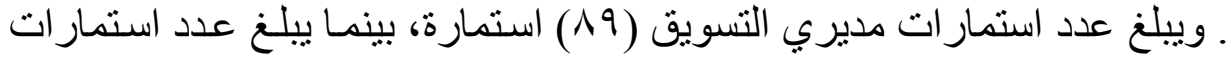

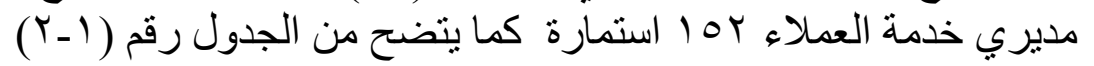

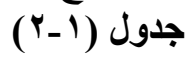

مجتمع وعينة البحث من مديري التسويق وخدمة العملاء

\begin{tabular}{|c|c|c|c|c|}
\hline \multirow{2}{*}{ القو ائم الصحيحة } & \multicolumn{3}{|c|}{ مديرو التسويق وخدمة العملاء } & \multirow{2}{*}{ عددمدير اللعملاء التسويق } \\
\hline & حجم العينة & النسبة & حجم المجتمع & \\
\hline 91 & 117 & $\% \sqcap q, 7$ & $\varepsilon \wedge 1$ & في البنوك الوطنية \\
\hline A. & 1.0 & \%ัт, r & $\varepsilon \varepsilon$. & في البنوك المشتركة \\
\hline $7 \pi$ & $\sqrt{11}$ & $\% Y \leq, r$ & rqs & في البنوك الأجنبية \\
\hline$r \leqslant 1$ & rqY & $\% 1 \ldots$ & 1,10 & إجمالي \\
\hline
\end{tabular}

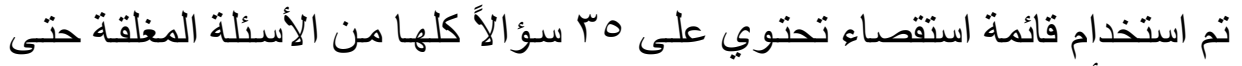

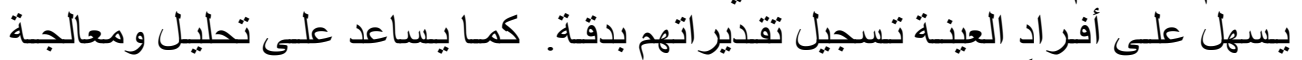

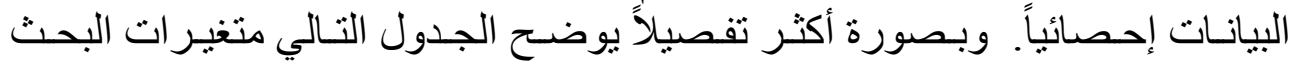

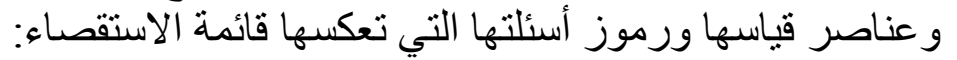

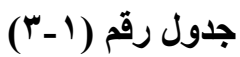

متفيرات البحث ومكوناتها

\begin{tabular}{|c|c|c|c|c|c|}
\hline الأسئلةد & قياس المتغير ات & الرمز & متغير ات البحث & ة ورموزها & المجمو= \\
\hline$\varepsilon-1$ & $\begin{array}{l}\text { (Akroush et al ., } 2011 \text {; Sin et } \\
\text { al et al., 2005) }\end{array}$ & $\mathrm{X}_{1}$ & التعلاء & \multirow{4}{*}{ 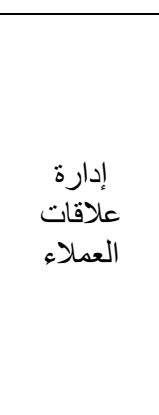 } & \multirow[t]{4}{*}{ المتنغلة ات } \\
\hline 9.0 & $\begin{array}{l}\text { (Akroush et al ., 2011;Sin et } \\
\text { al et al ., 2005) }\end{array}$ & $\mathrm{X}_{2}$ & تلتظقات العملاء إدارة & & \\
\hline $\mid r-1$. & $\begin{array}{l}\text { (Akroush et al ., } 2011 ; \text { Sin et } \\
\text { al et al ., 2005) }\end{array}$ & $\overline{X_{3}}$ & 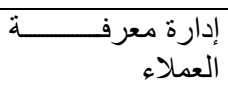 & & \\
\hline$\left|\Lambda_{-}\right| \varepsilon$ & $\begin{array}{l}\text { (Akroush et al ., } 2011 \text {; Sin et } \\
\text { al et al. ., 2005) }\end{array}$ & $\mathrm{X}_{4}$ & 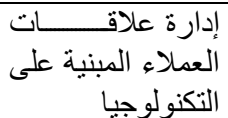 & & \\
\hline$r r-19$ & $\begin{array}{l}\text { (Morgan \& Hunt, 1994; De } \\
\text { Wulf et al ., 2001) }\end{array}$ & $\mathrm{Y}_{1}$ & ثقة العميل & \multirow{3}{*}{ جودة العلاقة } & \multirow[t]{3}{*}{ الوسيطة المتيرات } \\
\hline YY & $\begin{array}{l}\text { (Morgan \& Hunt, } 1994 \text {; (De } \\
\text { Wulf et al ., 2001) }\end{array}$ & $\mathrm{Y}_{2}$ & التزام العميل & & \\
\hline$r \cdot-r V$ & $\begin{array}{llll}\text { (De } & \text { Wulf et al } & \\
\text { 2001; Crosby, 1990). } & \end{array}$ & $\overline{Y_{3}}$ & رضا العميل & & \\
\hline ro-rt & (Liang et al., 2008). & $\mathrm{Y}$ & الاحتفاظ بالعميل & بالعميل & الت التغنير \\
\hline
\end{tabular}




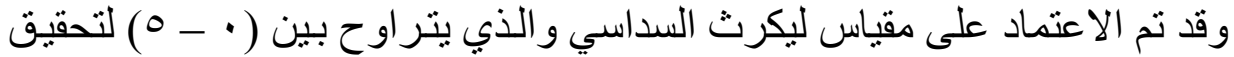

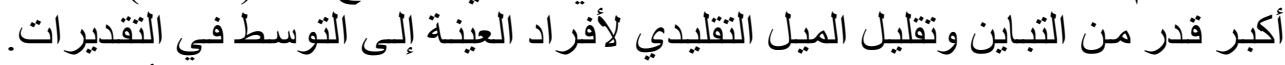

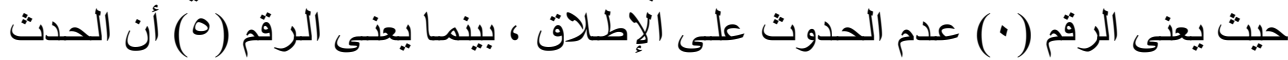

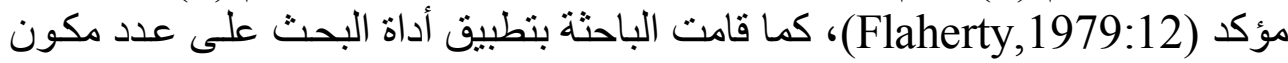

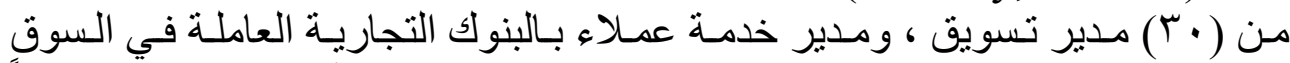

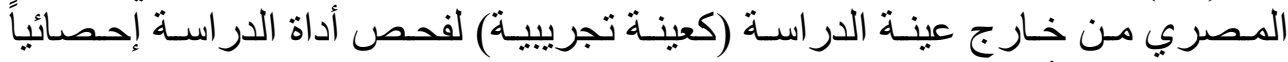

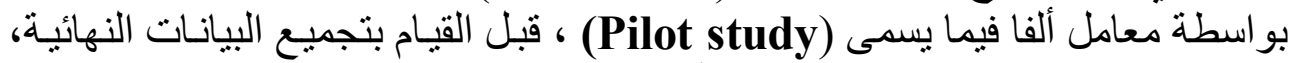

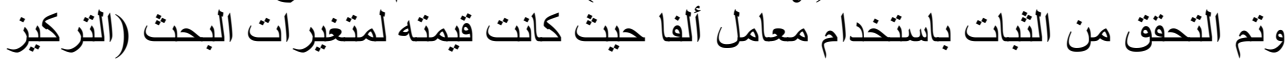

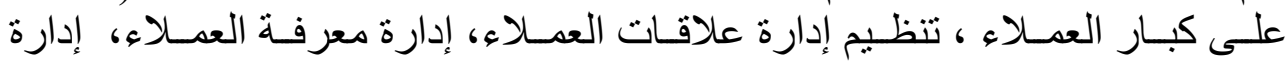

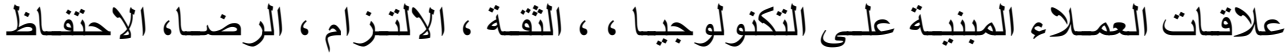

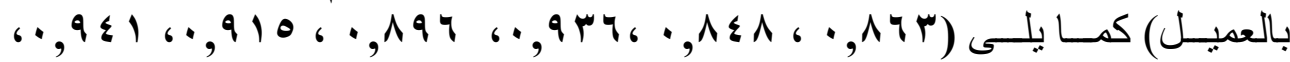

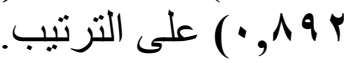

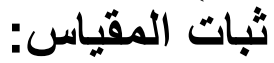

قامت الباحثة باختبار ثبات المقياس (Reliability) و الذي يثير إلى دقة القياس

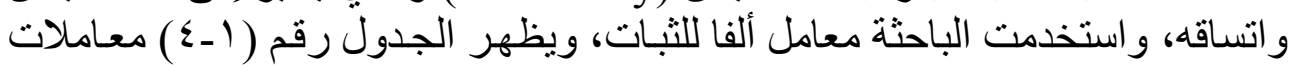
الثبات لمقاييس متغير ات البحث.

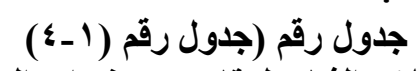

معاملات الثبات لمقاييس متغير رفات البحث

\begin{tabular}{|c|c|c|c|}
\hline معامل الثبات & عدد البنود & 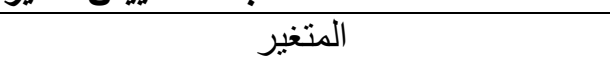 & 5 \\
\hline. .АTr & $\varepsilon$ & التركيز على كبار العملاء & 1 \\
\hline$\because \wedge \leqslant \wedge$ & 0 & تتظيم إدارة علاقات العملاء & r \\
\hline .947 & $\varepsilon$ & إدارة معرفة العملاء & $r$ \\
\hline..$\wedge 97$ & 0 & إدارة علاقات العملاء المبنية على التكنولوجيا & $\xi$ \\
\hline .910 & $\varepsilon$ & ثقة العميل & 0 \\
\hline$\cdot . \wedge \wedge 9$ & $\varepsilon$ & التز ام العميل & 7 \\
\hline $.9 \leqslant 1$ & $\varepsilon$ & رضا العميل & V \\
\hline.$\wedge 9 \mathrm{r}$ & 0 & الاحتفاظ بالعميل & $\Lambda$ \\
\hline
\end{tabular}

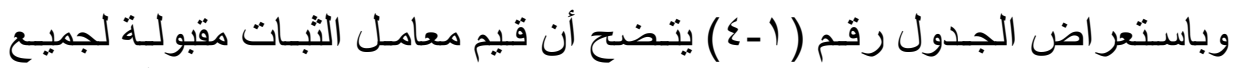

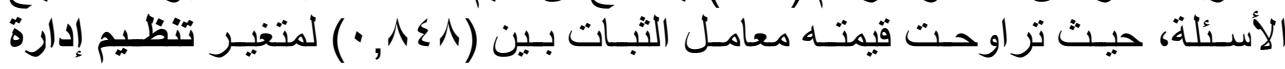

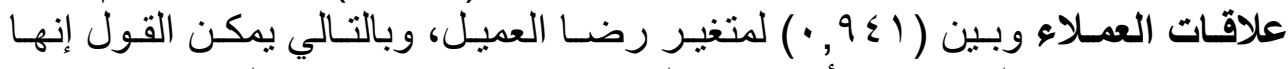

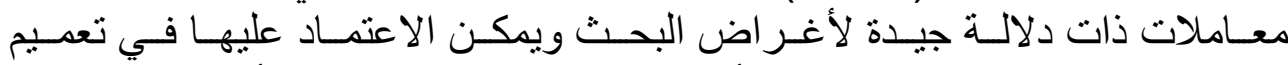

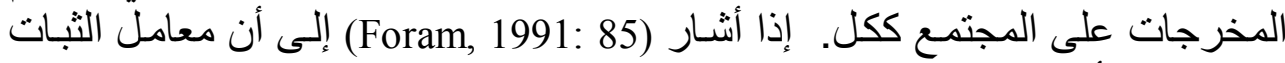

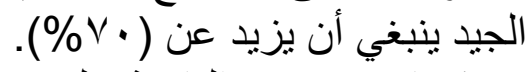

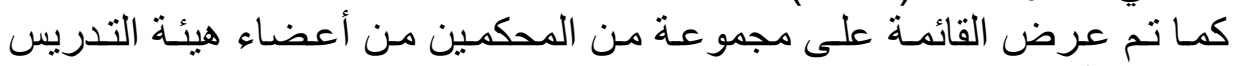

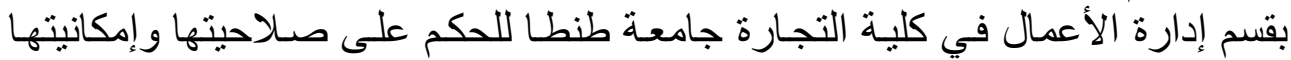
في قياس الخاصية المراد قياسها (Ebel, 1972:345). 


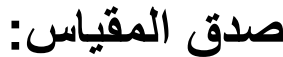

تم استخدام التحليل العاملي للتأكد من أن المقاييس المستخدمة في الدراسة تتسم

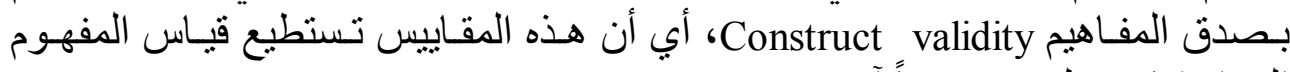

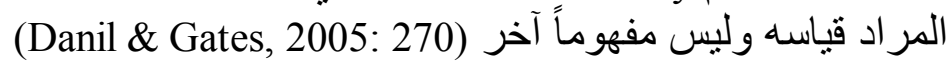

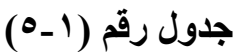

التحليل العاملي لعناصر متغيرات البحث

\begin{tabular}{|c|c|c|c|c|c|c|c|c|c|}
\hline \multicolumn{8}{|c|}{ معامل التحميل للمتغيرات } & \multirow{2}{*}{\multicolumn{2}{|c|}{ العواملغرات }} \\
\hline$\wedge$ & $\mathrm{v}$ & 4 & - & $\varepsilon$ & $r$ & $r$ & 1 & & \\
\hline & & & & & & & 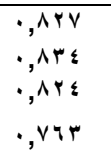 & $\begin{array}{l}X 11 \\
X 12 \\
X 13 \\
X 14\end{array}$ & التركيز على كبار العملاء \\
\hline & & & & & & 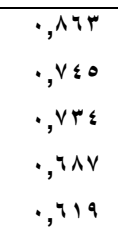 & & $\begin{array}{l}\mathbf{X 2 1} \\
\mathbf{X} 2 \\
\mathbf{X} 23 \\
\mathbf{X} 24 \\
\mathbf{X} 25\end{array}$ & تنظيم إدارة علاقات العملاء \\
\hline & & & & & $\begin{array}{l}\cdot, A \cdot \theta \\
\cdot, \wedge \cdot \varepsilon \\
\cdot, \text {, } \\
\cdot, \text {, }\end{array}$ & & & $\begin{array}{l}\mathbf{X 3 1} \\
\text { X32 } \\
\text { X33 } \\
\text { X34 }\end{array}$ & إدارة معرفة العملاء \\
\hline & & & & 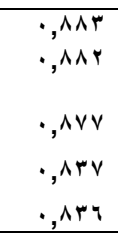 & & & & $\begin{array}{r}\text { X41 } \\
\text { X42 } \\
\\
\text { X43 } \\
\text { X44 } \\
\text { X45 } \\
\end{array}$ & على التكنولواتيات العملاء المبنية \\
\hline & & & 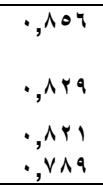 & & & & & $\begin{array}{l}\text { Y11 } \\
\text { Y12 } \\
\text { Y13 } \\
\text { Y14 }\end{array}$ & 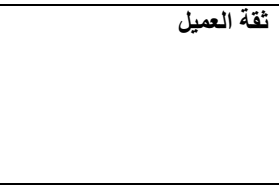 \\
\hline & & 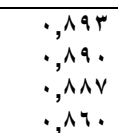 & & & & & & $\begin{array}{l}\text { Y21 } \\
\text { Y22 } \\
\text { Y23 } \\
\text { Y23 }\end{array}$ & التزّام العيل \\
\hline & 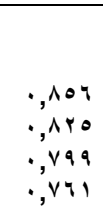 & & & & & & & $\begin{array}{l}\text { Y31 } \\
\text { Y32 } \\
\text { Y33 } \\
\text { Y34 }\end{array}$ & رضا العميل \\
\hline 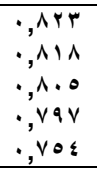 & & & & & & & & $\begin{array}{l}\text { Y41 } \\
\text { Y42 } \\
\text { Y43 } \\
\text { Y44 } \\
\text { Y45 } \\
\end{array}$ & الاحتفاظ بالعملاء \\
\hline 76.687 & 73.752 & 70.082 & 65.831 & 61.501 & 53.542 & 45.143 & 35.970 & & نسبة التباين المفسر \\
\hline
\end{tabular}




$$
\text { يتضح من الجدول رقم ( - -0) ما يلي: }
$$

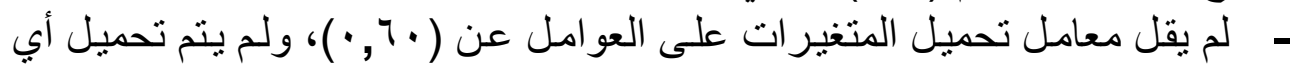

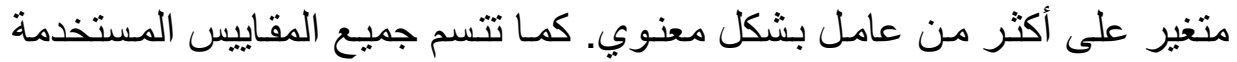

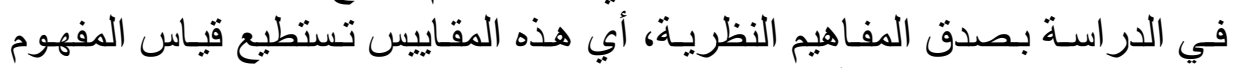

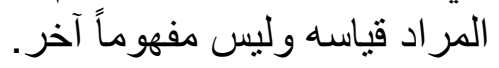

\section{- خصائص عينة الدراسة:}

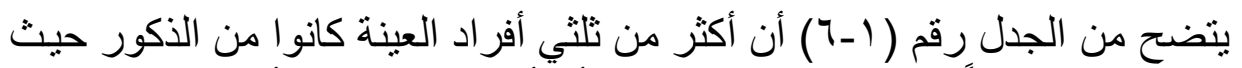

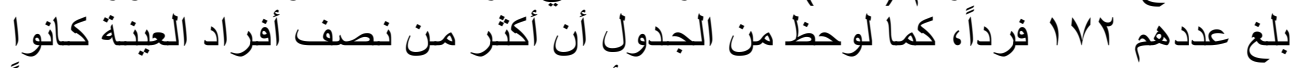

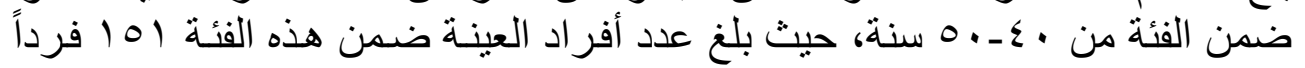

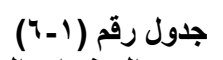

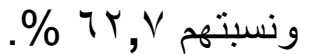

\begin{tabular}{|c|c|c|c|}
\hline النسبة & 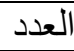 & \multicolumn{2}{|c|}{ 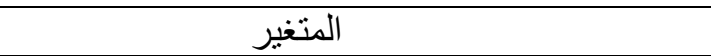 } \\
\hline$\% \vee, r$ & TVY & ـ - ذكر & النوع النوع \\
\hline$\% \curlyvee \wedge . \vee$ & 79 & ــ أنثى & \\
\hline- & - & ـ أقل من · ع & 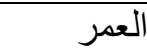 \\
\hline \%rr.V & 101 & - من •ـ-.0 & \\
\hline$\% r V . r$ & 9. & ــ أكثر من ـ0 & \\
\hline$\%$ \%V & \&1 & - من r إلى 0سنوات & مدة الخذمة \\
\hline$\%$ \%र & r.. & ـ أكثر من 0 سنوات & \\
\hline$\%$ \& & 91 & - حكومي & 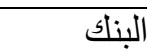 \\
\hline$\%$ & ᄉ. & 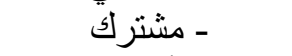 & \\
\hline$\%$ \% & זד & ـ ا أجنبي & \\
\hline$\% \leftarrow 4.9$ & 19 & ـ ـ مدير تسويق & الوظيفة الوظة \\
\hline \%тr.1 & 104 & ـ مدير خدمة العملاء & \\
\hline
\end{tabular}

خصائص عينة البحث حسب المتغيرات الديموغرافية والوظيفية

أما بالنسبة لمدة الخدمة فكانت تشير إلى أن النسبة الأكبر من أفر اد العينة ضمن

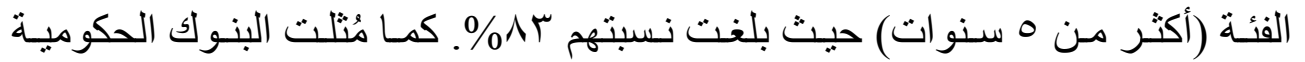

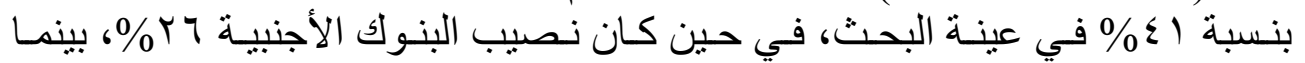

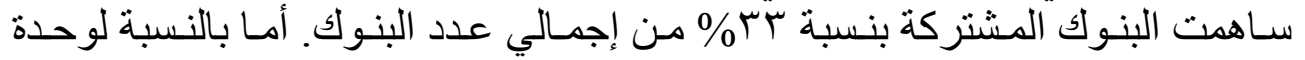

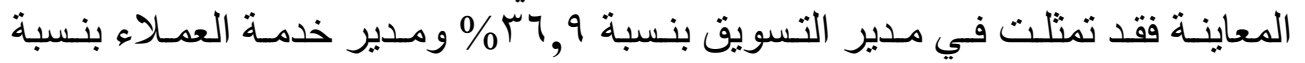

$$
\% \text { \% }
$$
إجراءات جمع البيانات:

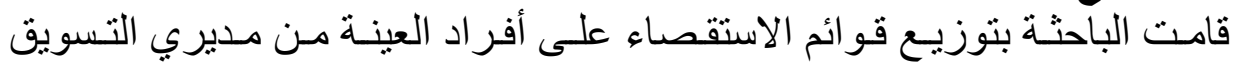

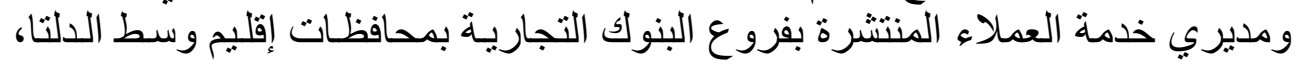
ووزعت القو ائم بشكل مباشروتم توضيح الهذف من الدراسة. 


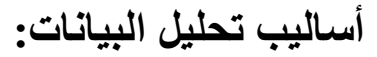

يتم استخدام الأساليب الإحصائية التالية:

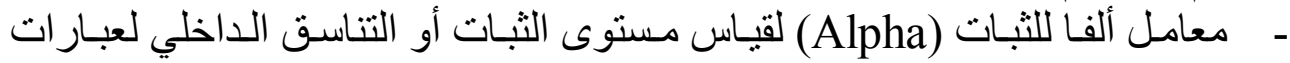
مقياس كل متغير.

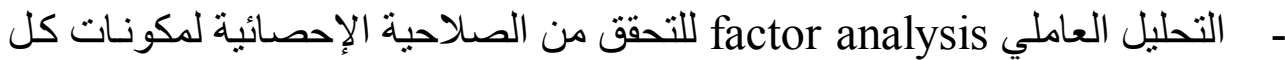
مقياس، وتكوين الدقاييس المجمعة للمتغير ات ذات ذات الأبعاد الكثيرة.

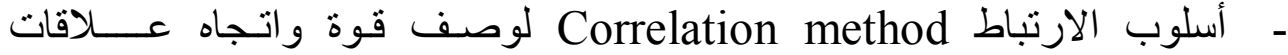
الارتباط بين جميع متغير ات الدار اسة.

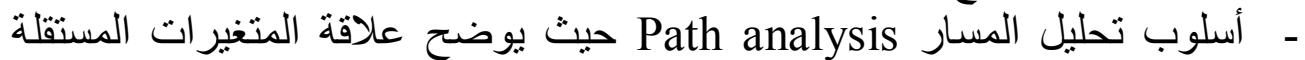

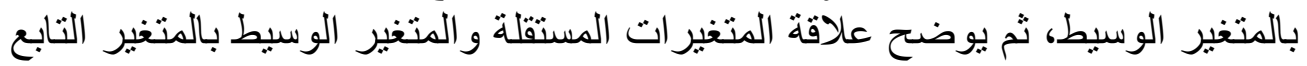

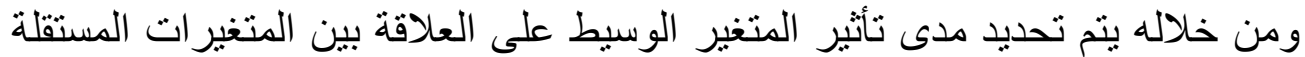
و المتغير التابع.

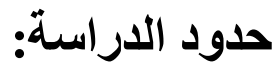

ـالحدود المكانية: تحددت بيئة الدر اسة في فروع البنوك التجارية بجميع محافظات إقليم

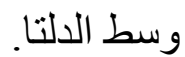

ـالحدود البشرية: طبقت الدراسة على عدد من مديري تسويق ومديري خدمـة العملاء

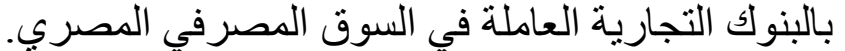

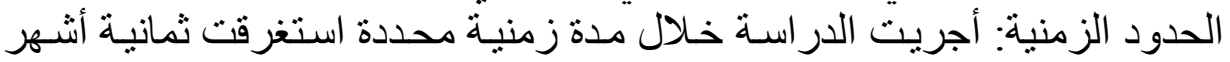

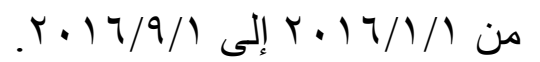
نتائج الاراسة الميدانية:

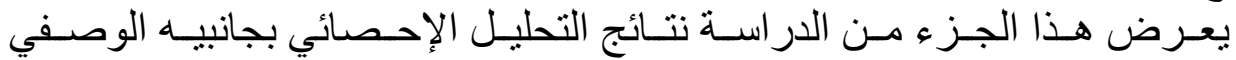

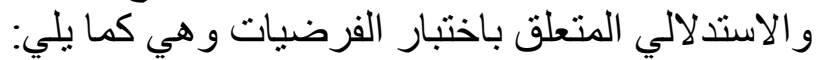

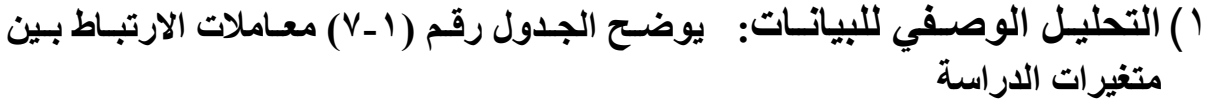

\begin{tabular}{|c|c|c|c|c|c|c|c|c|c|}
\hline \multicolumn{10}{|c|}{ معاملات الارتباط بين المتغيرات } \\
\hline المستبي & | الاحتفاظ & الرضا & الالتزام & الثقة & 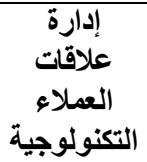 & العملافة & إلتظيم & العلى كبار & ? \\
\hline$r . \wedge r \wedge$ & & & & & & & & & كبار التعملاء على \\
\hline Y.YYVE & & & & & & & & $.199^{* * *}$ & تلتظقاتِ ت إدارة \\
\hline r. Tro & & & & & & & $\because 1 \leqslant \Lambda^{*}$ & $\cdot r \sum^{* * *}$ & إلعارة معرفة \\
\hline
\end{tabular}




\begin{tabular}{|c|c|c|c|c|c|c|c|c|}
\hline$r .111 r$ & & & & & $\because 9$ & $\cdot . \leqslant \cdot 1^{* * *}$ & $\because 110^{* * *}$ & $\begin{aligned} \text { الدارةلاء علاقات } \\
\text { التكنولوجية }\end{aligned}$ \\
\hline$r . \Lambda .74$ & & & & $. V \leqslant V^{* k}$ & $\cdot v r q^{* * *}$ & $\cdot V \mu r^{* * *}$ & $\cdot \vee \wedge \wedge q^{* * *}$ & الثقة \\
\hline r.VOT\& & & & $\cdot \wedge 1 . * *$ & $. V \leqslant \Lambda^{* * *}$ & $.9 V Y^{* * *}$ & $\cdot . V \cdot q^{* *}$ & $\cdot .7 V \cdot \cdot^{* * *}$ & الالتزام \\
\hline r.quq. & & $\because v \otimes \Lambda^{* * *}$ & $\cdot \wedge 04^{* \pi}$ &.$V 9 V^{* * *}$ &.$V \sim q^{* * *}$ & $\cdot . V \cdot q^{* * *}$ & $\cdot V / r^{* * *}$ & الرضا \\
\hline$r . . r q \Lambda$ & $\because 910^{*}$ & $\cdot \wedge \leq 0^{* *}$ & $\cdot . \wedge \wedge 7^{* *}$ & $\cdot \wedge \leqslant r^{* * *}$ & $\therefore \vee \vee q^{* *}$ & $\cdot V V r^{* * *}$ & $\cdot \vee \wedge \wedge \Lambda^{* * *}$ & الاحعلفاء \\
\hline
\end{tabular}

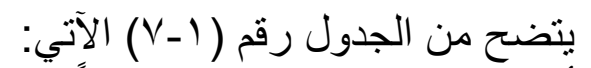

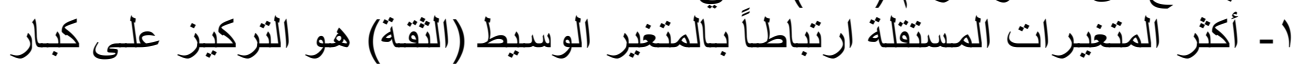

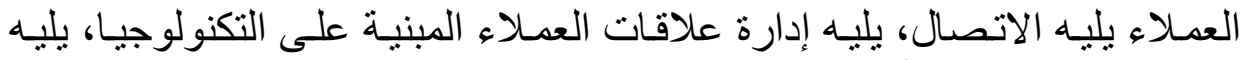

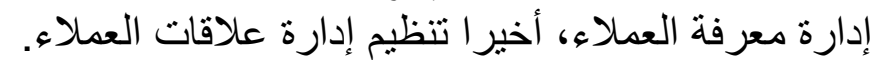

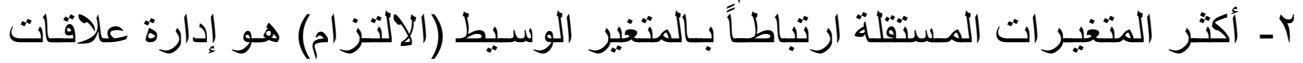

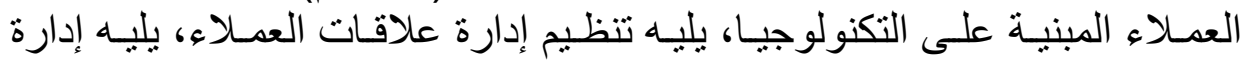

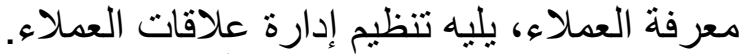

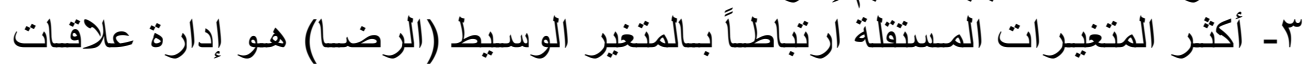

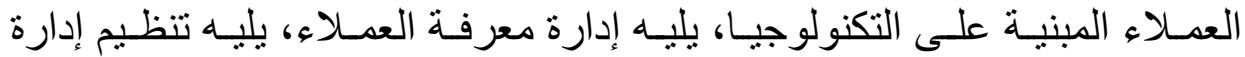

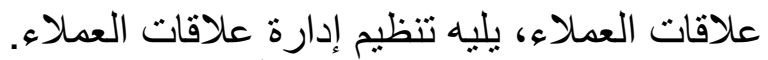

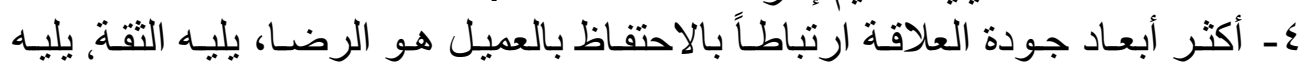

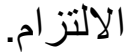
نتائج تحليل المسار:

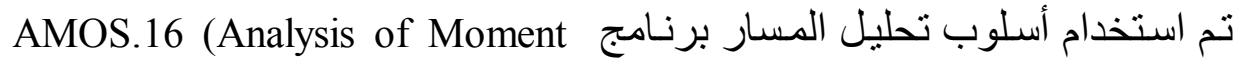

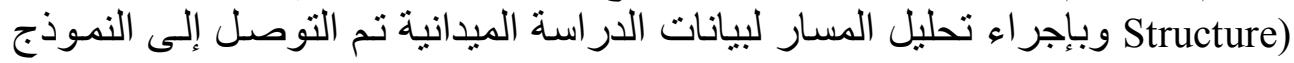
النهائي لتحليل المسار كما يوضحه الثنكل التالي:

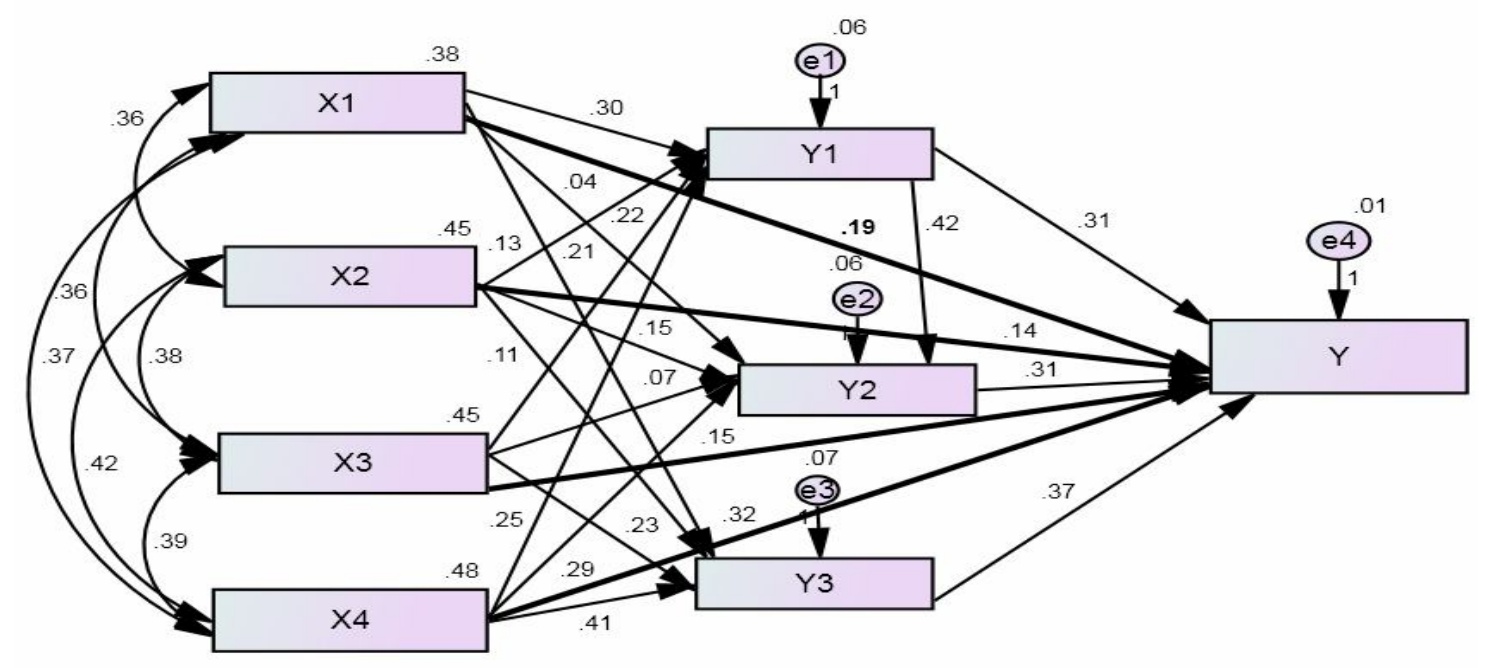

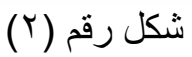

نتائج تحليل المسار 


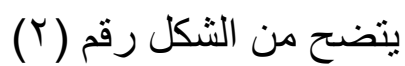

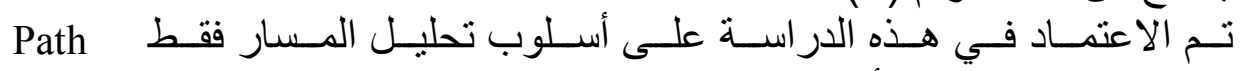

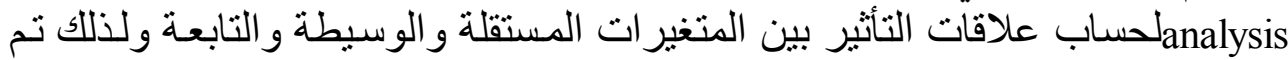

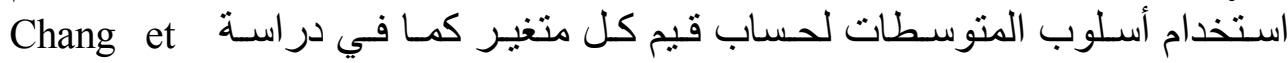
al.(2010) مؤشرات الجودة الكلية لنموذج تحليل المسار:

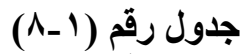

مؤشرات الجودة الكلية لنموذج تحليل المسار

\begin{tabular}{|c|c|c|}
\hline التفسير & الاختبار & اختبار جودة النموذج \\
\hline القيمة أقل من 0 . . مما يشبر إلى كفاءة عالية للنموذج & $\because .41$ & RMSEA \\
\hline صلاحية عالية للنموذج حيث تقترب القيمة من الواحد الصحيح & $.9 \times 1$ & GFI \\
\hline صلاحية عالية للنموذج حيث تقترب القيمة من الواحد صحيح & $\therefore .911$ & A GFI \\
\hline صلاحية عالية للنموذج حيث تقتزب القيمة من الواحد صحيح & $\therefore .94 \lambda$ & $\mathrm{NFI}$ \\
\hline صلاحية تامة للنموذج حيث تقترب القيمة من الواحد صحيح & .970 & CFI \\
\hline
\end{tabular}

CMIN=13.572 DF=8 CMIN/DF=1.697

- GFI $\rightarrow$ Goodness of Fit Index , RMSEA $\rightarrow$ Root Mean Square error of Approximation

- $\quad$ NFI $\rightarrow$ Normed Fit Index ,CFI $\rightarrow$ Comparative Fit Index

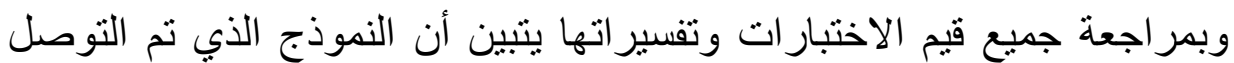

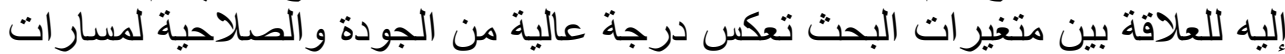

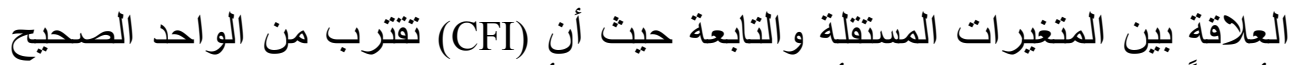

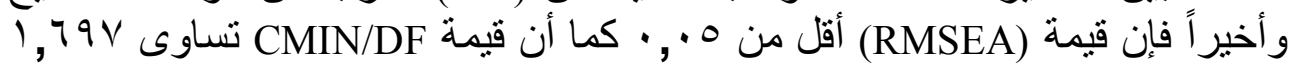

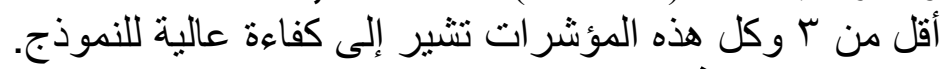
نتائج اختبار فروض البتر البحث:

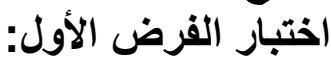

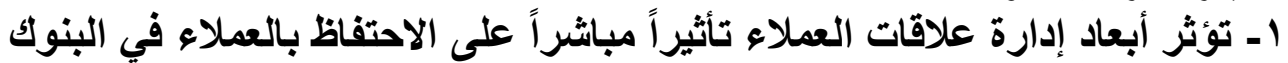

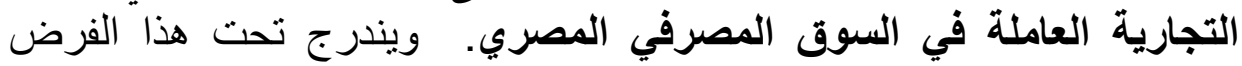

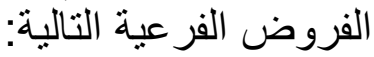

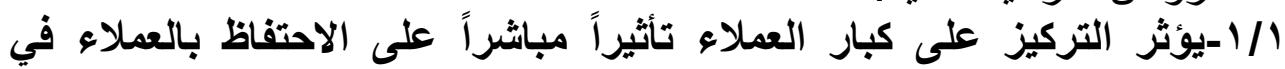
البنوك التجارية العاملة في السوق المصريز التصفي المصري.

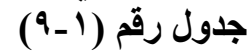

نتائج العلاقة بين أبعاد إدارة علاقات العملاء والاحتفاظ بالعملاء

\begin{tabular}{|c|c|c|c|c|c|}
\hline الترتيب & مستوى & المعيارئ & t- قيمة & معلمة المسار & المتغير \\
\hline r & $\because \cdots 1$ & $\therefore \leqslant 0$ & 0.109 & - YTY & التزكيز على كبار العملاء \\
\hline$\varepsilon$ & $\because \cdots 1$ & 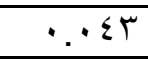 & 5.199 & $\cdot .11$ & تنظيم إدارة علاقات العملاء \\
\hline$\mu$ & $\because \cdots 1$ & $\because \mathrm{r \Lambda}$ & $\varepsilon . \vee 09$ &. $.1 \mathrm{~N}$ & إدارة معرفة العملاء \\
\hline 1 & $\because \cdots 1$ & ץ & $9 . Y \wedge 0$ & roo & 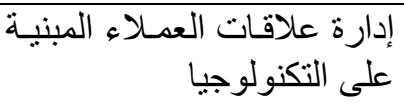 \\
\hline
\end{tabular}


يتضح من الجدول رقم (1 (9) أن قيمة t المحسوبة (0,109) أكبر من قيمتئها

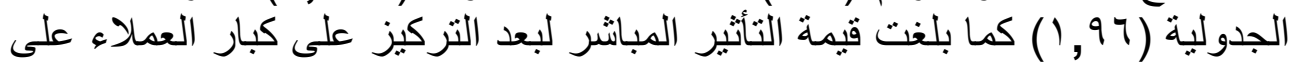

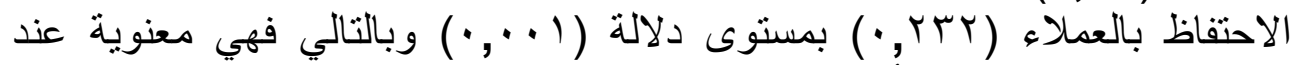

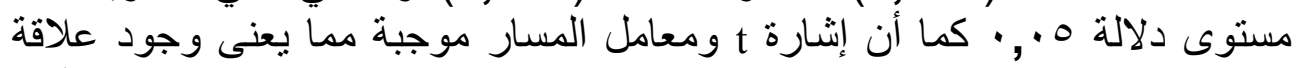

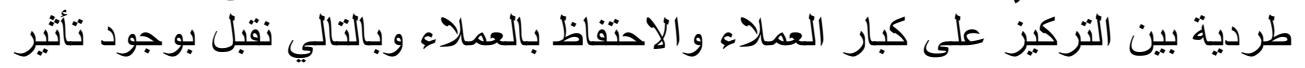

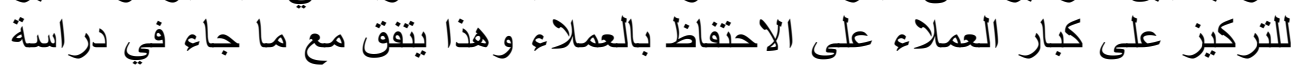

(Bavarsad\& Hosseinipour. 2013)

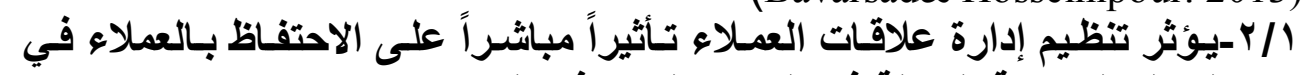

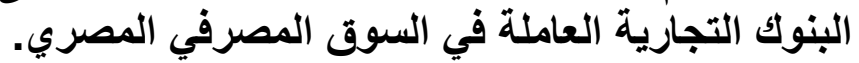

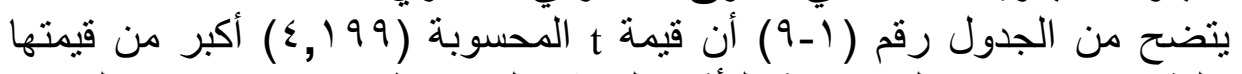

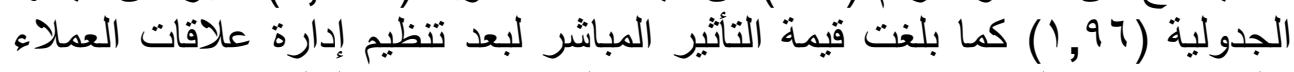

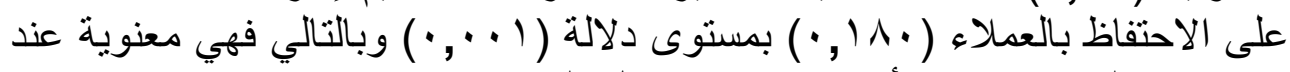

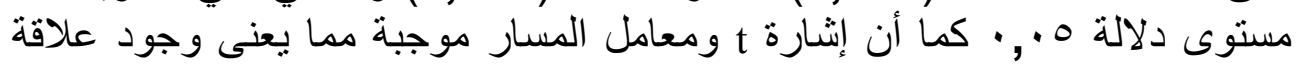

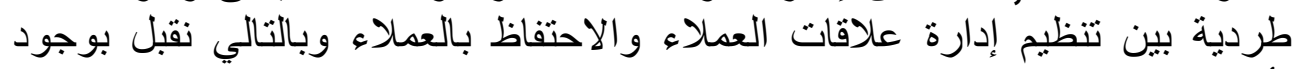

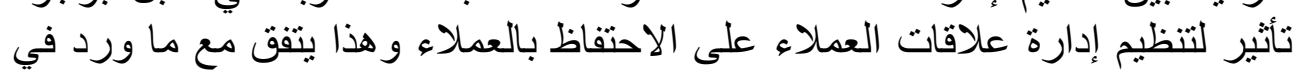

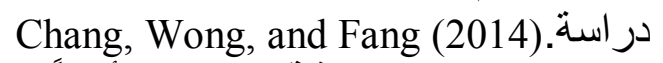
الجار-تؤُثر إدارة معرفة العملاء تأثتيراً مباثراً على الاحتفـاظ بـالعملاء في البنوك التجارية العاملة في السوق المعرة المصرفي المصري.

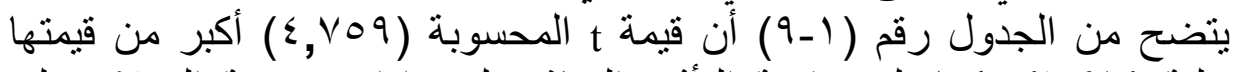

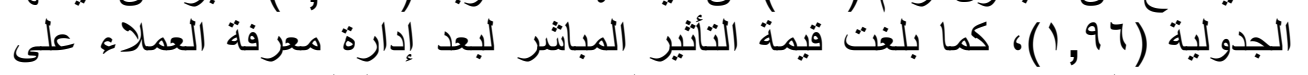

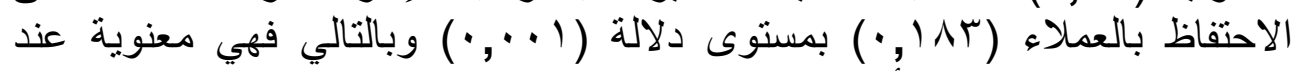

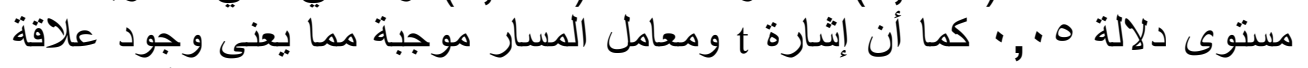

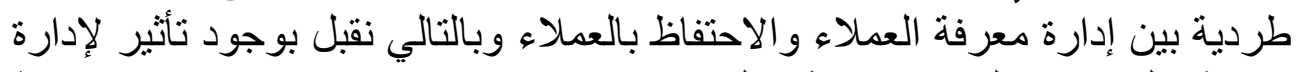

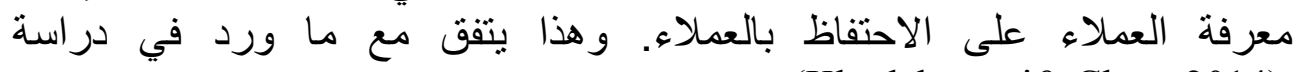
(Khodakarami\& Chan, 2014).

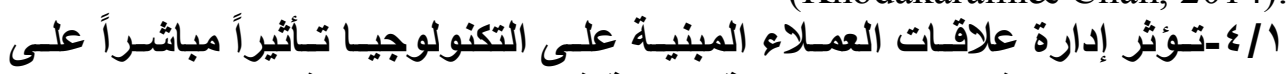

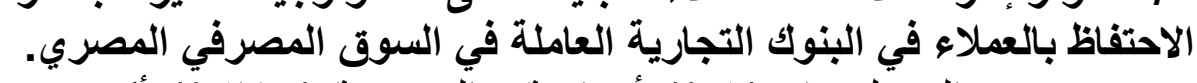

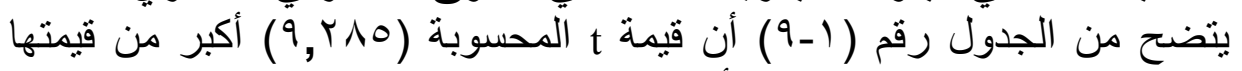

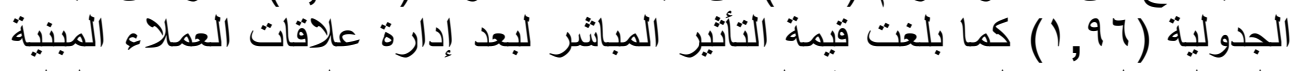

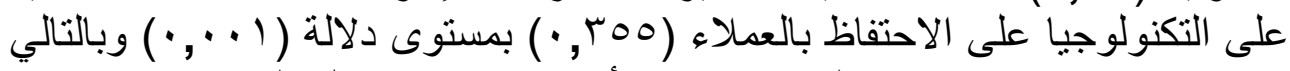

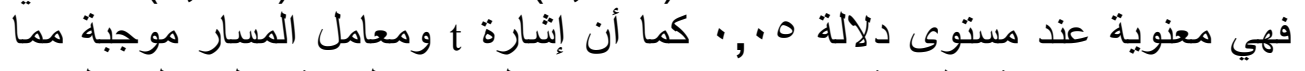

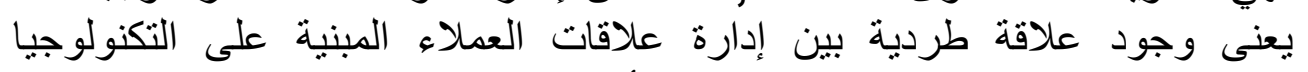

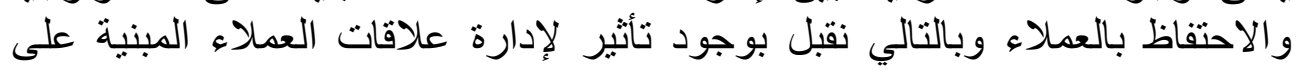

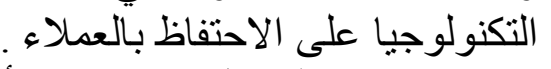

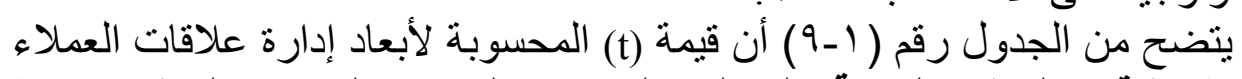

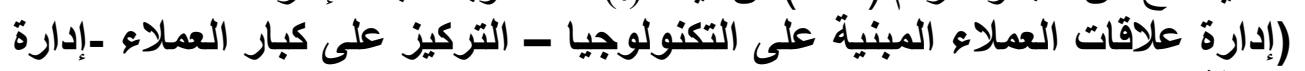

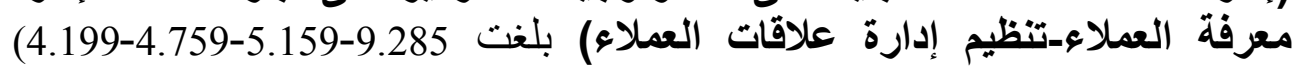

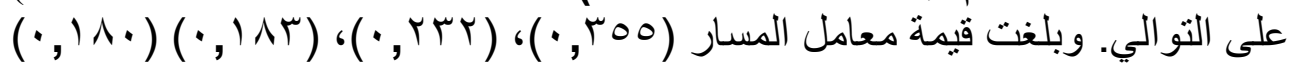




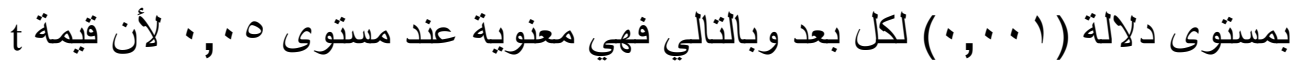

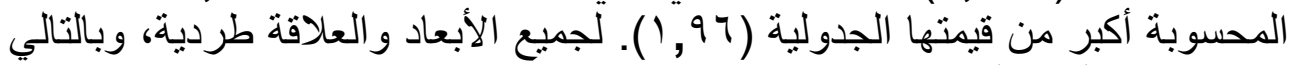
نقبل بوجود تأثثير لأبعاد إدارة علاقات العدية العملاء على الاحتفاظ بالعميل.

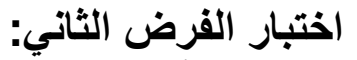

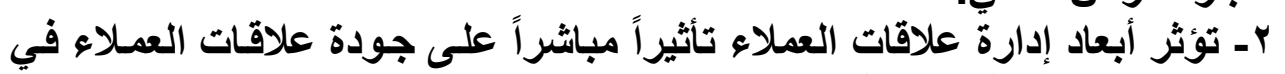

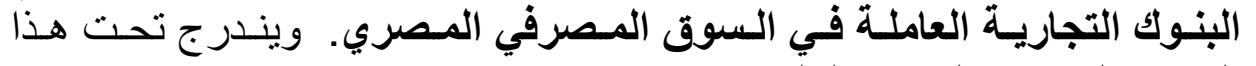
الفرض الفروض الفرو عية التالية:

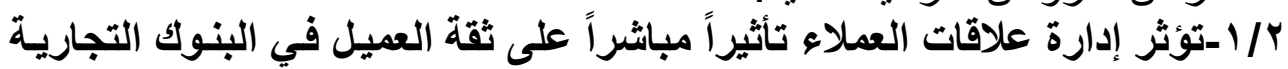

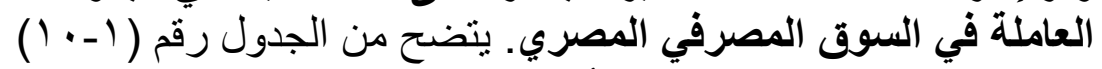

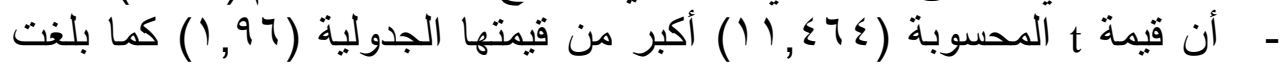

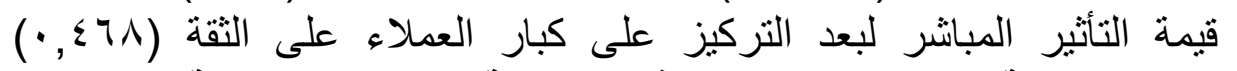

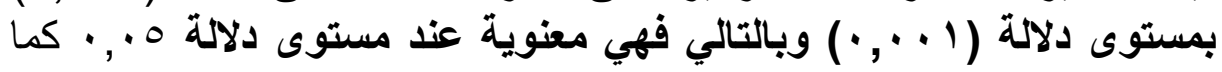

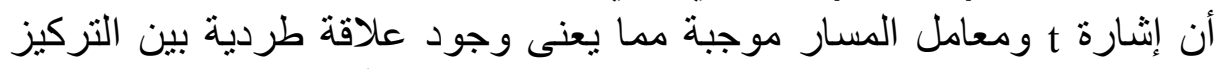

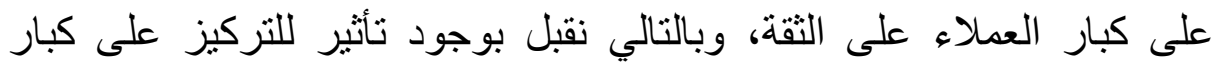
العملاء على الثقة.

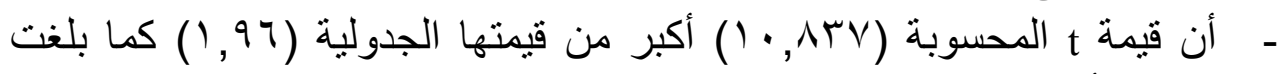

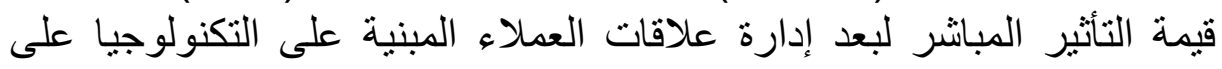

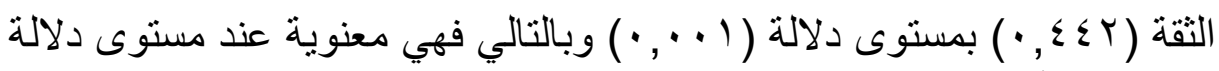

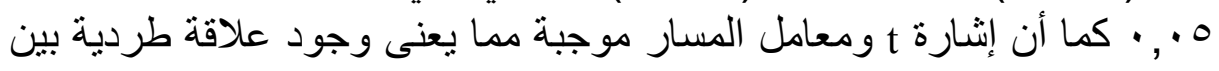

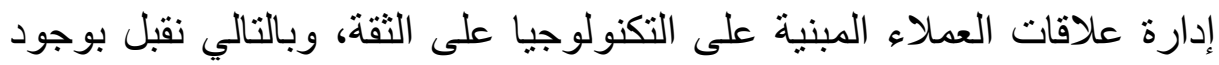

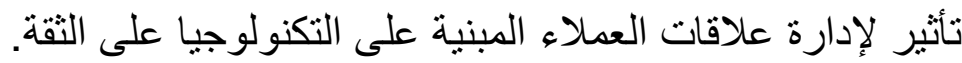

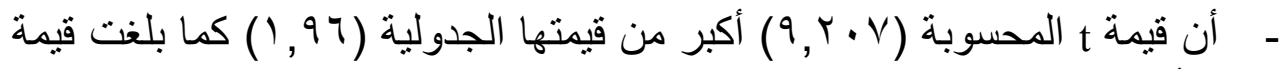

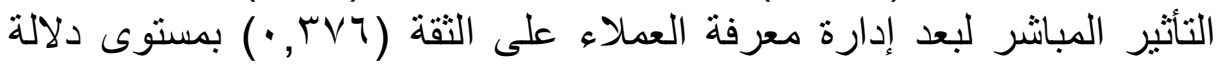

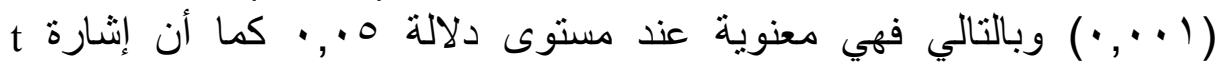

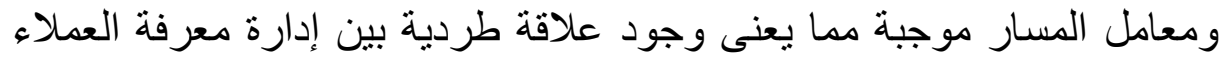

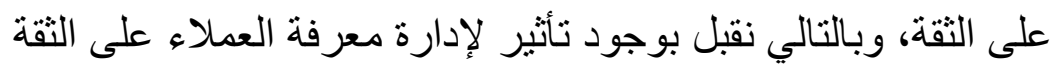

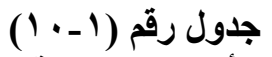

نتائج العلاقة بين أبعاد إدارة علاقات العملاء و الثقة

\begin{tabular}{|c|c|c|c|c|c|c|}
\hline معامد & الترتيب & مستوي & المعياري & t- قيمة & المسلار & المتغير \\
\hline \multirow[t]{4}{*}{$\cdot, \pi$} & 1 & $\cdot, \cdots 1$ & $\cdot, \cdot Y T$ & $11, \leqslant 7 \varepsilon$ & $\left.\cdot, \sum\right\rceil \uparrow$ & التركيز على كبار العملاء \\
\hline & $\varepsilon$ & $\cdot, \cdots 1$ & $\cdot, \cdot Y \xi$ & 0,110 & $\cdot, Y, Y$ & تنظيم إدارة علاقات العملاء \\
\hline & $\Gamma$ & $\because, \cdots 1$ & $\cdot, r \xi$ & $9, Y \cdot V$ & $\cdot, r Y 4$ & إدارة معرفة العملاء \\
\hline & $r$ & $\cdot, \cdots 1$ & $\cdot, \cdot T$ & 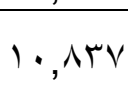 & $\cdot, \sum \leqslant r$ & 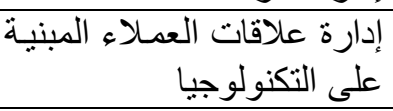 \\
\hline
\end{tabular}

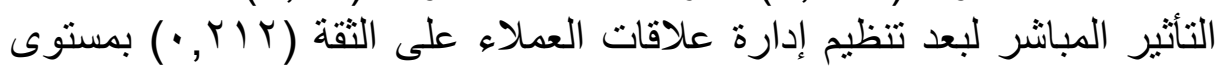




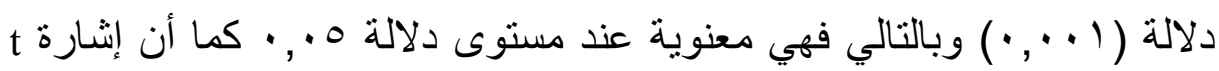

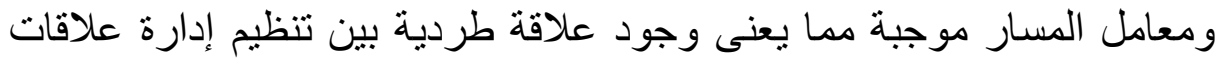

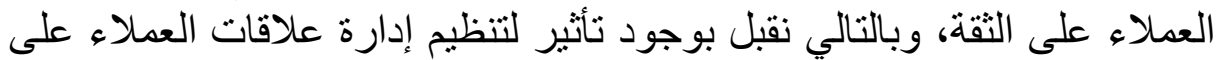

الثقة.

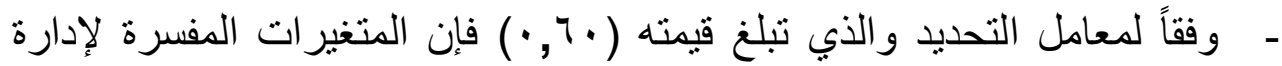

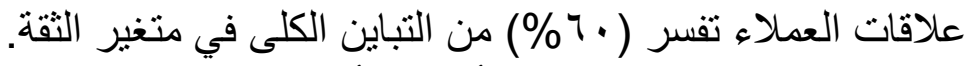

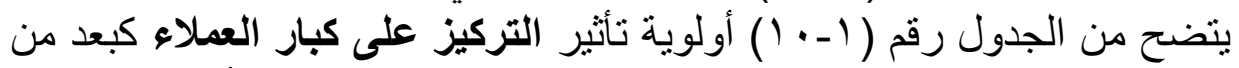

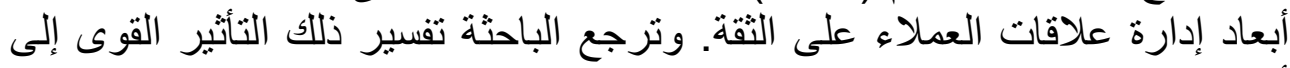

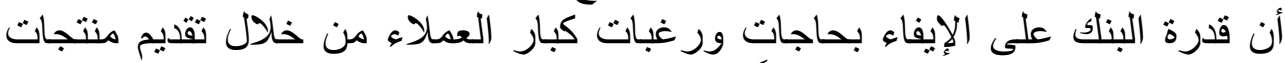

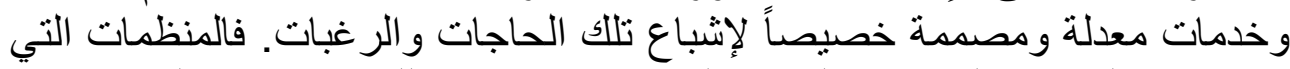

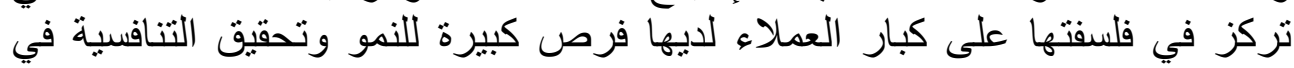

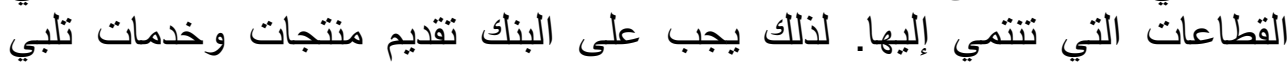

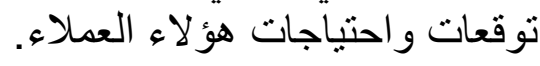

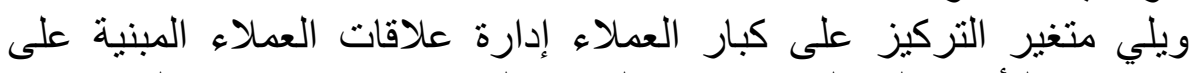

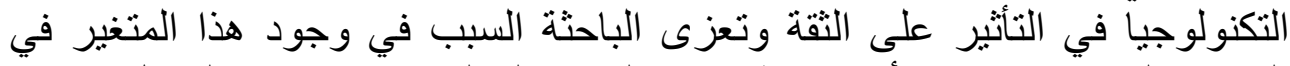

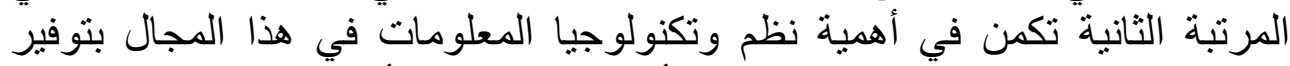

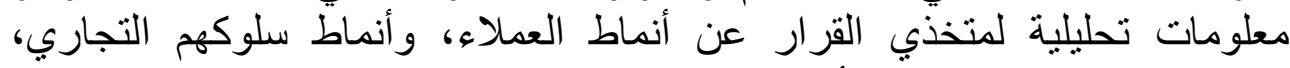

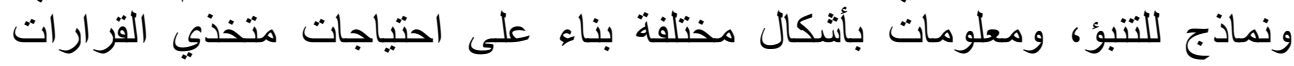
وصناع السياسات هذا يتفق مع ما جاء في دراسة (2011).

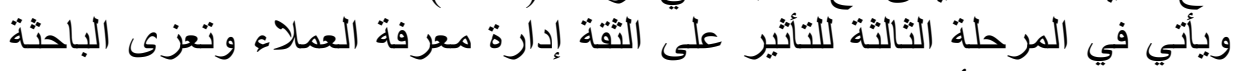

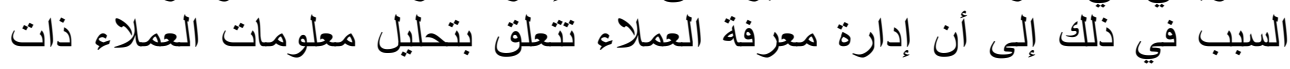

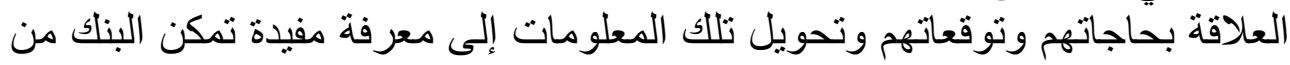

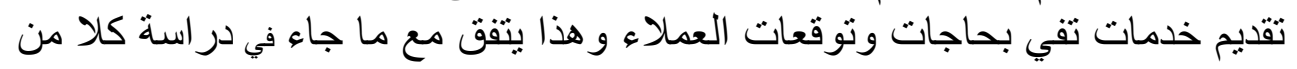
( Murillo \& Anrobi,2002; Moreno \& Morales, 2014)

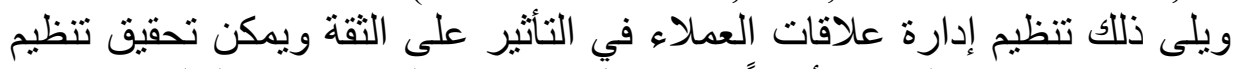

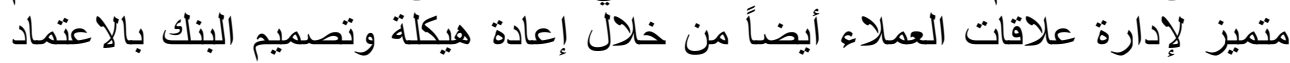

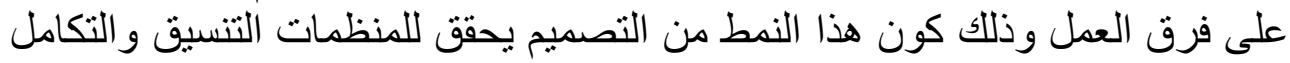

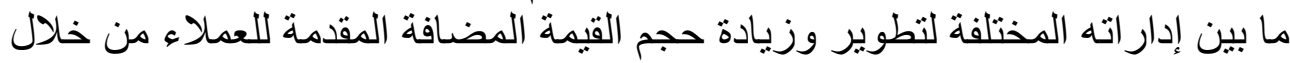

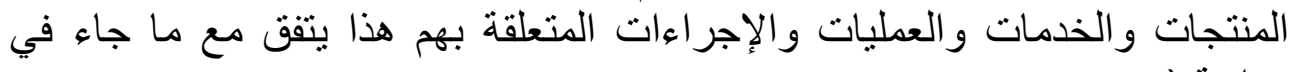

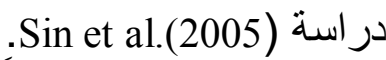

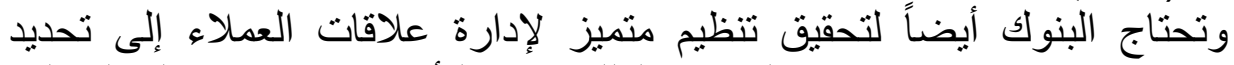

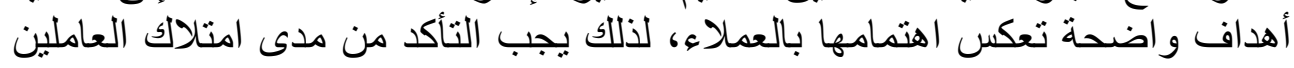

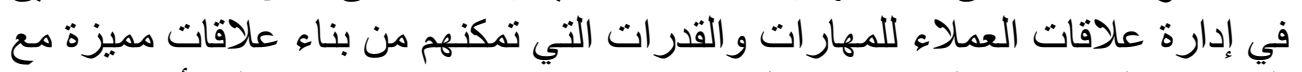

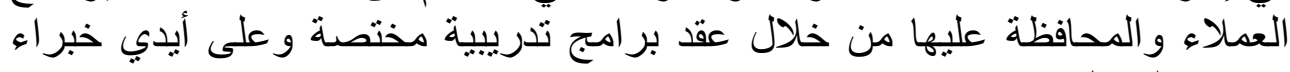

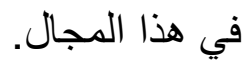




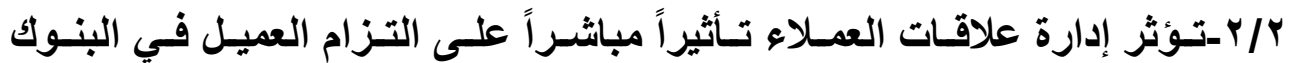

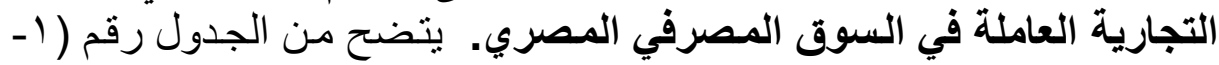

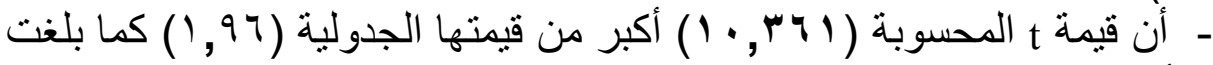

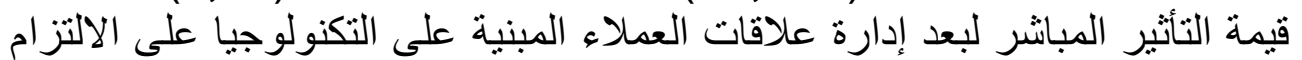

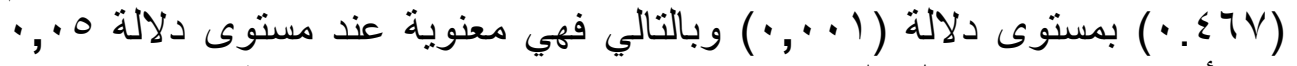

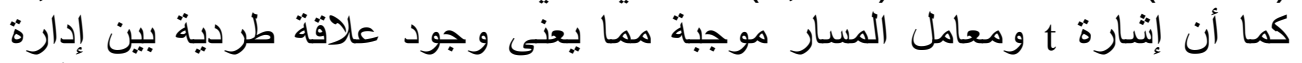

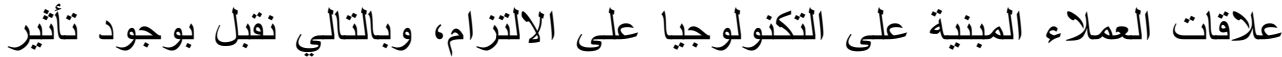

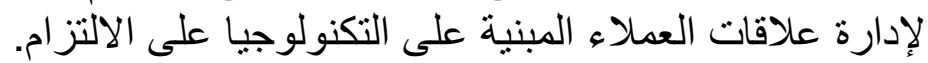

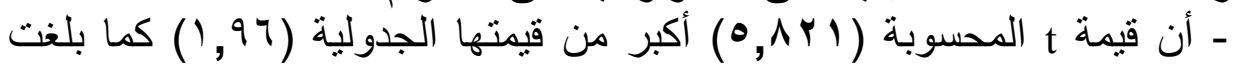

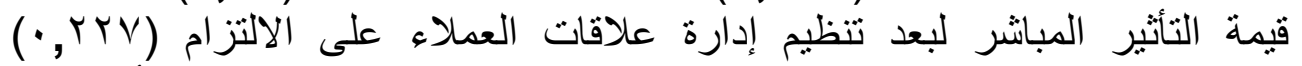

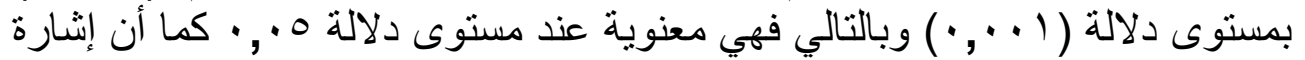

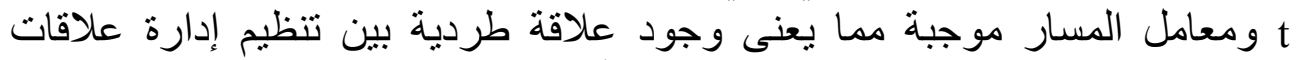

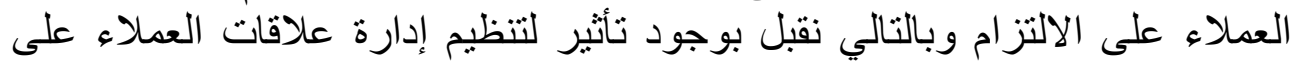
الالنز ام ام إع

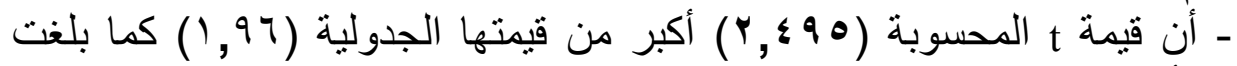

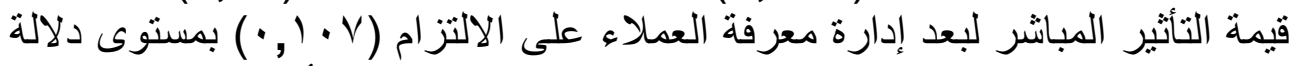
(T)

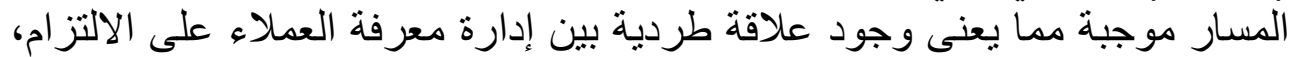
وبالتالي نقبل بوجود تأثير لإدارة معرفة العملاء الالتز ام.

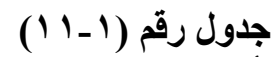
نتائج العلاقة بين أبعاد إدارة علاقات العملاء والالتزام

\begin{tabular}{|c|c|c|c|c|c|c|}
\hline التحديد & الترتيب & الدلالة & المعياري & قيمة & المستار & المتغير \\
\hline \multirow[t]{4}{*}{$\cdot .707$} & - & . ITY & $\cdot . r \pi$ & 1.519 & $\because .07$ & التركيز على كبار العملاء \\
\hline & r & $\because \cdots 1$ & $\because . r 4$ & $0 . \wedge r$ & $\cdot$ UTV & تنظيم إدارة علاقات العملاء \\
\hline & $r$ & $\because .1 \%$ & $\because \cdot{ }^{\prime} \wedge$ & $r . \leqslant 90$ & $.1 \cdot \mathrm{V}$ & إدارة معرفة العملاء \\
\hline & 1 & $\therefore \cdots$ & $\because \cdot \uparrow \wedge$ & $1 \cdot .471$ &..$\leqslant \mathrm{TV}$ & علـ التكنو لـ حيات العمـلاء المبنيـة \\
\hline
\end{tabular}

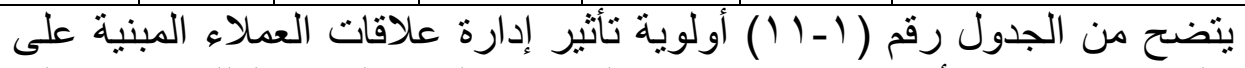

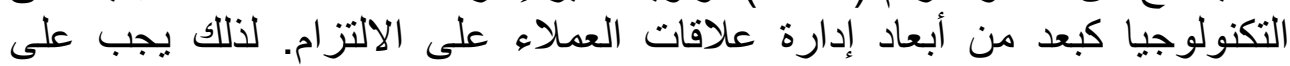

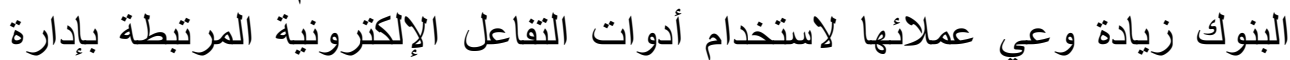

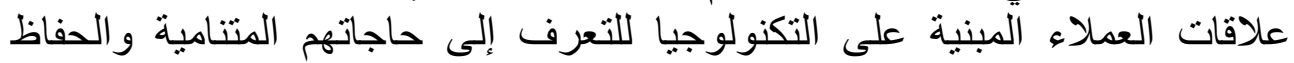

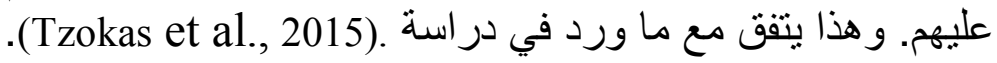

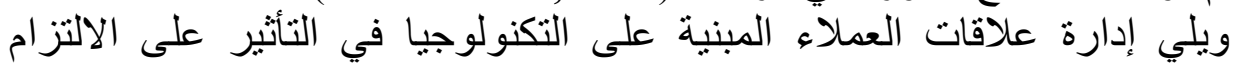

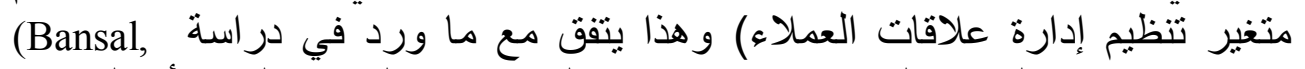

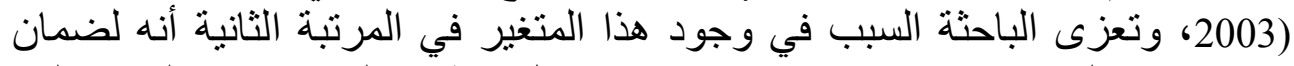
نجاح إدارة العلاقة في مهنها لابد من توفر هيكل تتظيمي لها ينسجم والكيفية التي التي 


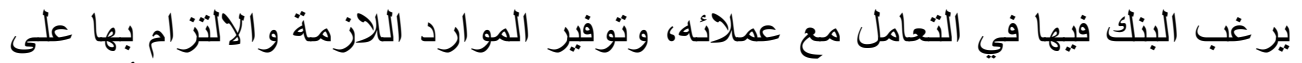

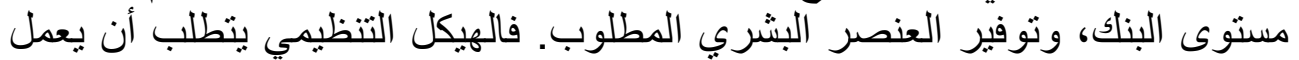

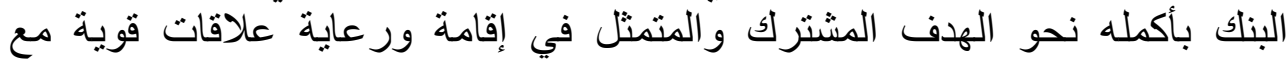
العملاء.

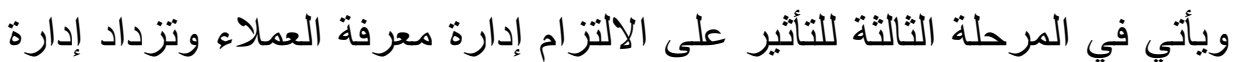

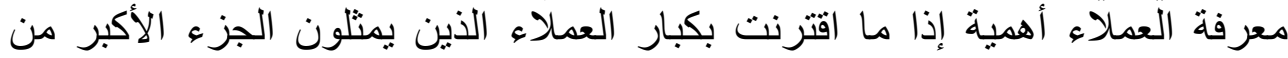

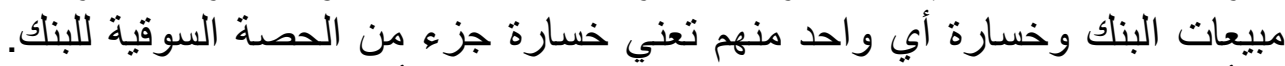

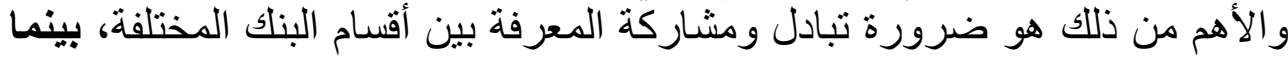

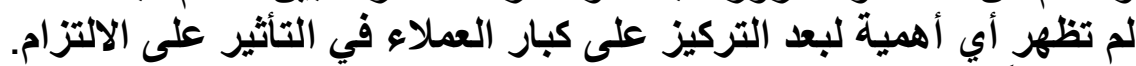

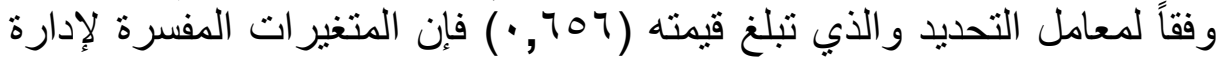

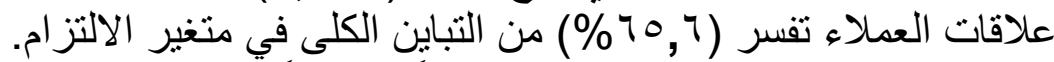

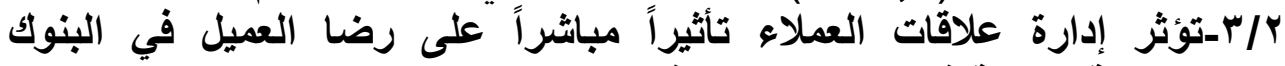

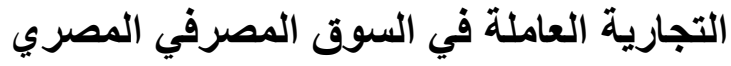

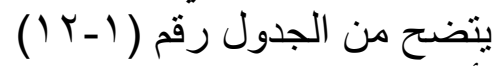

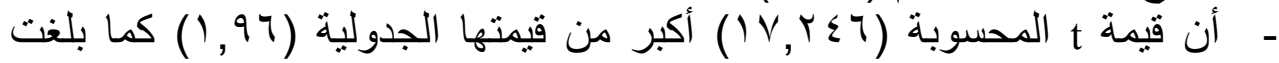

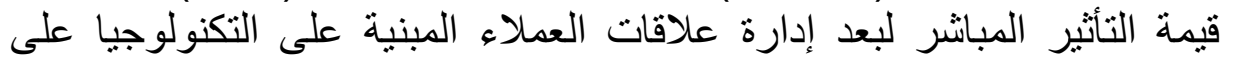

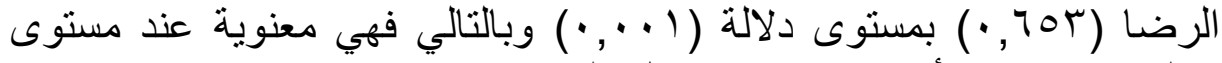

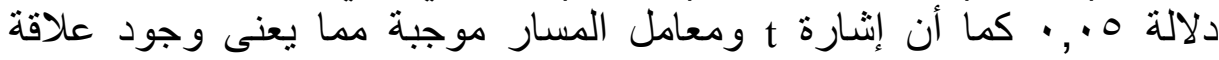

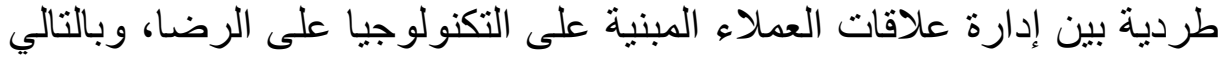

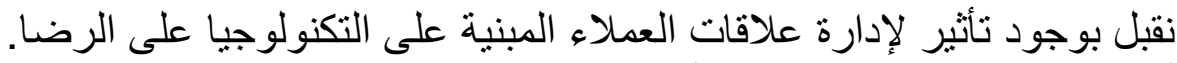

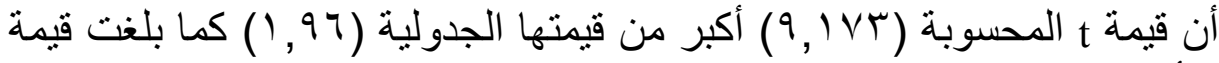

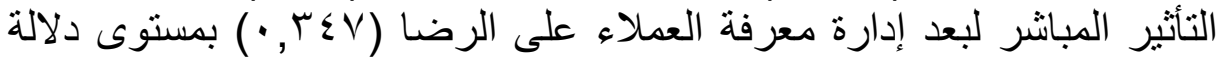

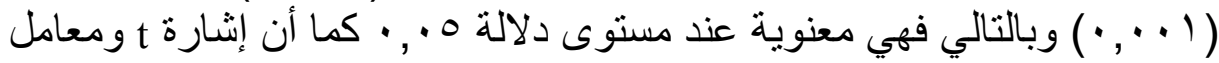

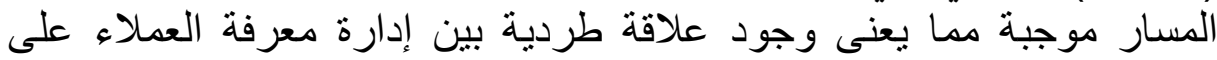

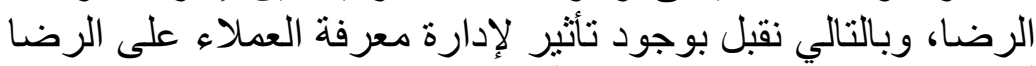

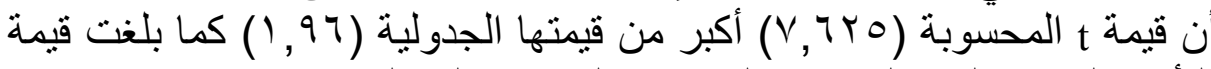

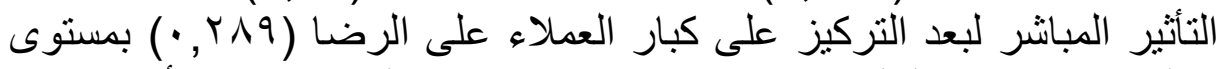

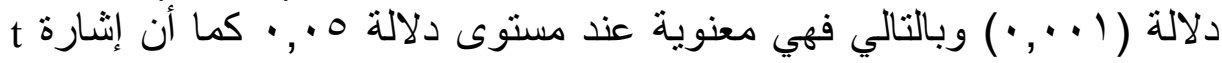

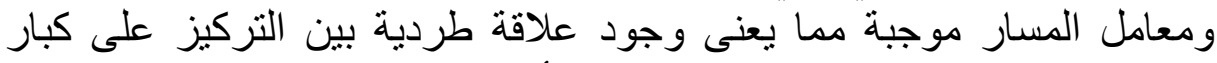

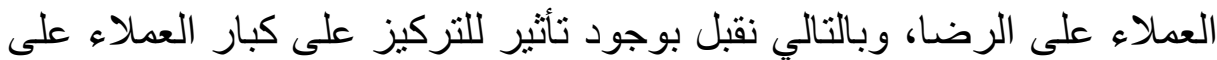

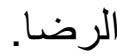

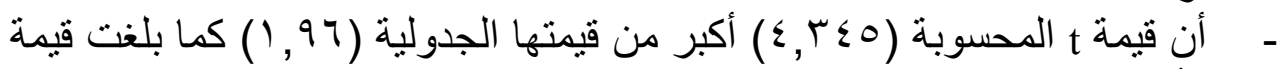

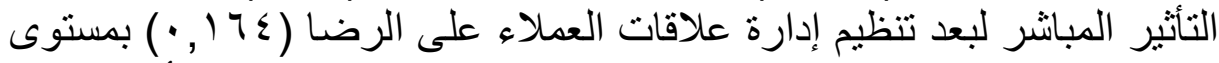

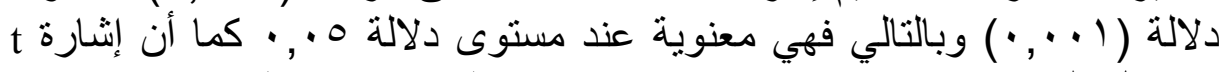

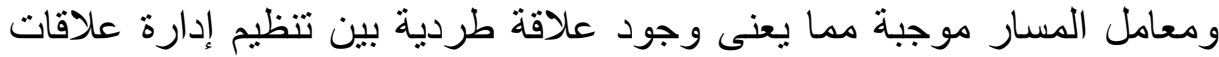

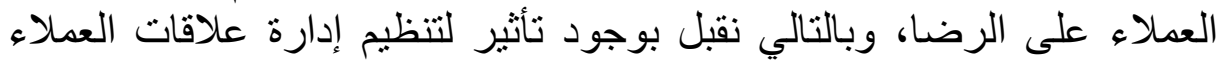

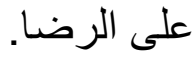




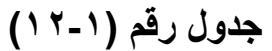

نتائج العلاقة بين أبعاد إدارة علاقات العملاء والرضا

\begin{tabular}{|c|c|c|c|c|c|c|}
\hline معامل & الترتيب & الدلالة & المعياري & قيمة t- ق & المسارة & المتغير \\
\hline \multirow[t]{4}{*}{$\cdot . T V Y$} & $r$ & $\because \cdot 1$ & $\because \cdot Y V$ & V.TYO & $\cdot r \wedge q$ & 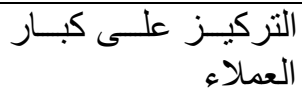 \\
\hline & $\varepsilon$ & $\because \cdots 1$ & $\because$ ro & $\varepsilon, \Gamma \leqslant 0$ & $.17 \varepsilon$ & تلتظـيمة إدارة علاقــات \\
\hline & $r$ & $\because . \cdots 1$ & $\because$. YO & $9.1 \mathrm{VT}$ & $\cdot r \leqslant \leqslant$ & إدارة معرفة العملاء \\
\hline & 1 & $\because \cdots 1$ & $\because \cdot Y \varepsilon$ & $I V . Y \leq 7$ & .704 & 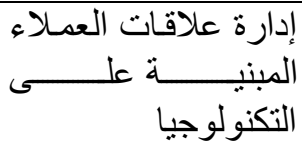 \\
\hline
\end{tabular}

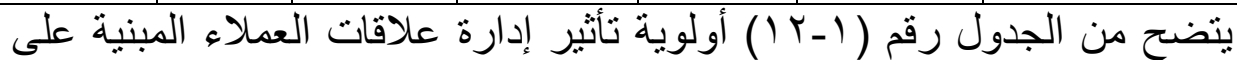

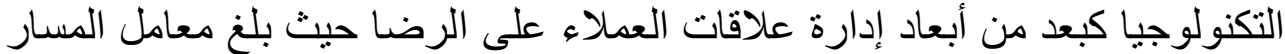

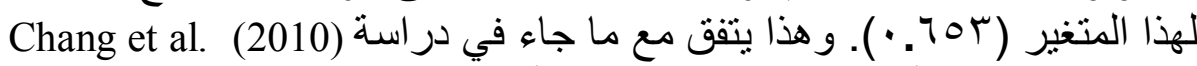

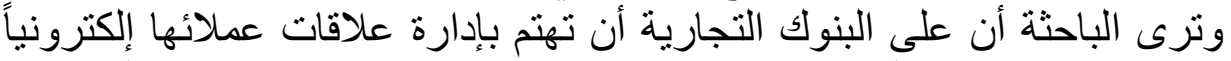

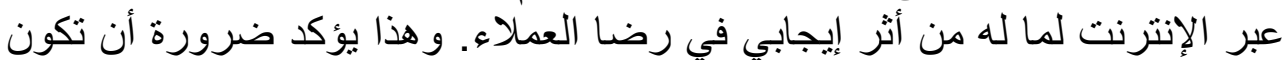

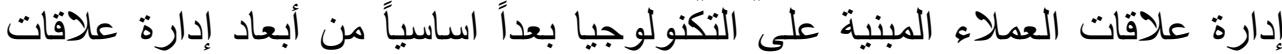

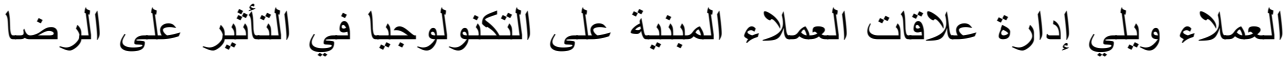

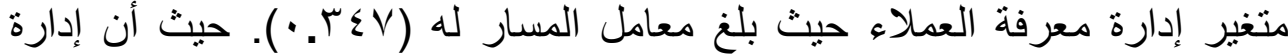

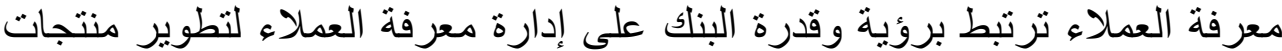

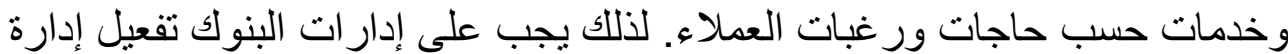

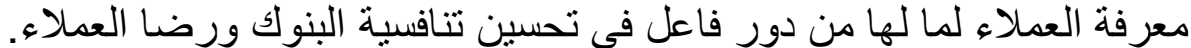

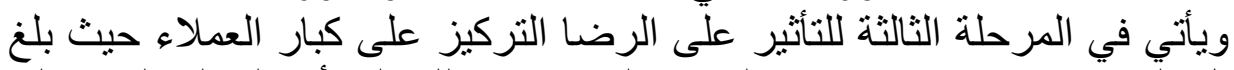

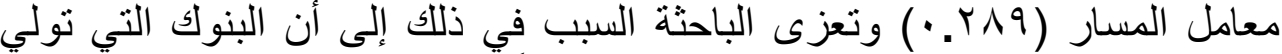

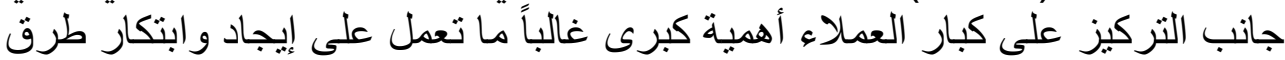

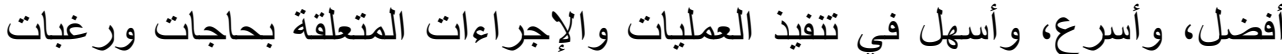

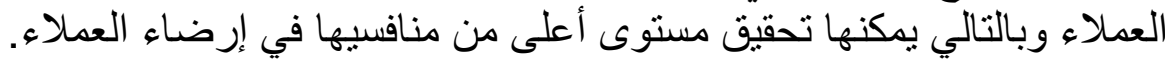

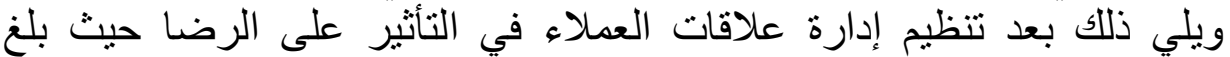

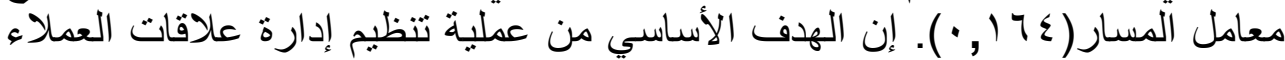

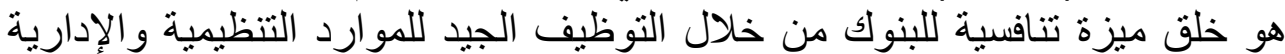

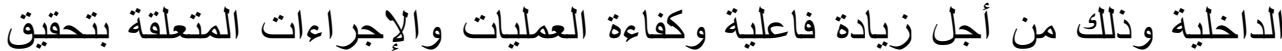

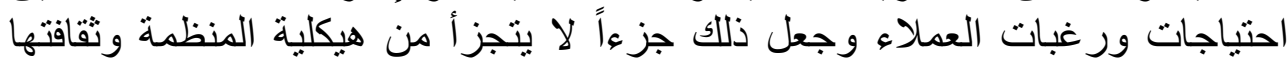

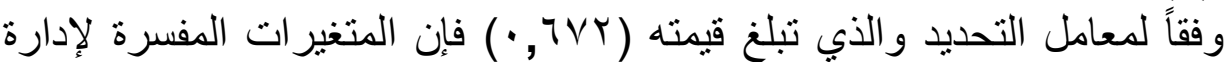

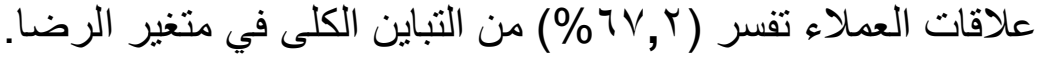




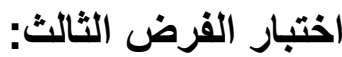

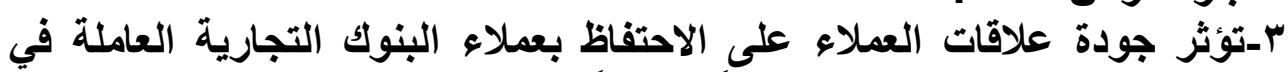

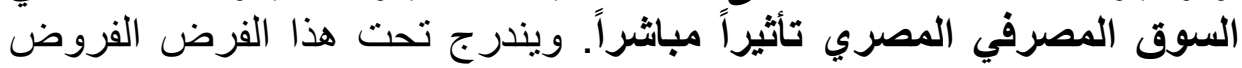

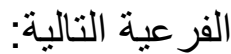
//1/ تؤُثر الثقة على الاحتفاظ بعملاء البنوك التجارية العاملة في السوق المصرفي

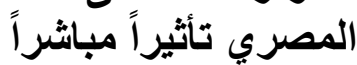

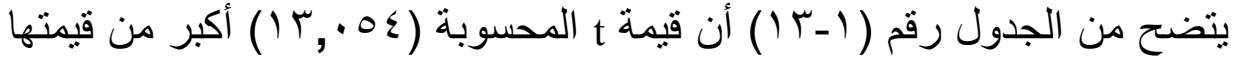

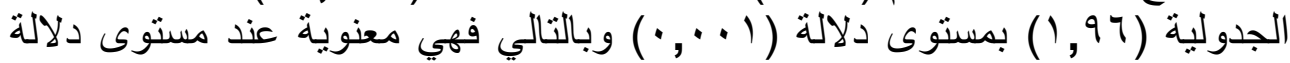

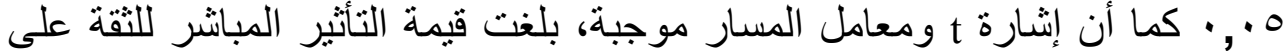

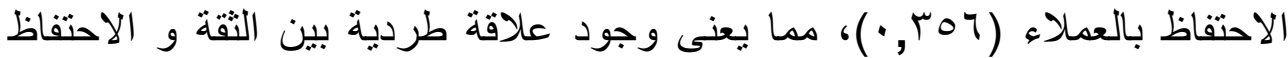

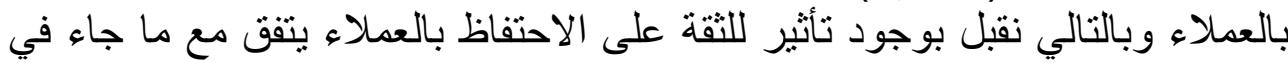

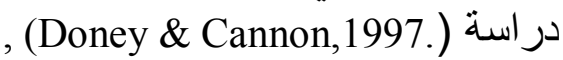

وترى الباحثة أن الثقة تُعد أهم عنصر من عناصر جودة العلاقة خصوصا

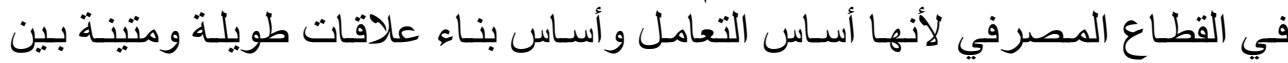

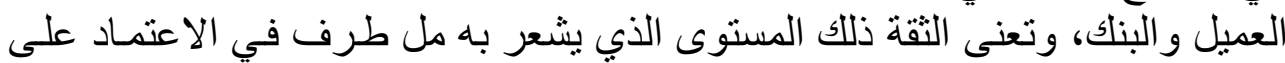

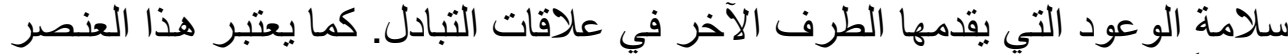

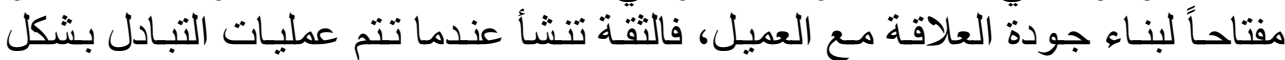
/ آץ-يؤثر الالتزام على الاحتفاظ بعملاء البنوك التجارية العاملة في السوق المصرفي المصري تأثيراً مباشراً

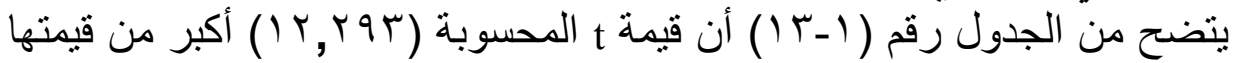

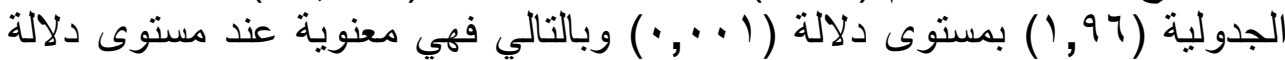

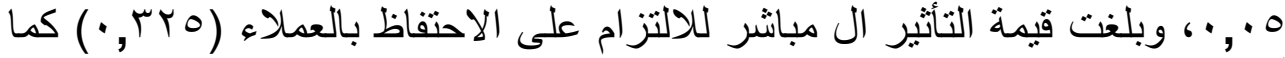

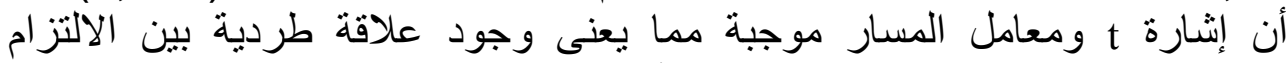

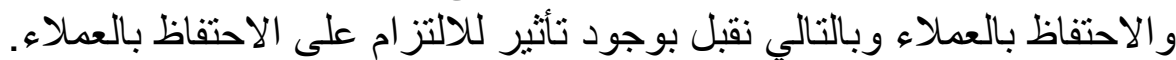

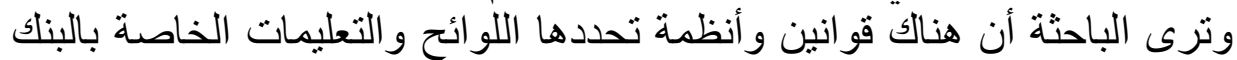

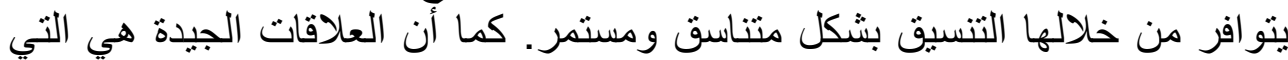

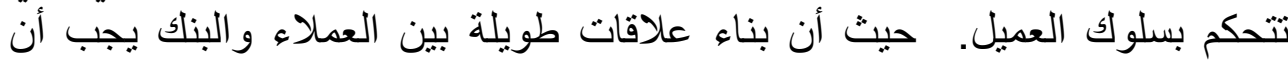

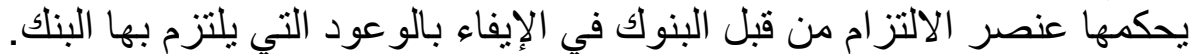

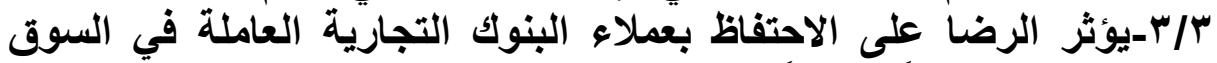
المصرفي المصري تأثيراً مباشراً.

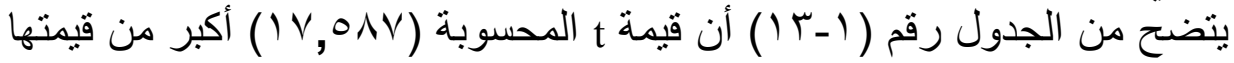

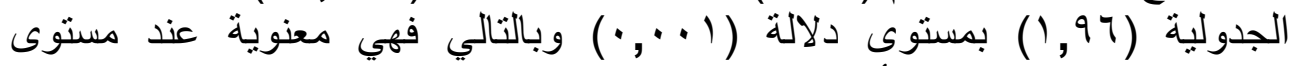

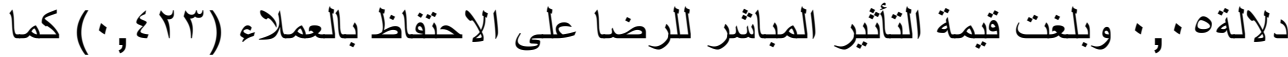

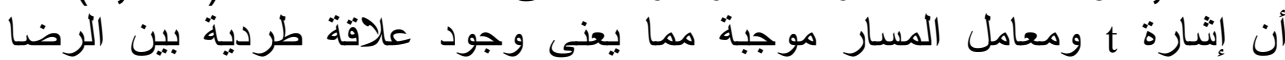

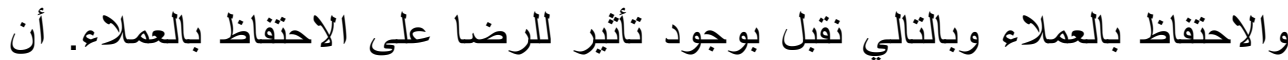


رضا العملاء هي المرحلة التي تسبق الاحتفاظ بالعملاء، فالرضا هو الوسيط الفعال،

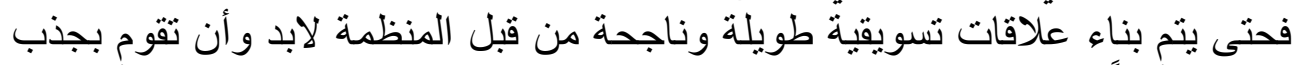

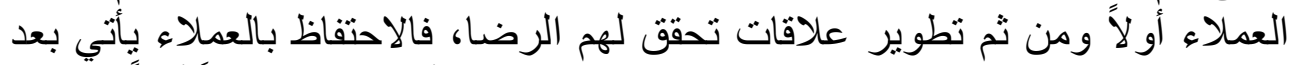

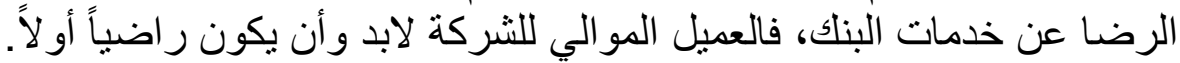

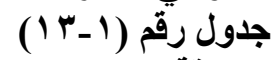
تأثير جودة العلاقة على الاحتفاظ بالعملاء

\begin{tabular}{|c|c|c|c|c|c|c|}
\hline الوسط الحسابي & الترتيب & الدلالة & المعياري & t- قيمة & المسدار & المتغير \\
\hline$r .1 .77$ & $r$ & $\because \cdots 1$ & $\because \cdot Y \xi$ & $15.0 \leq$ &. .507 & الثقة \\
\hline r.V० द & $r$ & $\therefore \cdots 1$ & $\because Y Y$ & Ir.rqu &.. MYO & الالتزام \\
\hline r.qrq. & 1 & $\because \cdots 1$ & $\because \cdot Y I$ & $1 V .0 V \wedge$ &.$\& Y r$ & الرضا \\
\hline
\end{tabular}

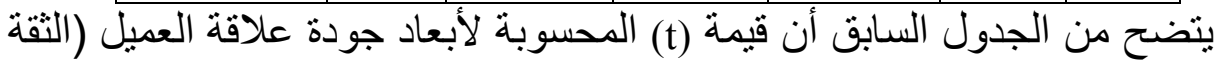

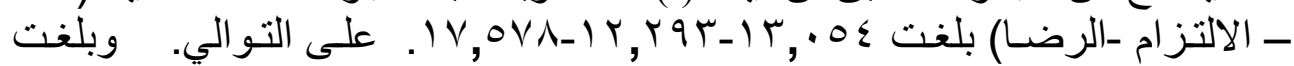

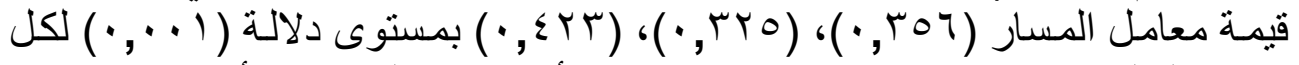

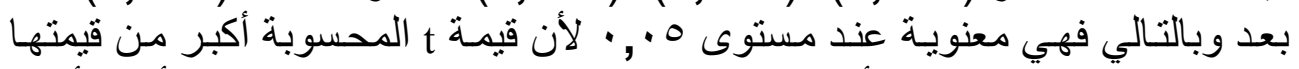

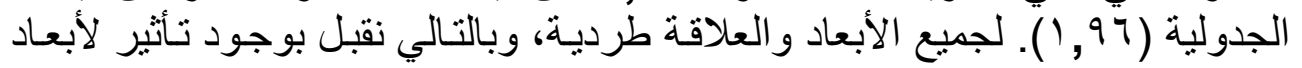

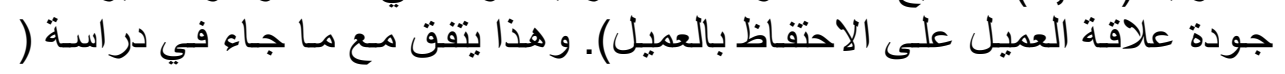

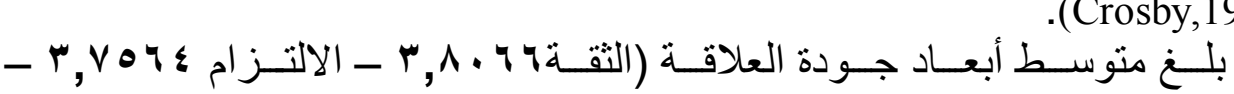

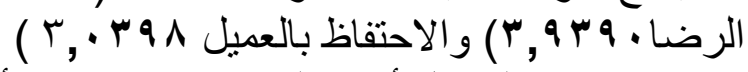

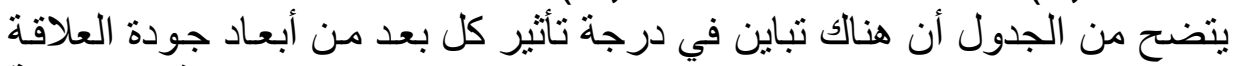

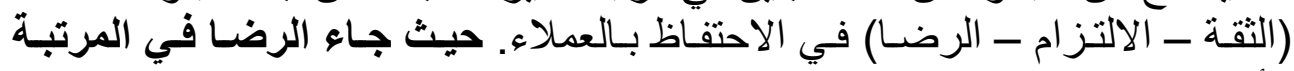

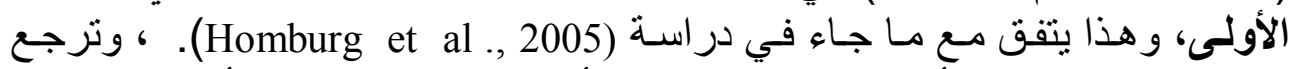

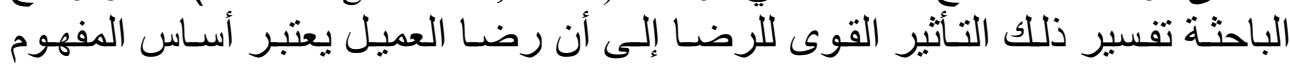

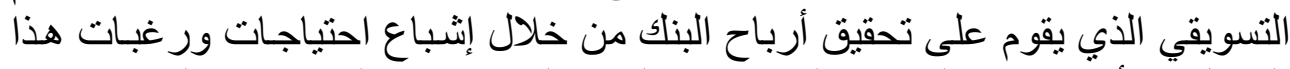

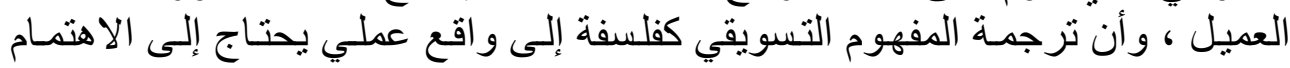

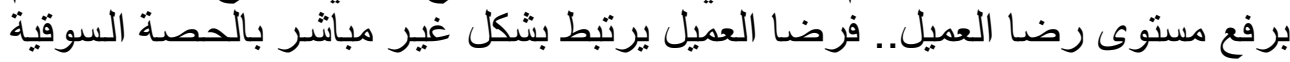

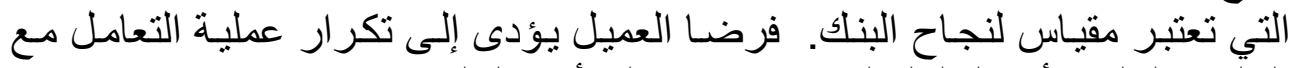

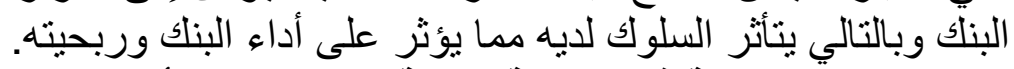

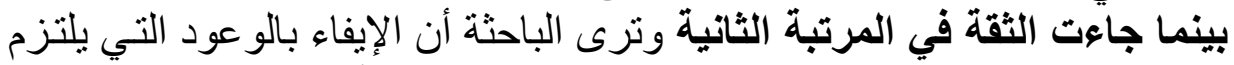

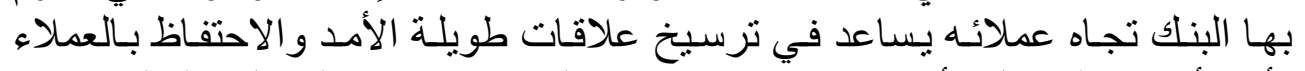

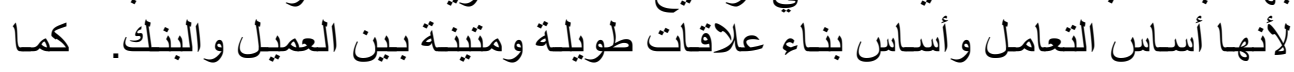

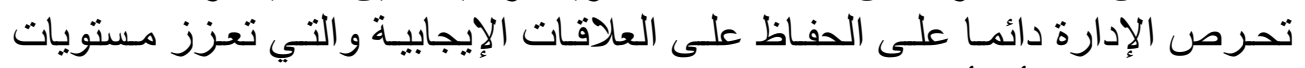

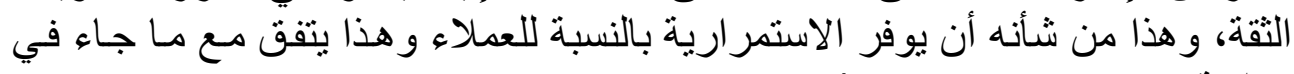
دراسة (Dorsch et al.,1998). في حين جاء الالتزام في المرتبة الأخيرة، حيث يعد الالتزام عنصر أساسي وهام

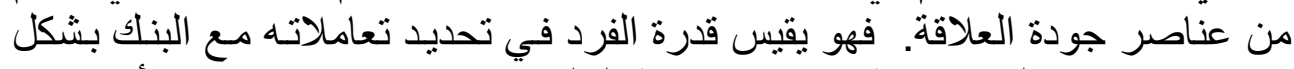

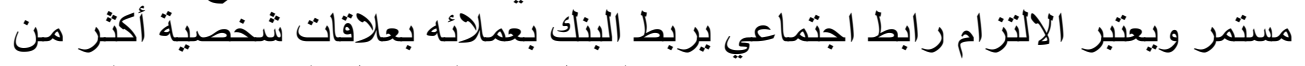

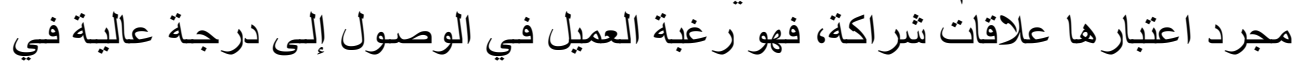




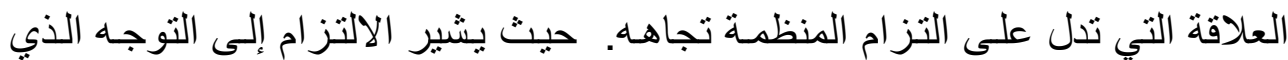

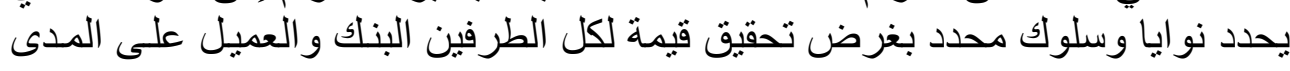

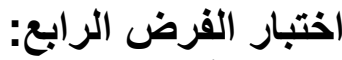

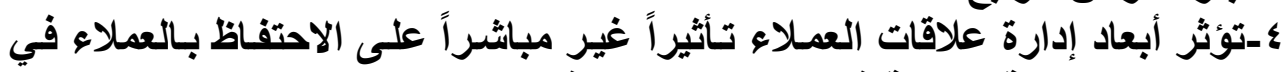

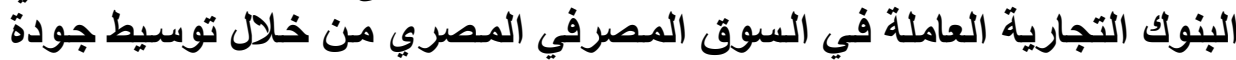

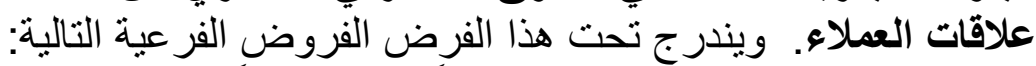

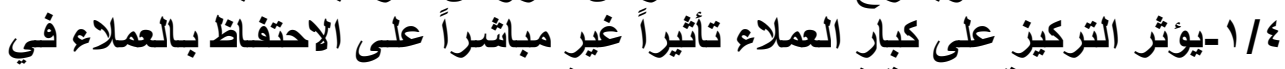

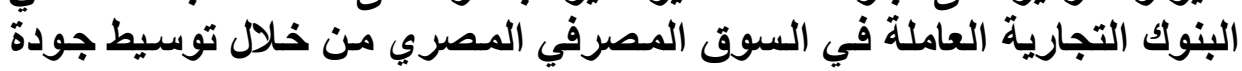
علاقات العملاء.

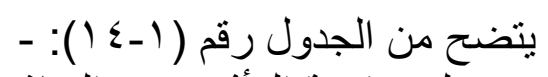

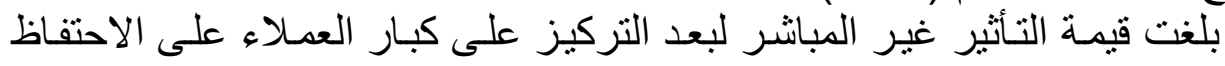

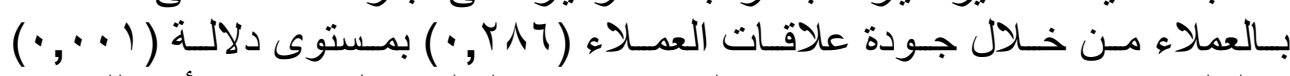

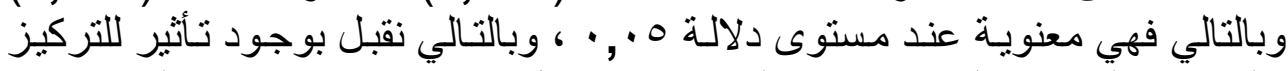

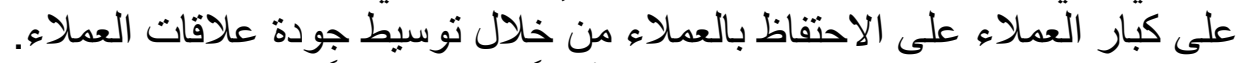

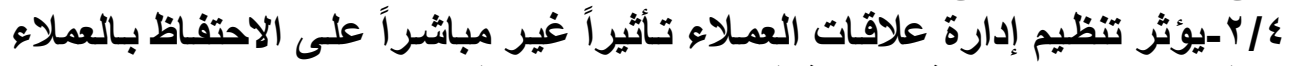

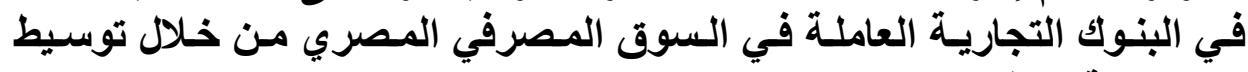
جودة علاقات العملاء. بلغت قيمة التأثير غير العباثر لبعرة لبعد تتظيم إدارة علاقات العملاء على الاحتفاظ

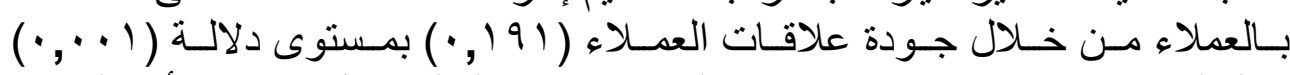

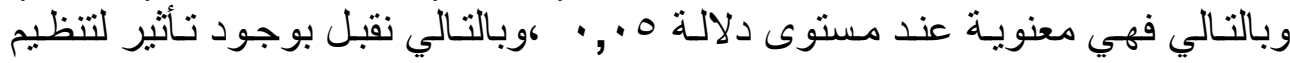

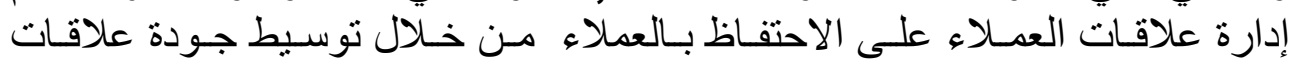

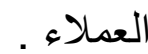

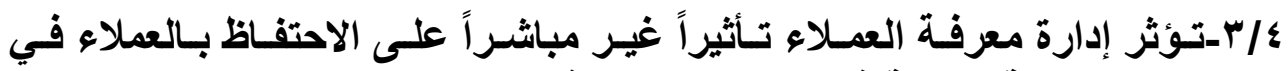

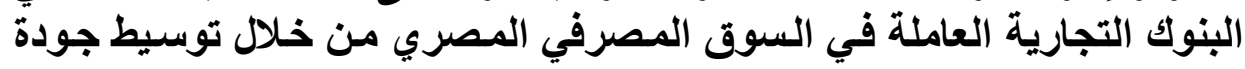
علاقات العملاء.

بلغت قيمة التأثير غير المباشر لبعد إدارة معرفة العملاء على الاحتفاظ بالعملاء

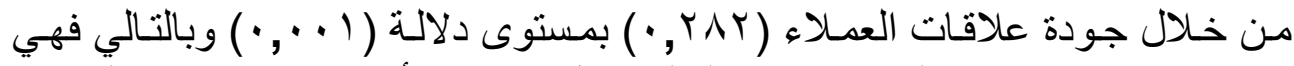

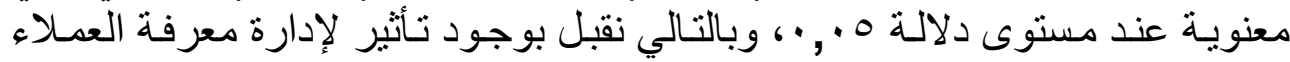

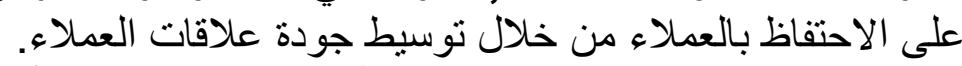

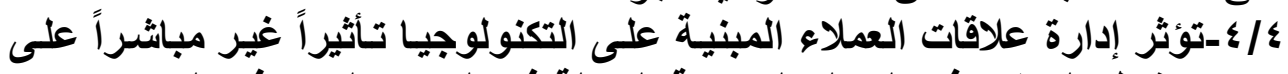

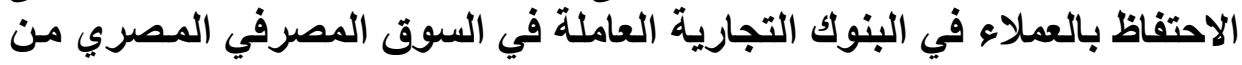
خلال توسيط جودة علاقات العملاء.

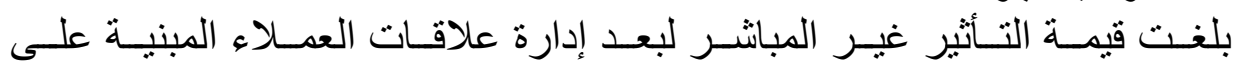

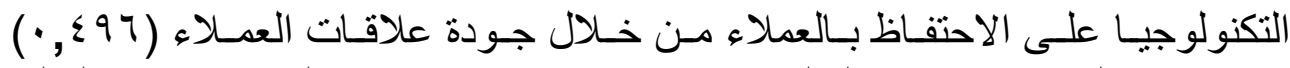

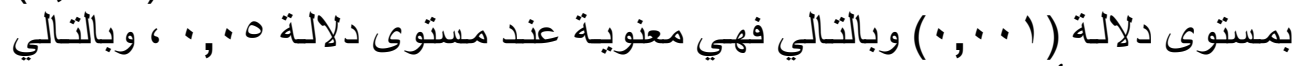

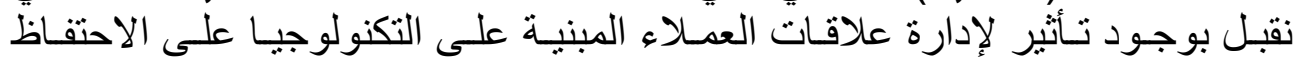

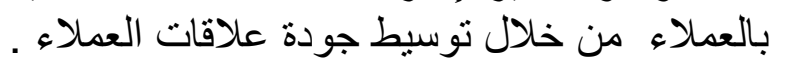




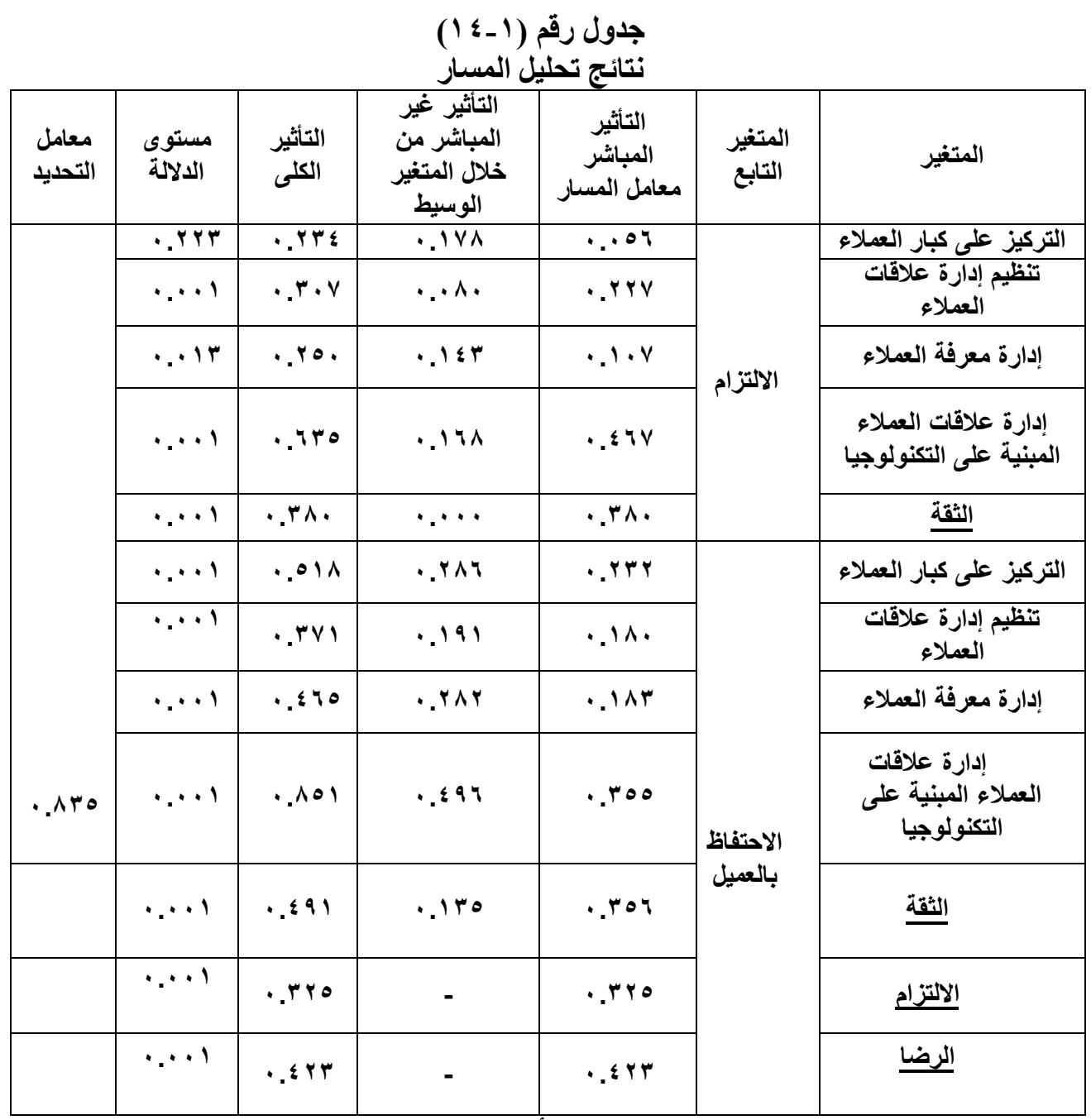

يتضح من الجدول رقم رقم ( ـ ـ ( ) تأثثر نـاتج عن دخول جودة العلاقة كمتغير

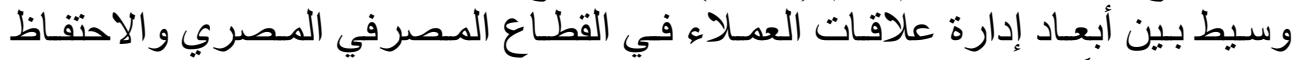

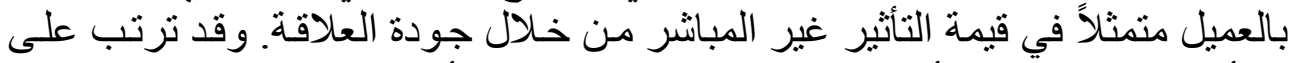

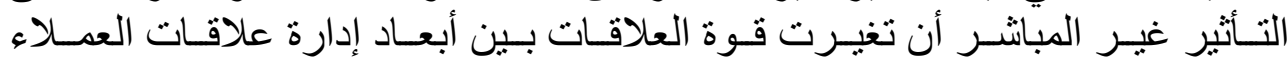

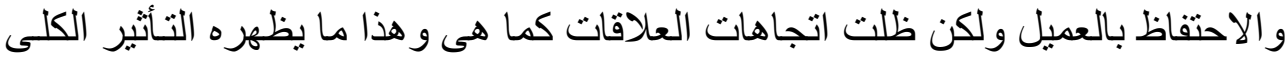

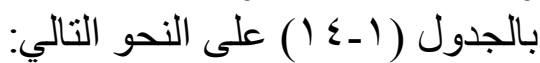

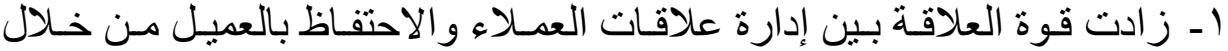

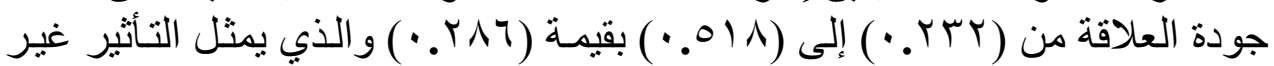

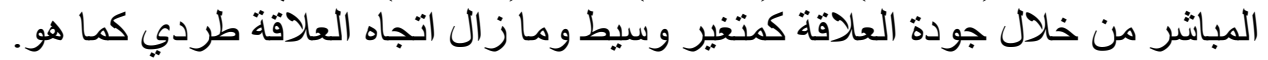

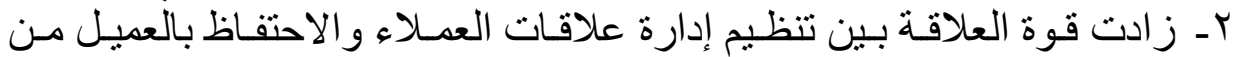

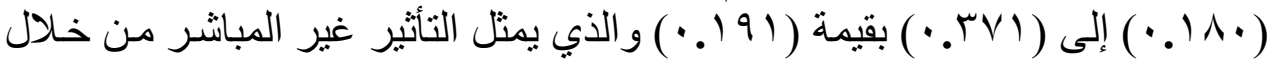

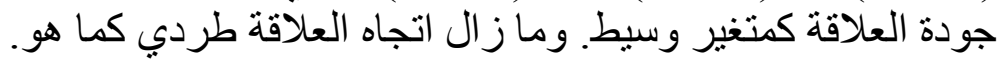




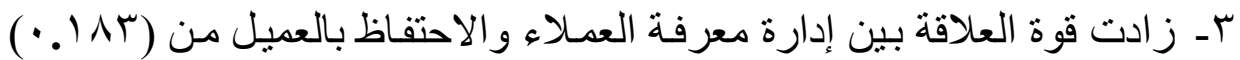

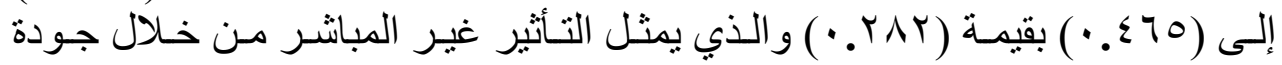

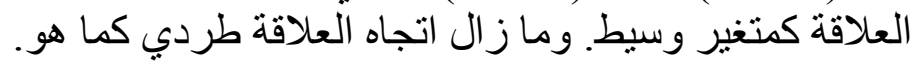

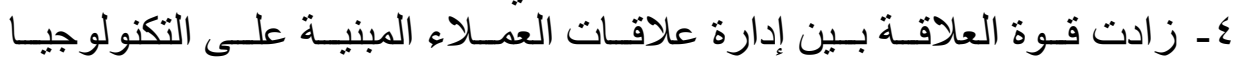

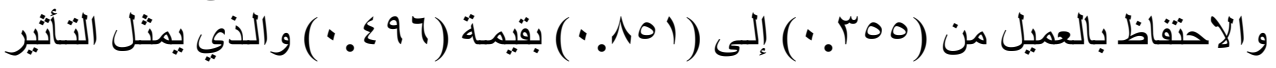

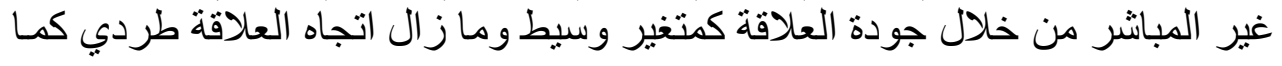

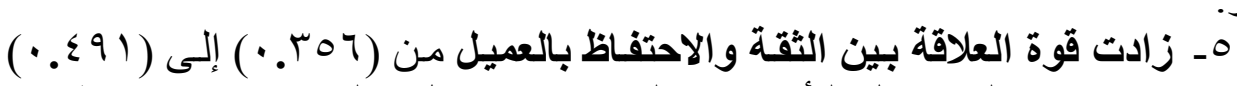

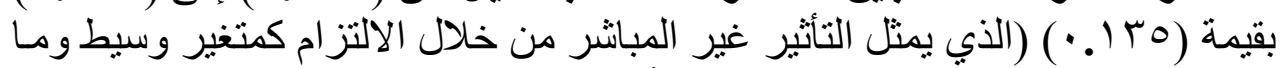

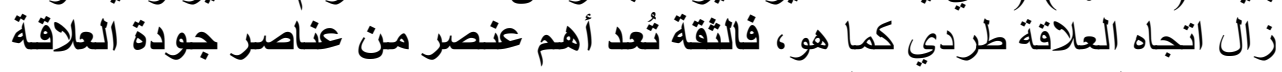
خصوصا في القطاه القطاع المصرفي.

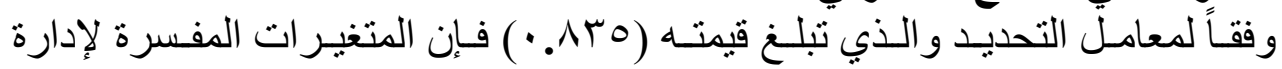

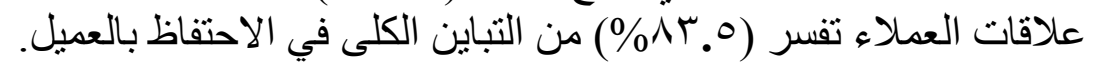

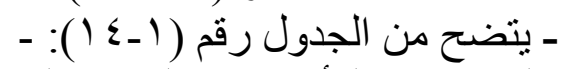

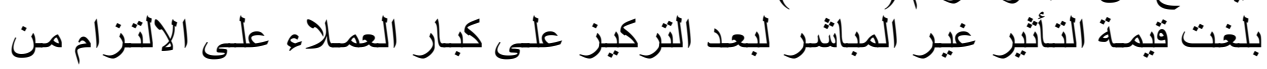

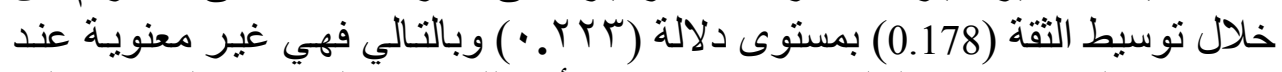

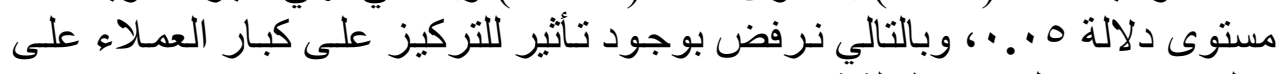
الالتز ام من خلال توسيط الثنة.

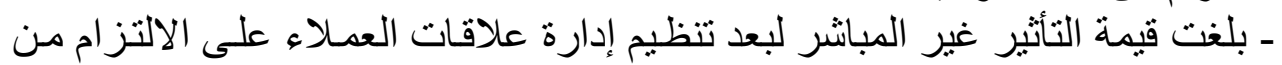

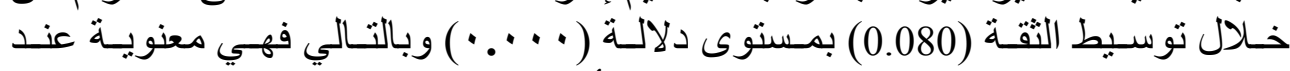

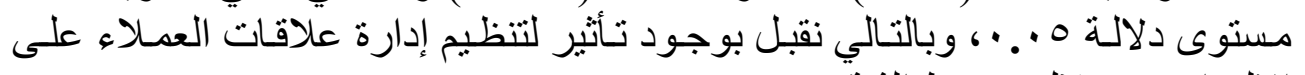
الالتز ام من خلال توسيط الثقة.

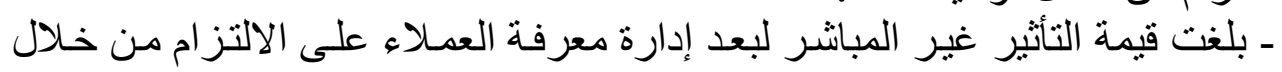

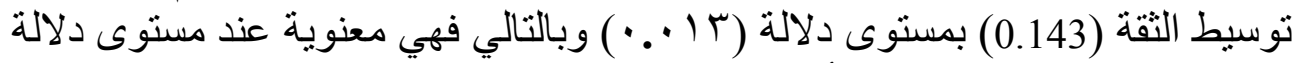

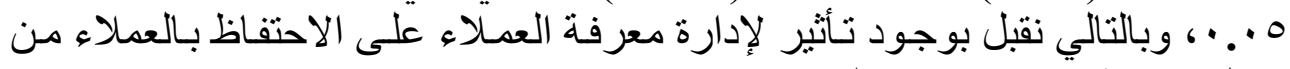

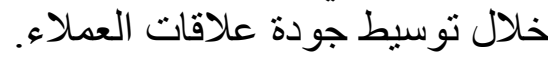

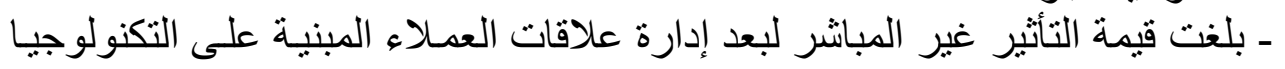

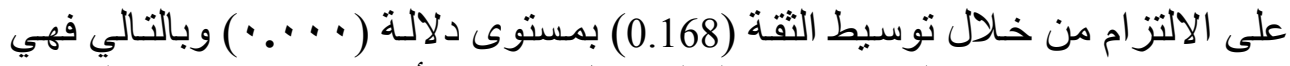

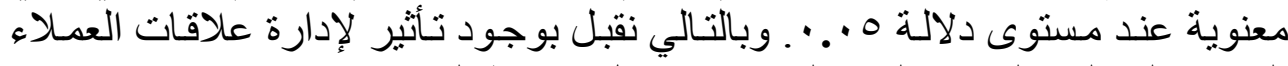

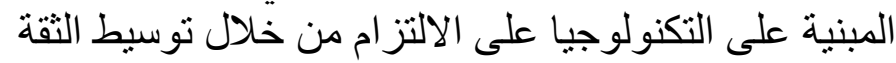

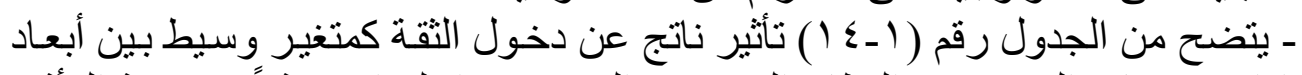

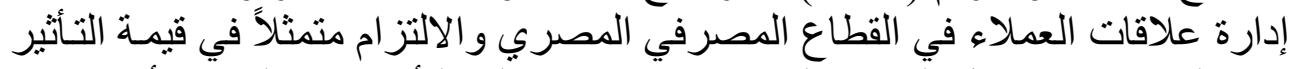

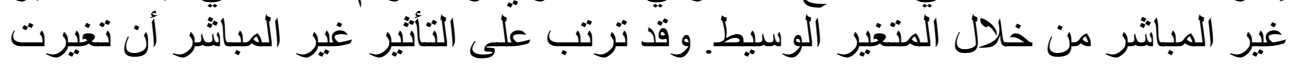

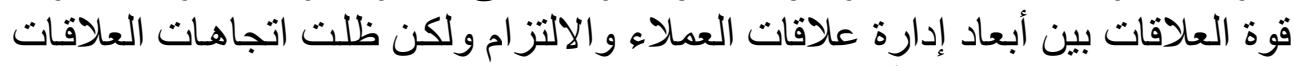

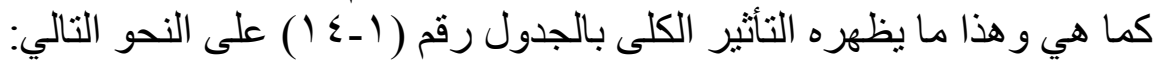




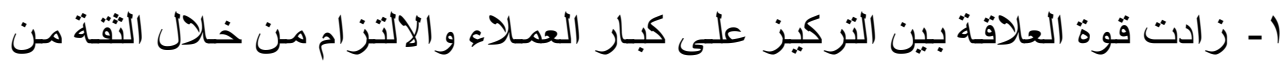

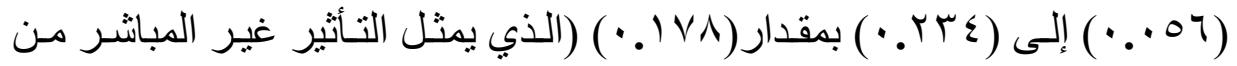

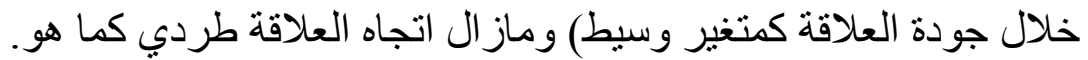

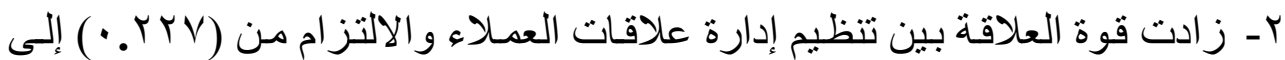

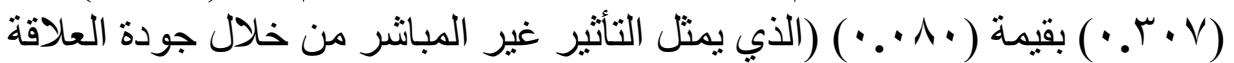
كمتغير وسيط) وماز ال اتجاه العلاقة طردي كما هو.

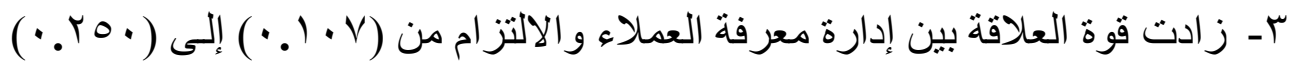

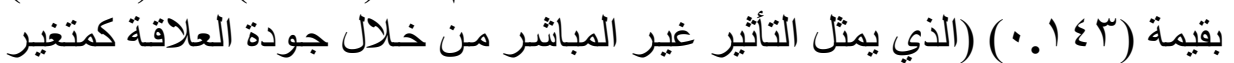

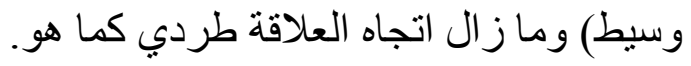

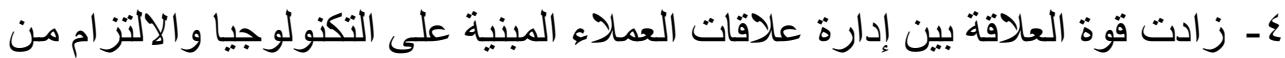

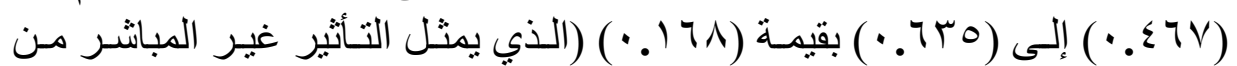

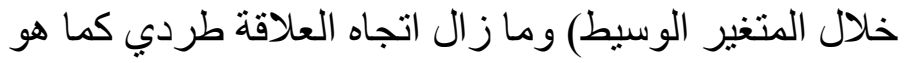

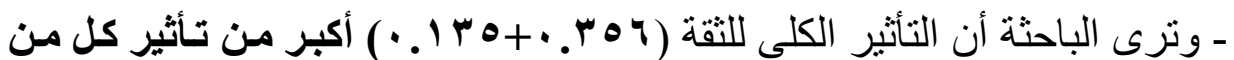

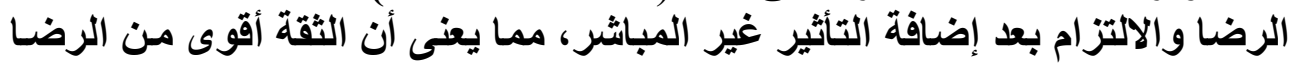

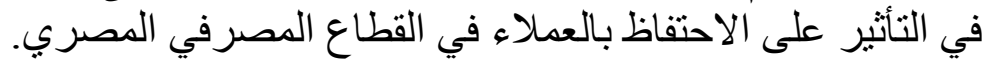

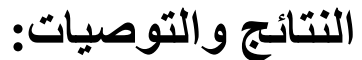

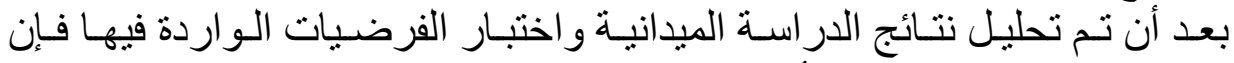

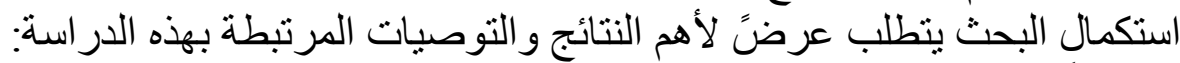

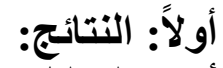
أسفر التحليل الإحصائي للبيانات و الدراسة الميدانية إلى النتائج التالية:

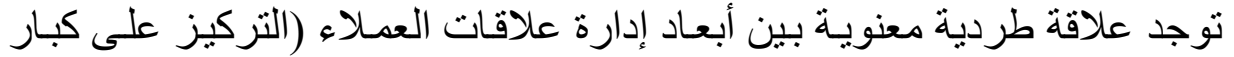

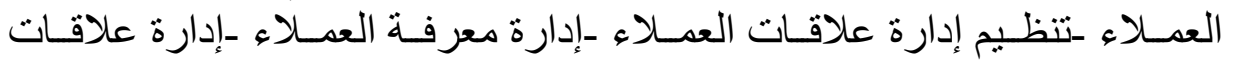

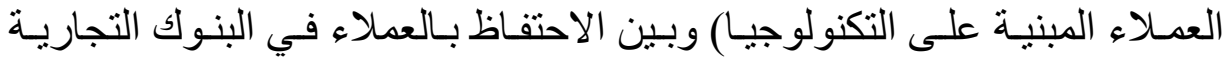

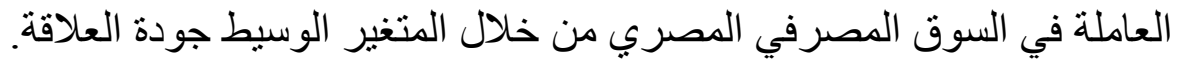

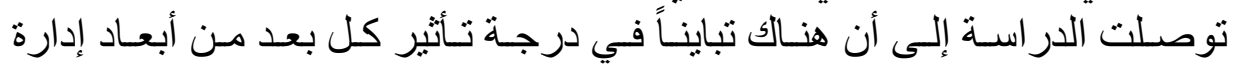

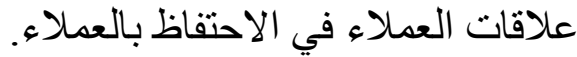

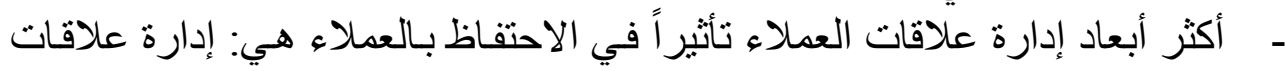

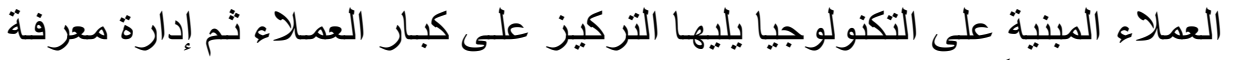
العملاء وأخير أ تنظيم إدارة علاقات العنات العملاء.

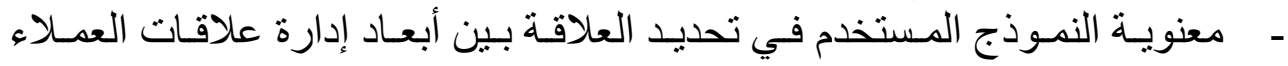

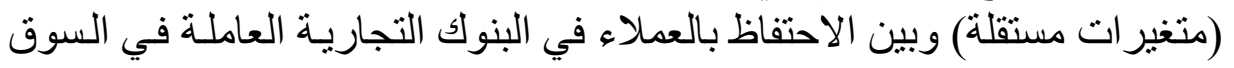

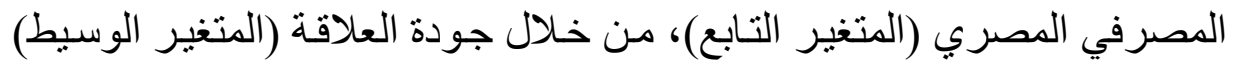

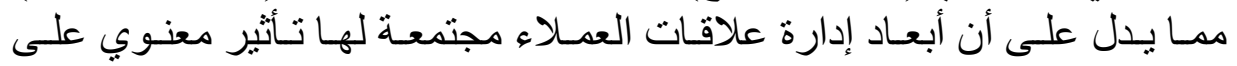




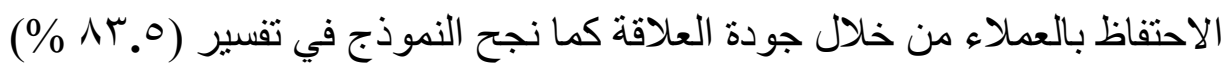

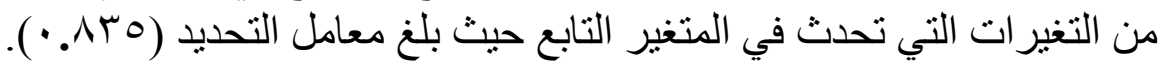

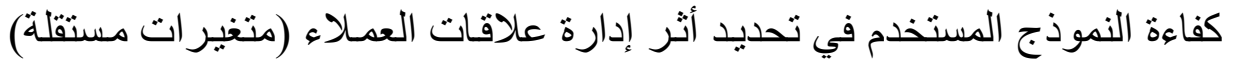

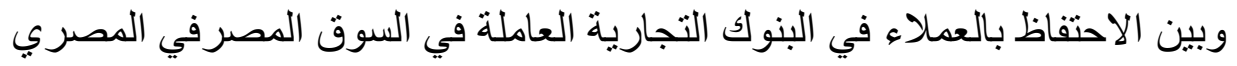

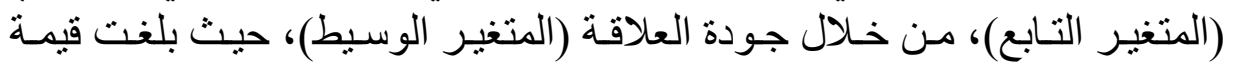
( $(\because \cdot \cdot)=$ P. Value $،(\cdot . r)=($ RMSEA $)$

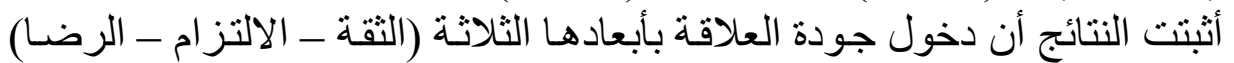

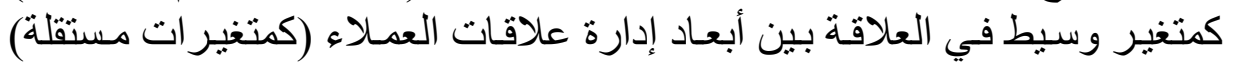

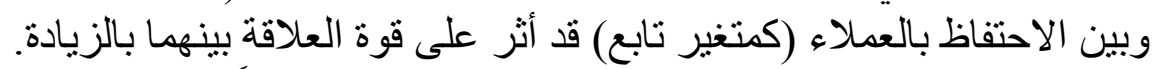

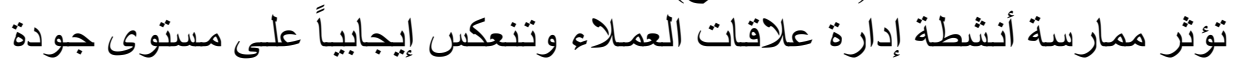

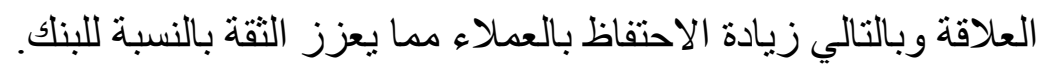

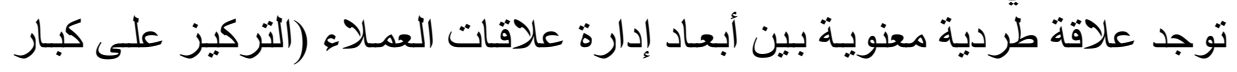

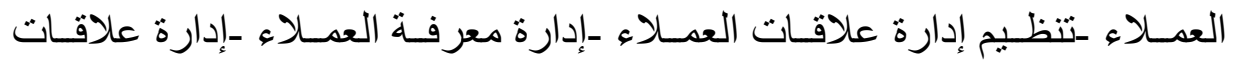

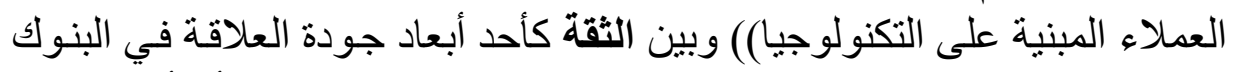

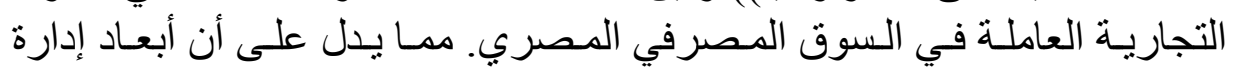

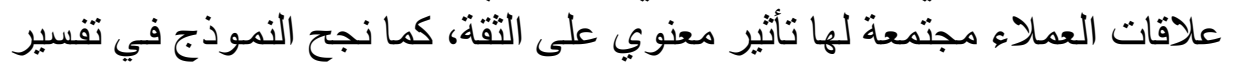

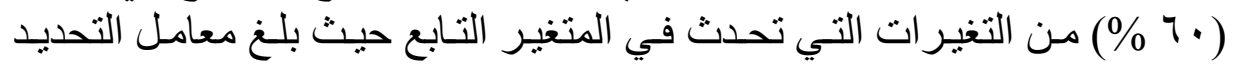
.$(\cdot 7 \cdot)$

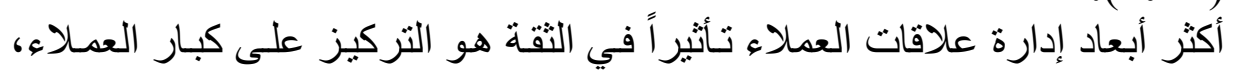

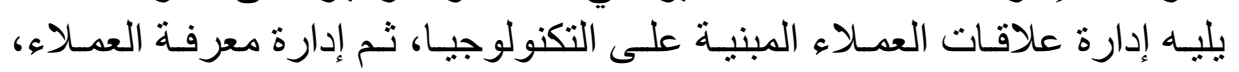
و وأخير التظيم إدارة علافات علاقات العملاء العناء.

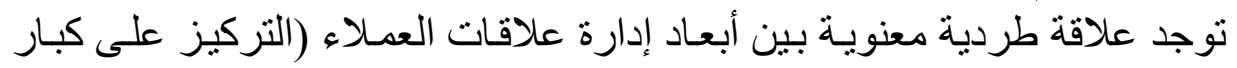

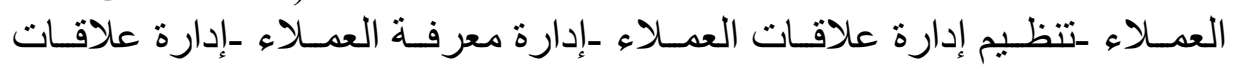

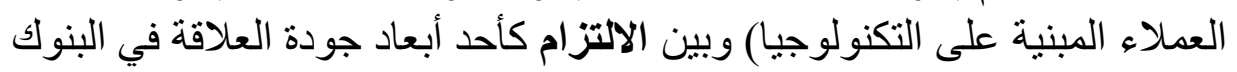

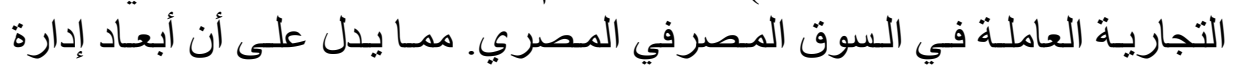

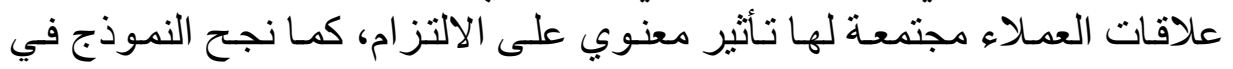

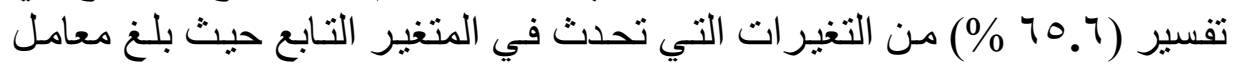

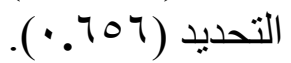

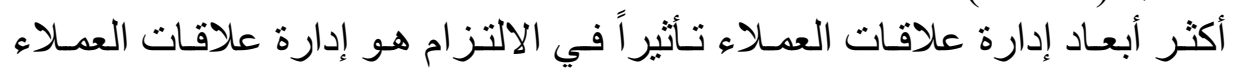

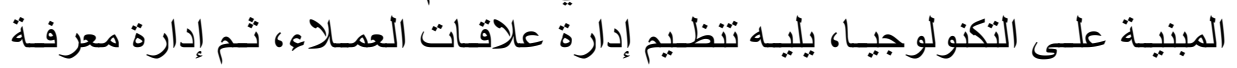

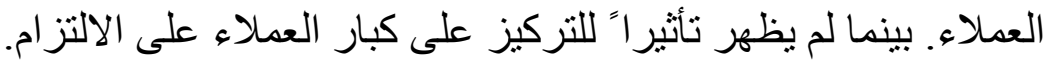

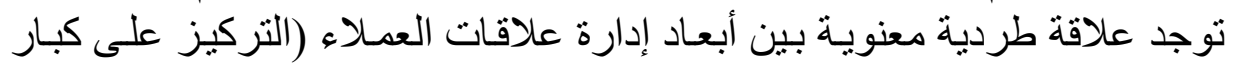

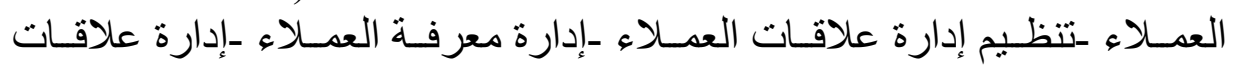

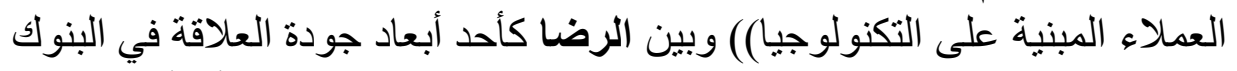

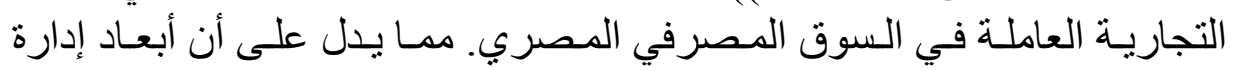




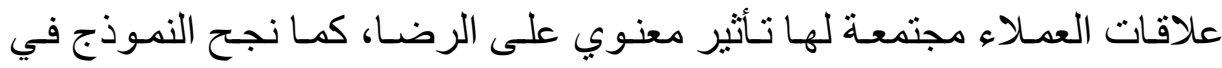

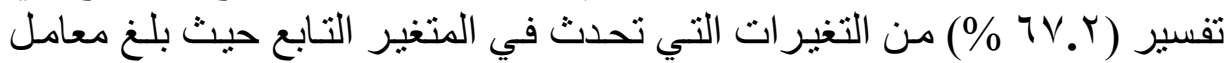

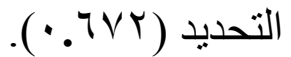

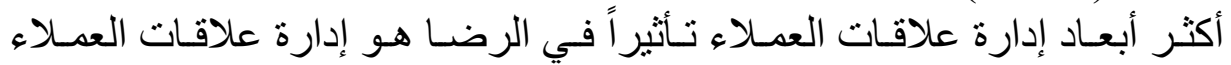

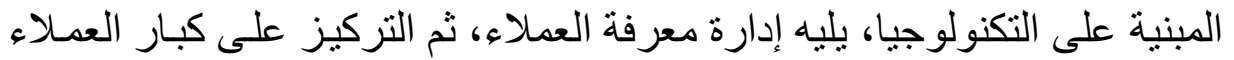
و وأخير ا تنظيم إدارة علاقات العملاء.

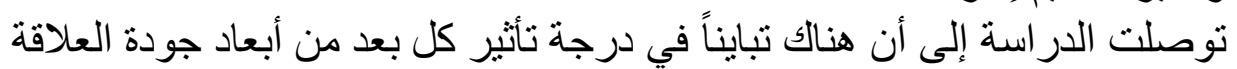

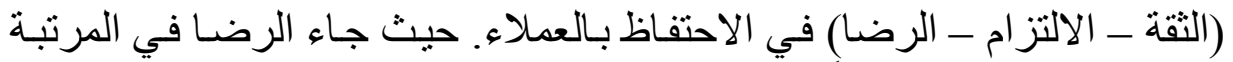

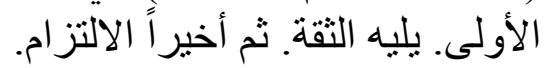

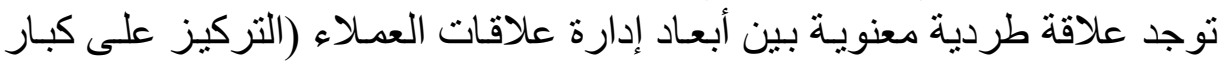

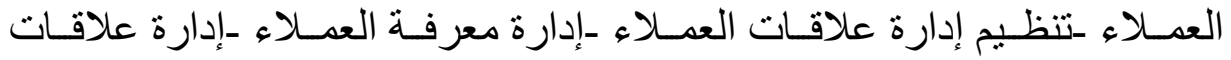

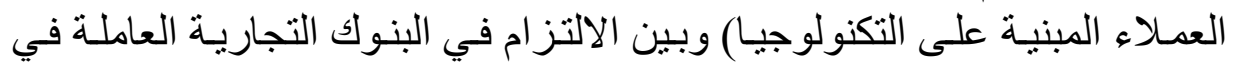

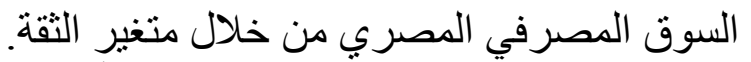

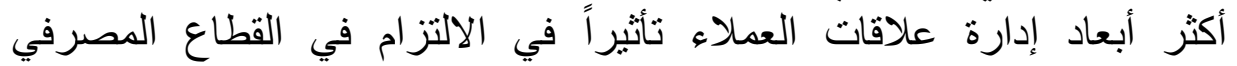

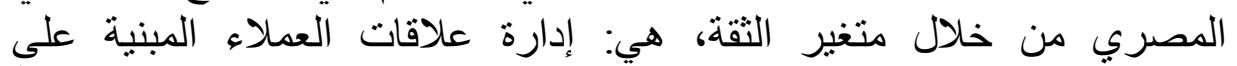
التكنولوجيا يليها تنظيم إدارة علاقات العير العملاء ثم إدارة معرفة العملاء وأخيراً

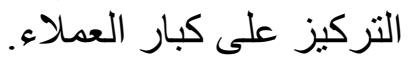

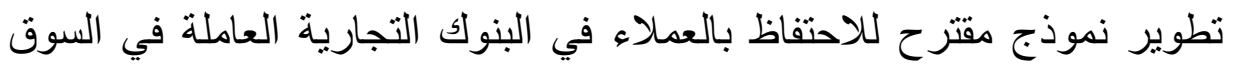

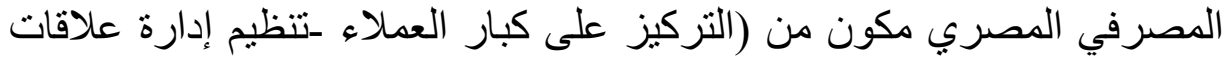

العملاء ـإدارة معرفة العملاء ـإدارة علاقات كات العملاء المبنية على العلى التكنولوجيا).

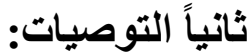
سنركز هنا على أهم التوصيات المرتبطة بنتائج هذه الدر اسة:

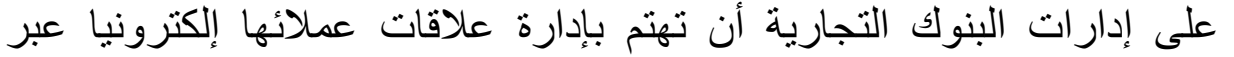
الإنترنت لما له من أثر إيجابي في رضان التها العملاء.

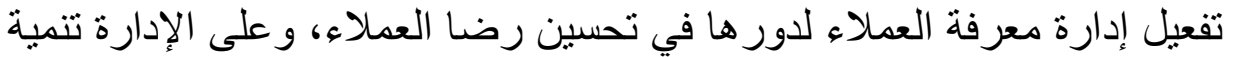

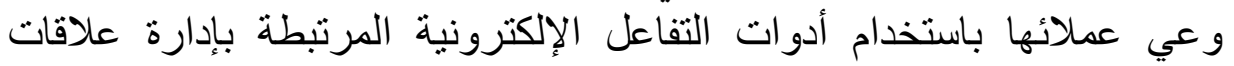

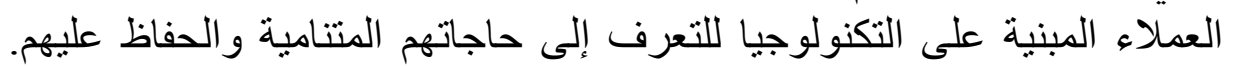

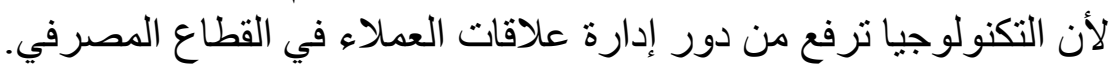

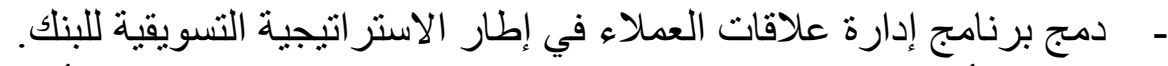

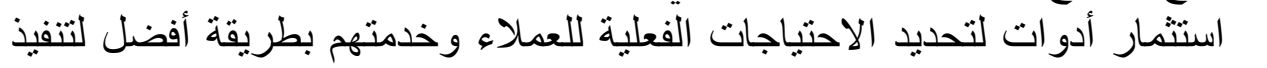
نظم ادارة علاقات العملاء في اماكن عملهم. تحديد موظف معين يكون متخصص في في الماكن في التعامل مع كبار العملاء.

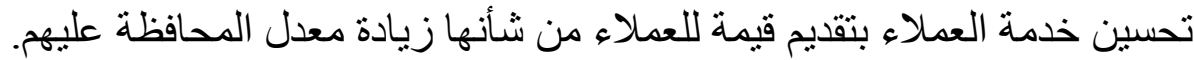

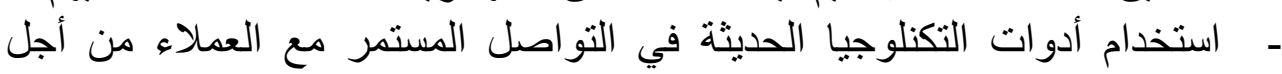
تحقيق واثباع رغباتهم، مما يعزز أداء البنوك ويرفع مستوى النمو النئ في السوق. 
ووضع استر اتيجيات لتحسين كيفية التواصل مع العملاء، وتتظيم و ابتكار أساليب

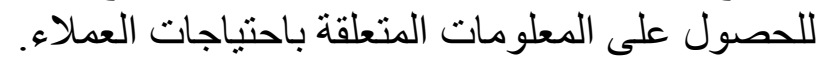

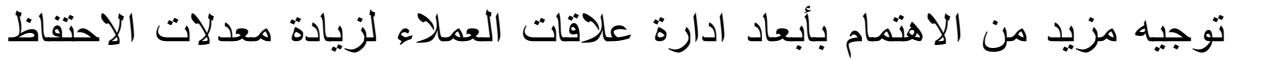

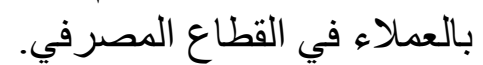

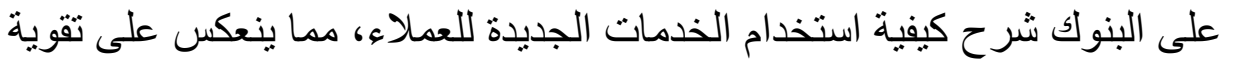

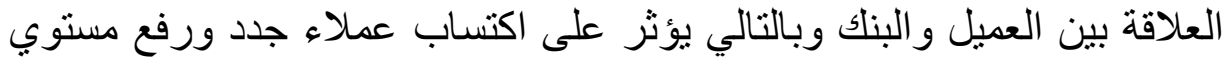

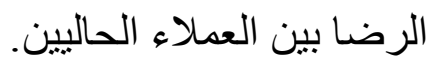
ايجاد طرق و آليات لحل النزاعات مع العملاء وكيفية التعامل معها في حال فثل

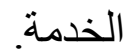
تعزيز قدرات التكنولوجيا في ادارة علاقات العملاء يؤدي إلى تقوية العلاقة بين

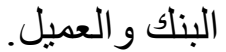

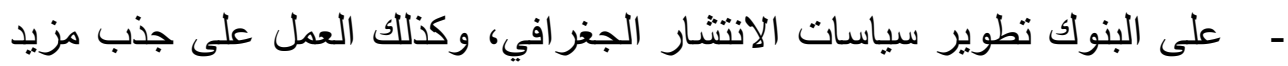

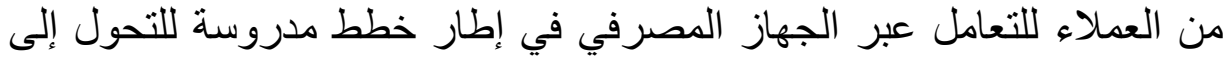

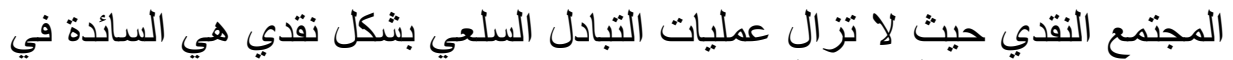

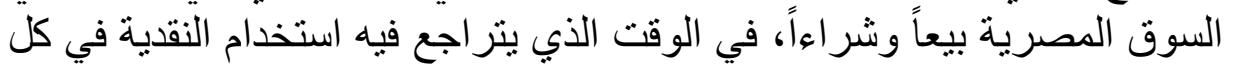

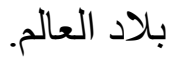

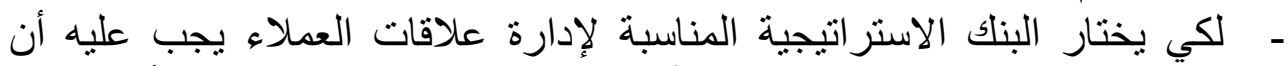

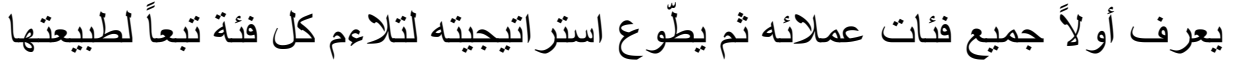

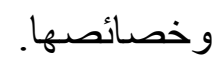

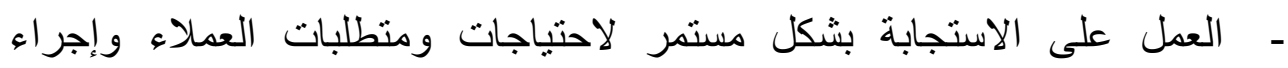

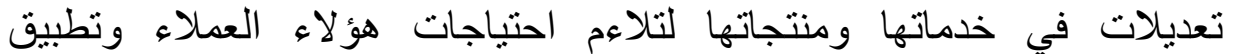

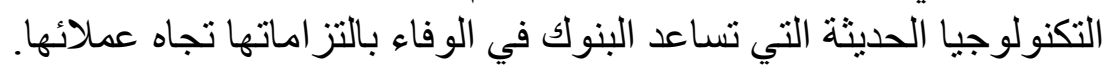

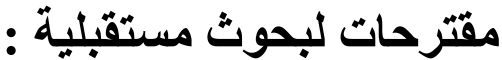

أسهمت هذه الدراسة في التعرف على على أثر جودة العلاقة على العلاقة بين إدارة

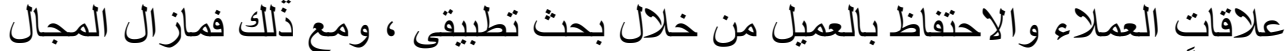

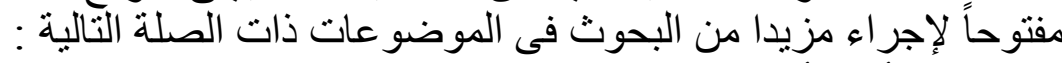
- إستخدام أبعاد أخري لإدارة علاقات العات العملاء في الاحتفاظ بالعميل. ـ ـ تطبيق النموذج في قطاعات خدمية أخري. - در اسة مقارنة بين إدارة علاقات العملاء في البنوك المحلية والأجنبية. 


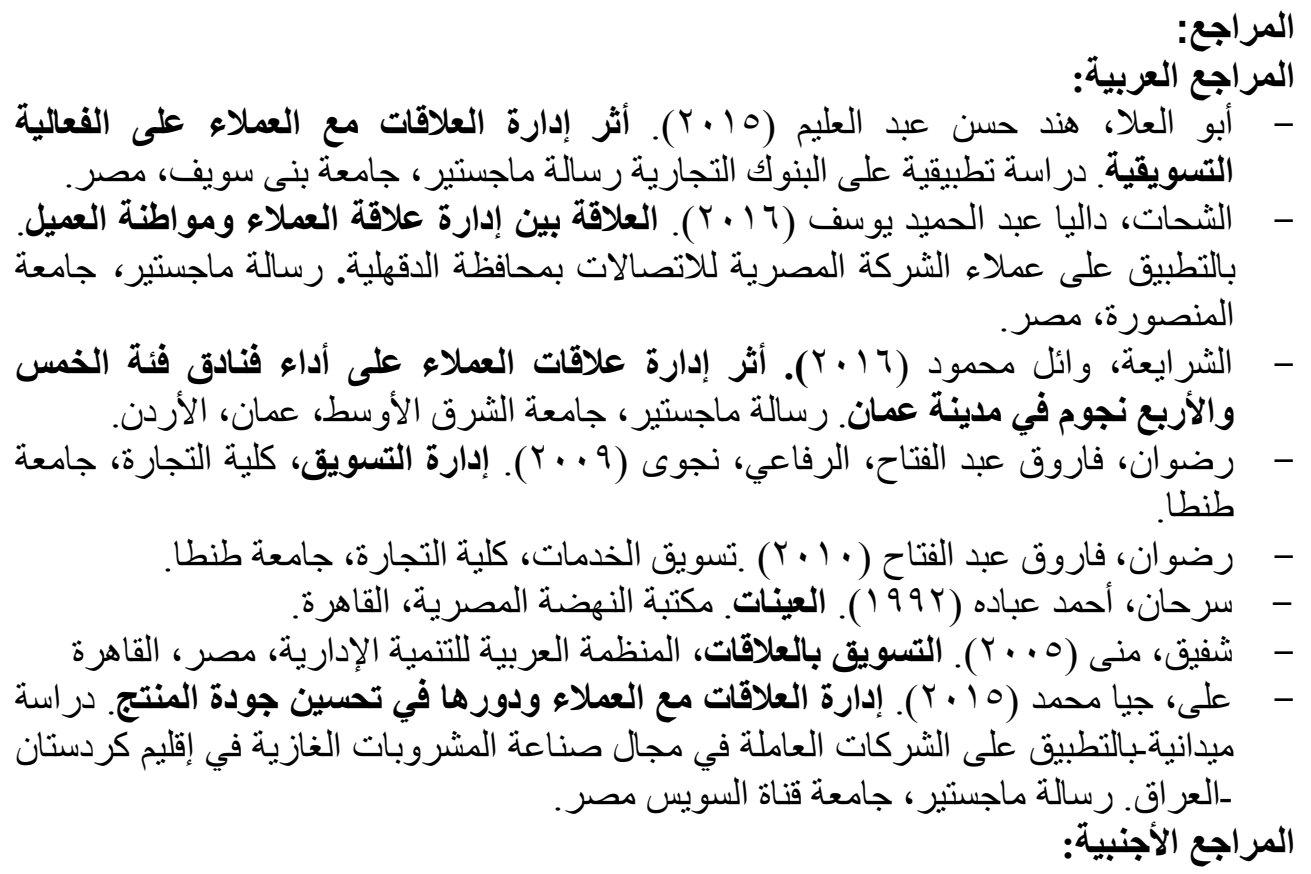

- Ahmed, T. (2016). "An empirical Examination Of customer relationship management (CRM) Implementation in Islamic Banks". International Journal of Academic Research and Reflection, 4 (2): 14-25.

- Akroush, M. N., Dahiyat. S. E., Gharaibeh. H. S., \& Abu-Lail. B. N. (2011). "Customer relationship management implementation: an investigation of a scale's generalizability and its relationship with business performance in a developing country context". International Journal of commerce and Management, 21(2): 158-190.

- Auruskevicience, V., Salciuviene. L., \& Skudiene, V. (2010). "The Relationship Quality Effect on Customer Loyalty". Pecvnia, (10): 23-36.

- Awwad, M., \& AL-Qralleh, A.( 2014). "Relationship Marketing and Customer Retention: The Case of Jordanian Mobile Telecommunications Companies".Dirasat. Administrative Sciences, 41 (2): 435-450.

- Balla, B., Ibrahim. S., \& Ali, A. (2015). "The Impact of Relationship Quality onRrpurchase Intention ToardsThe Customers of Automotive Companies InSudan". British Journal of Marketing Studies, 3 (4): 1-15.

- Bansal, P., Harvir, S., Gregory Shirley F., \& Taylor. (2004). "AThree-Component Model of Customer to Service Providers". Journal of the Academy of Marketing Science,) 32): 234-250.

- Bavarsad, B., \& Hosseinipour, G. (2013). "Studying the Factors Affecting the Customer Relations Management (CRM) in Marun Petrochemical Company.Interdisciplinary" Journal of Contemporary Research in Business, 4(11):845-857.

- Chang, W., Park, J. E., \& Chaiy. S. (2010). "How does CRM technology transform into organizational performance? A mediating role of marketing capability".Journal of Business Research, 63(8) : 849-855.

- Chang, H., Wong, K., \& Fang, P. (2014). "The effects of customer relationship management relational information processes on customer-based performance". Decision Support Systems, (66):146-159.

- Chen, J. P. (2003). A Study of the Impacts of Banks' Relationship Marketing Strategies on Relationship Quality and Customer Loyalty-Taking the Cash Card Market as an Example.Unpublished Master's Thesis. Department of International Trade Soochow University. 
- Coltman, T., Devinney, T. M., and Midgley, D. F. "(2011).Customer relationship management and firm performance. A survey in the sector of Banking". International Journal of Business and Social Sciences, 3(3): 282-291.

- Crönroos, C. (1994). "From Marketing Mix to Relationship Marketing: Towards A paradigm shift in Marketing". Management Decision, 23(2): 4-20.

- Crosby, L. A., Kenneth R. E., \& Deborah, C. (1990). "Relationship Quality in Services Selling: Interpersonal Influence Perspective". Journal o f Marketing, 54 (July)": 68-81.

- Danil, C., \& Gates, R. (2005). Marketing Research. John wiley \& Sons.Inc.

- De Wulf, K., Gaby Odekerken-Schroder., \& Dawn Iacobucci. (2001). "Investments in Consumer Relationships": A Cross- Country and Cross-Industry Exploration.Journal of Marketing, 65 (October): 33-50.

- Doney, P., \& Cannon, J. P. (1997). "An examination of the nature of trust in buyer seller relationships".Journal of Marketing, 61 (2): 35-51.

- Dorsch, M. J., Swanson, S. R., \& Kelley, S. W. (1998). "The roleof relationship quality in the stratification of vendors as perceived by customers".Journal of Academy of Marketing Science, 26 (2): 128-143.

- Ebeid, A. Y. (2014). "Investigating the Role of Selected Marketing-Mix Variables in Formatting Corporate Image in Egyptian Market ". American Journal of Business and Management, 3 (4): 237-243.

- Ebel, R. (1972). Essentials of Educational Measurement. Prentice Hill.New Jersey.

- Eid, R. (2015). " Integrating Muslim Customer Perceived Value, Satisfaction, Loyalty and Retention in the Tourism Industry: An empirical study". International Journal of Tourism Research, 17:249-260.

- Ernst, H., Hoyer, W.D., Krafft, M., \& Krieger, K. (2011). "Customer relationship management and company performance -the mediating role ofnew productperformance".Journal of the Academy of Marketing Science, 39(2):290-306.

- Flaherty, R.E. (1979). The Core of Curriculum for Accounting Majors. American Management Association.

- Foram, G.(1991). Statistical Analysis in Psychology and Education. 2 ${ }^{\text {nd }}$. Mc_Graw- Hill. Newyork.

- Fournier, S., Susan, D., \& David, G.M. (1998). "Preventing the Premature Death of Relationship Marketing" . Harvard Business Review, 76(January/ February): 42-51.

- Francis, B. (2005). Customer Relationship Management. Elseliver. First Edition.

- Homburg, C., Nicole, K., \& Wayne, D. H. (2005). "Do Satisfied Customers Really Pay More? A Study of the Relationship between Customer Satisfaction and Willingness to Pay". Journal o f Marketing, 69 (2): 84-96.

Josiassen, A., Assaf, A., \& Cvelbar, L. (2014). "CRM and the bottom line: Do all CRM dimensions affect firm performance?" International Journal of Hospitality Management, (36): 130-136.

- Khodakarami, F., \& Chan, Y. (2014). "Exploring the role of customer relationship management (CRM) systems in customer knowledge creation".Information \& Management, (51): 27-42.

- Kim, J., Suh, E., \& Hwang, H.( 2003). "A model for evaluating the effectiveness of CRM using the balanced scorecard". Journal of interactive Marketing, 17(2): 5-19.

-Kotler, P. (2006). Marketing Management. New Jersey: Prentice Hall.

- Long. C. S., Khalafinezhad. R. ., Wan Ismail. W. K., Rasid. A.,\&Zaleha. S. (2013). "Impact of CRM Factors on Customer Satisfaction and Loyalty". Asian Social Science, 9(10): 247253.

- Liang, C., Chen, H., \& Wang, W. (2008). "Does online relationship marketing enhance customer retention and cross-buying?" The Service Industries Journal, 28(6): 769-787.

- Meier, J. (1995). "The Importance of Relationship in establishing successful Interorganizational system". Journal of strategic Information systems, 4(2): 135:148. 
- Mithas, S., Krishnan, M.S., \& Fornell, C. (2005). Why Do Customer Relationship Management Applications Affect Customer Satisfaction? Journal of Marketing, 69(4): 201-209.

- Moreno, A., Lockett, N., \& Morales, V. (2014). "Paving the way for CRM success: The mediating role of knowledge management and organizational commitment".Information \& Management, 51: 1031-1042.

- Morgan, R., \& Hunt, S. (1994). The Commitment-Trust Theory of Relationship Marketing. Journal of Marketing, 58 (7): 20-38.

- Murillo, G., \& Anrobi, H. (2002). "Custumer knowledge management" .Journal of operational Research society, 3(3):212- 225.

- Mullins, R., Ahearne, M., Lam, S., Hall, Z., \& Boichuk, G. (2014). "Know Your Customer: How Salesperson Perceptions of Customer Relationship Quality Form and Influence Account Profitability".Journal of Marketing, 78(4): 38-58.

- Narver, j.C., \& Slater, S.F. (1990). "The effect a Market Oriientation on Business Profitability".Journal of Marketing,October : 20-35.

- Nikhashemi, S. R., Paim, L., Haque, A., Khatibi, A., \&Tarofder, A. K. (2013). "Internet Technology. CRM and Customer Loyalty: Customer Retention and Satisfaction Perspective". Middle-East Journal of Scientific Research, 14(1): 79-92.

- Oliver, R.A. (1999). "Whence consumer Loyalty". Journal of Marketing, 63(Special Iissue):33-44.

- Paliouras, K., \& Siakas, K. (2017). "Social Framework for Customer Relationship Management: Acase Study". International Journal of Entrepreneurial Knowledge, 5 (1): 20-34.

- Palmer, R., Lindgreen, A., \& Vanhamme, J. (2005). "Relationship marketing: schools of thought and future research directions". MarketingIntelligence \& Planning, 23(3): 313330.

- Payne, A., \& Frow, P. (2005). "Astrategic Framework for Customer Relationship Management: from strategy to implementation".Journal of Marketing, 69 (October): 167176.

- Rajiv, R., Dant, D. G., \& Kenneth, R. E. (2006). "Factors Influencing the Effectiveness of Relationship Marketing: A Meta-Analysis." Journal o f Marketing, 70 (3): 136-153.

- Rashid, T. (2003). "Relationship Marketing: Case studies of Personal Experience of eating out". British food Journal, 105(10): 742- 750.

- Reinartz, W., Krafft, M., \& Hoyer, W. D. (2004). "The customer relationship management process: its measurement and impact on performance". Journal of marketing research, 41(3): 293-305.

- Roberts-Lombard, M., \& du Plessis, L. (2012). "Customer relationship management (CRM) in a South African service environment: An exploratory study". African Journal of Marketing Management, 4(4): 152- 165.

- Santouridis, I., \& Tsachtani, E. (2015). "Investigating the Impact of CRM Resources on CRM Processes: a Customer Life Cycle Based Approach in the Case of a Greek Bank". Procedia Economics and Finance, (19): $304-313$.

- Sawhney, M., \& Zabin, J.( 2001). The Seven Steps to Nirvana: Strategic Insights into eBusiness Transformation. McGraw-Hill. New York.

- Sirdeshmukh, D., Jagdip, S., \& Barry, S. (2002). "Consumer trust. Value. and loyalty in relational exchanges".Journal of Marketing, (66): 15-37.

- Sin, L. Y., Alan, C. B., \& Yim, F. H.( 2005). "CRM: conceptualization and scale development". European Journal of Marketing, 39 (11/12): 1264-1290.

- Srinivasan, R., \& Moorman, C. (2005). "Strategic firm commitments and rewards for customer relationship management in online retailing". Journal of Marketing, 69(October): 193-200. 
- Tzokas, N., Kim, Y., Akbar, H., \& Al-Dajani, H. (2015). "Absorptive capacity and performance: The role of customer relationship and technological capabilities in high-tech SMEs".Industrial Marketing Management, (47): 134-142.

- Verhoef, P.C., \& Leeflang, P.S. (2009). "Understanding the Marketing Department's Influence Within theFirm". Journal of Marketing, 73 (March): 14-36.

- Wilson, A., Zeithaml, V. A., Bitner, M. J., \& Gremler, D.D. (2012).Services marketing: Integrating customer focus across the firm (No. 2nd Eu) -Palmatier، Robert.McGraw Hill.

- Yli-Renk, H., \& Janakiraman, R. (2008). How Customer Portfolio Affects NewProduct Development in Technology-Based Entrepreneurial Firms. Journal of Marketing, 72 (September): 131-148.

- Zhang, X., \& Feng, Y. (2009). The Impact of Customer Relationship Marketing Tactics of customer Loyalty. Within Swedish Mobile Telecommunication Industry. Master's Dissertation in International Marketing. Halmstad University.

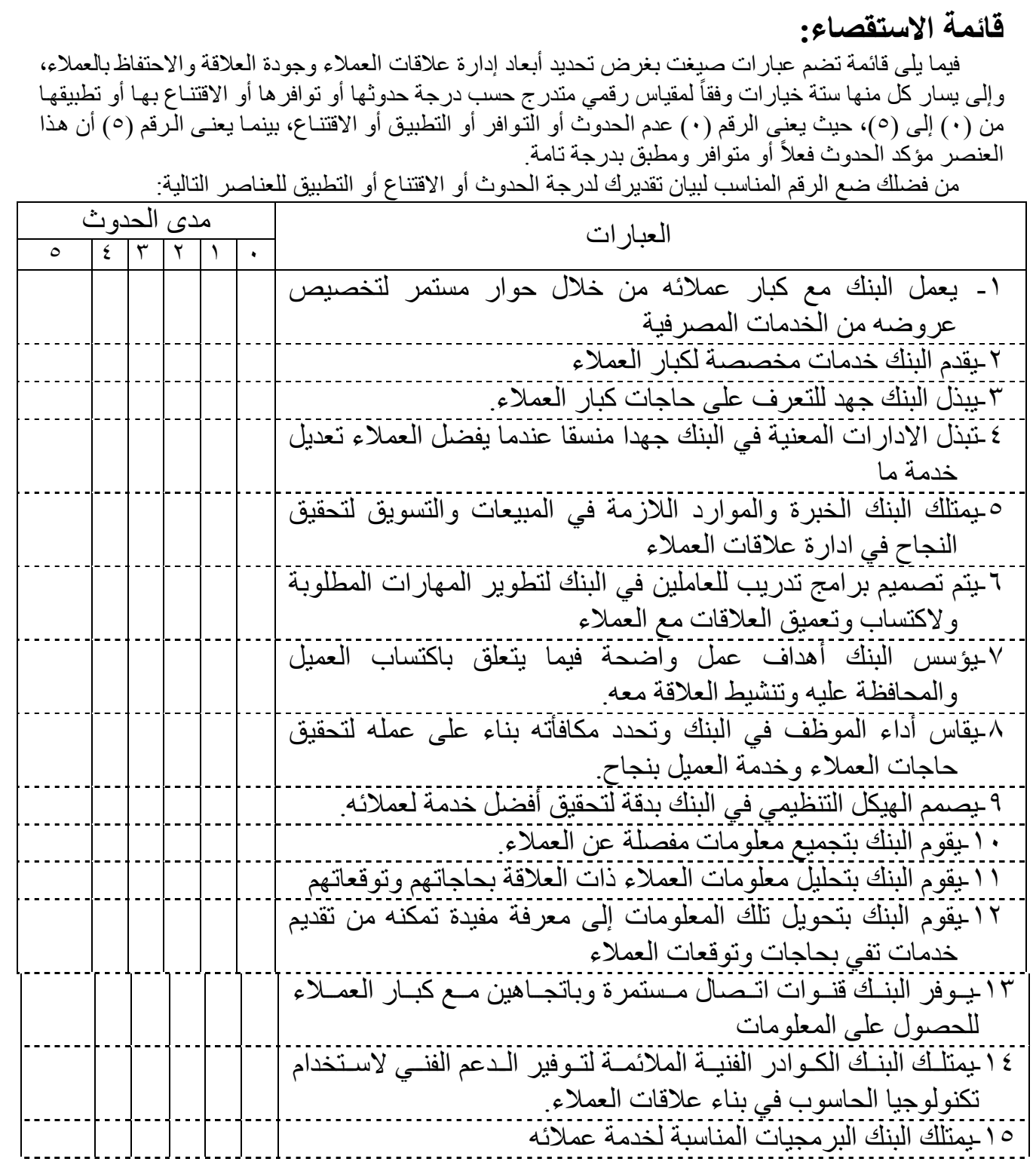




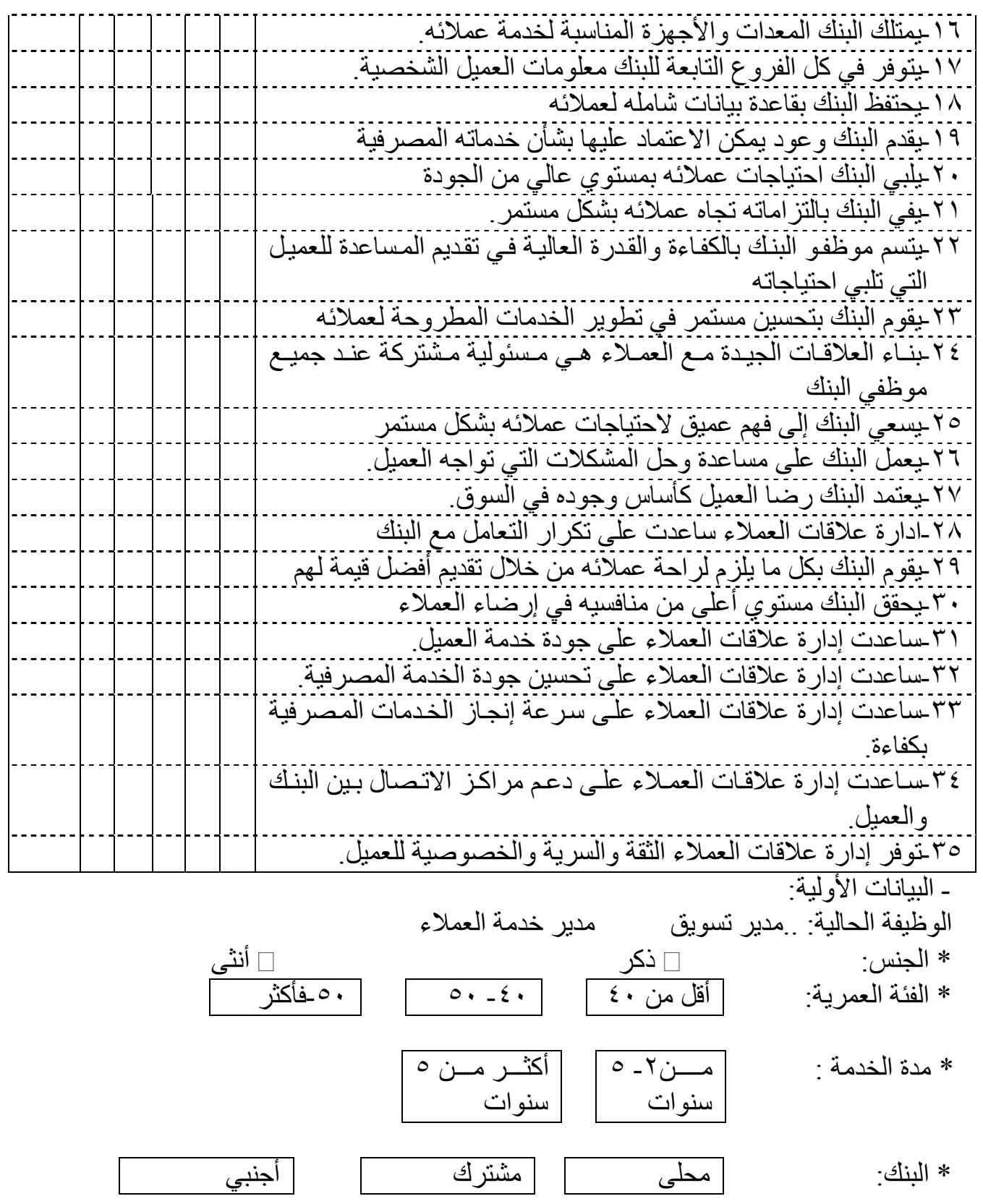




\begin{abstract}
:
The aim of this study is to explore the impact of relationship quality (trust-commitment- satisfaction) in the relationship between Dimensions Customers Relationships Management "key customers focus, Customers relationships management organization, Customers Knowledge management, and technology-based customers' relationships management " and customer's Retention, to build a model for Customers Relationships Management in the Egyptian banking sector by using Path analysis and partial correlations analysis. In addition to identifying both relationship quality and customer's Retention.

The questionnaire has been designed to gather data. The sample size is 241 customers' service managers, marketing managers.

According to results obtained from structural model, the study concluded that dimensions of Customers Relationships Management can be arranged as followed: " technology-based customers' relationships management, key customers focus, Customers Knowledge management, and Customers relationships management organization" to ensure customer's Retention. Technology-based customers' relationships management is the most important dimension in building long-term relationship with customers. The results support the indirect effect of Customers Relationships Management on Customer commitment through Customer trust, and Customer trust has positive direct affect on Customer commitment, and indirect effect on customer retention through commitment the trust has stronger than satisfaction in impact on customer retention in the Egyptian banking sector. Furthermore, the study has suggested model of Customers Relationships Management to Retain the Customers with reliable degree.

Relationship quality is placed as intermediate variable between Customers Relationships Management dimensions and customer Retention. This affects the strength of the relationship between them.
\end{abstract}

Keywords: Customers Relationships Management - Relationship quality -customer's Retention. 